\title{
Geology of the Decaturville Impact Structure, Missouri
}

GEOLOGICAL SURVEY PROFESSIONAL PAPER 1042

Work done in behalf of National Aeronautics and Space Administration
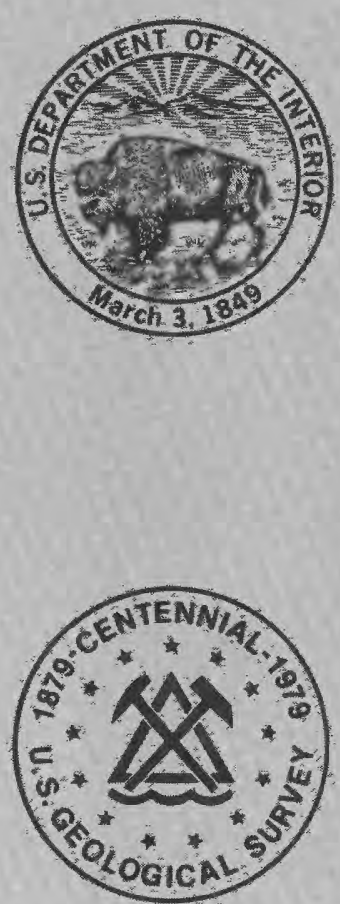



\section{Geology of the Decaturville Impact Structure, Missouri}

By T. W. OFFIELD and H. A. POHN

GEOLOGICAL SURVEY PROFESIONAL PAPER 1042

Work done in behalf of National

Aeronautics and Space Administration

A detailed description of stratigraphy, style of deformation, and shock features at the Decaturville structure. Origin of

the structure by impact is indicated

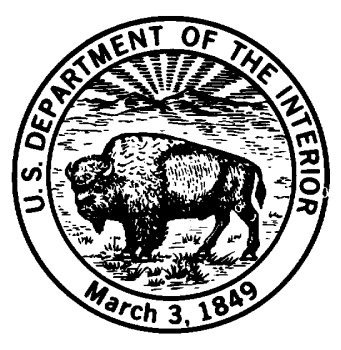

UNITED STATES GOVERNMENT PRINTING OFFICE, WASHINGTON : 1979 


\section{UNITED STATES DEPARTMENT OF THE INTERIOR}

\section{CECIL D. ANDRUS, Secretary}

\section{GEOLOGICAL SURVEY}

H. William Menard, Director

Library of Congress Cataloging in Publication Data

Offield, Terry W.

Geology of the Decaturville impact structure, Missouri.

(Geological Survey Professional Paper 1042)

Bibliography: p. 46

Supt. of Docs. no.: I 19.1 6:1042

1. Cry ptoex plosion structures-Missouri-Decaturville region. 2. Geology-Missouri-Decaturville region.

I. Pohn, Howard A., joint author. II. Title. III. Series: United States Geological Survey Professional Paper 1042.

QE613.5.U5035

551.8

77-608119

For sale by the Superintendent of Documents, U.S. Government Printing Office

Washington, D.C. 20402

Stock Number 024-001-03166-3 


\section{CONTENTS}

\begin{tabular}{|c|c|}
\hline Page & Page \\
\hline Abstract & Regional paleogeographic implications .................................... 10 \\
\hline Introduction & 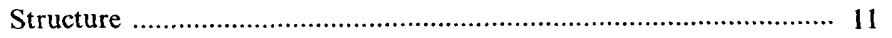 \\
\hline 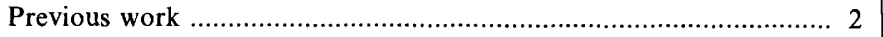 & 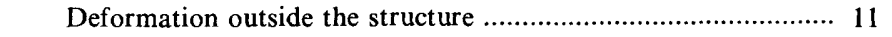 \\
\hline Acknowledgments ................................... & 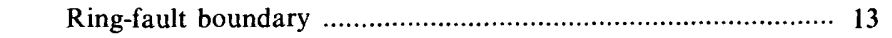 \\
\hline 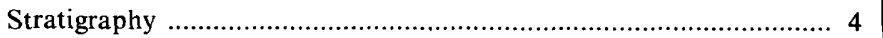 & 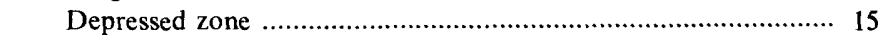 \\
\hline Precambrian rocks ................................ & Exotic blocks in the depressed zone ................................. 16 \\
\hline 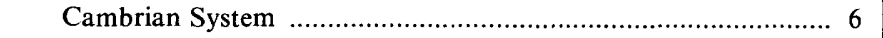 & 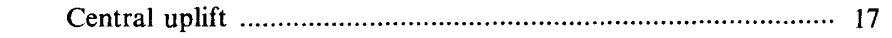 \\
\hline 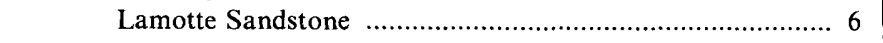 & 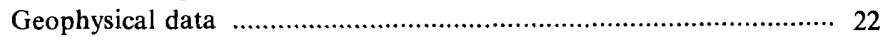 \\
\hline Bonneterre Dolomite .................................................... 6 & Shock-related deformation features ...... \\
\hline Davis Formation ............................................................ 7 & Monolithologic breccias ........... \\
\hline Derby and Doe Run Dolomites ...................................... 7 & 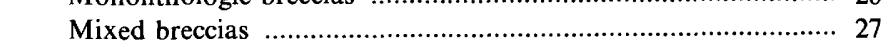 \\
\hline 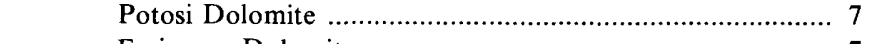 & 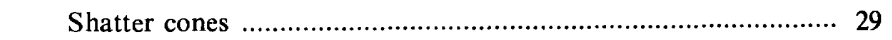 \\
\hline Eminence Dolomite ..................... & Planar elements in quartz ............... \\
\hline Ordovician System & 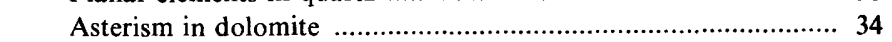 \\
\hline Gasconade Dolomite .................................................... 7 & 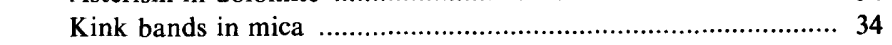 \\
\hline 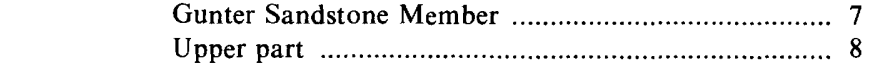 & 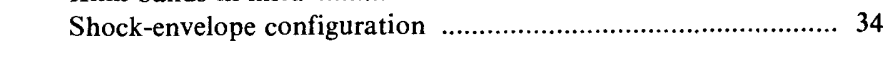 \\
\hline 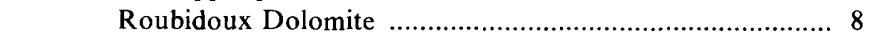 & 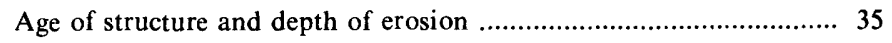 \\
\hline Jefferson City Dolomite ............................................... 8 & 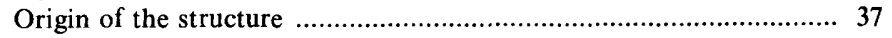 \\
\hline 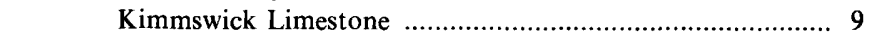 & 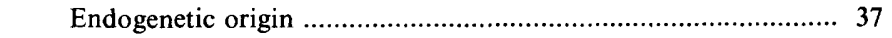 \\
\hline 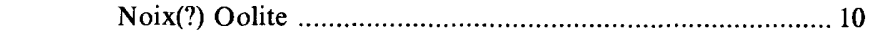 & 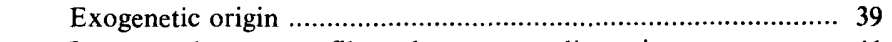 \\
\hline 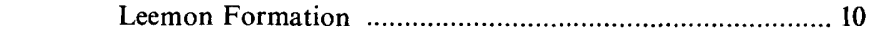 & Interpreted crater profile and postcrater disruption $\ldots \ldots \ldots \ldots \ldots \ldots .41$ \\
\hline Silurian System . ............................ & Implications for other astroblemes \\
\hline Bainbridge Limestone .................................................. 10 & 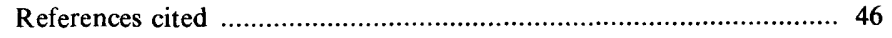 \\
\hline
\end{tabular}

\section{ILLUSTRATIONS}

Plate 1. Geologic map of Decaturville structure, Missouri...

2. Block diagrams showing structural detail, Decaturville impact structure, Missouri ......................................... In pocket

FIGURE 1. Index map of southern Missouri, showing location of Decaturville structure, outline of area shown in figure 2, and features

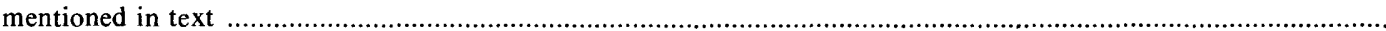

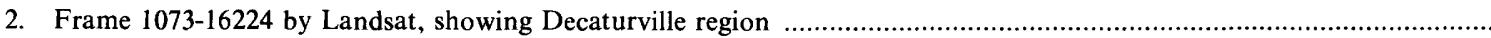

3. High-altitude aerial photograph showing circular patterns of Decaturville structure

4. Column showing lithologies and estimated thicknesses of formations present in Decaturville structure

5. Structure contour map on the base of upper part of the Gasconade Dolomite

6. Map of isopleths showing vertical displacements relative to prestructure configuration

7. Photograph showing drill hole numbers and locations at center of structure, and diagrams of sections cut in drill holes around pegmatite locality and sulfide pit

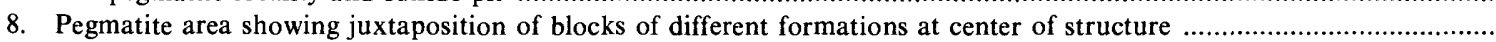

9. Sulfide pit showing juxtaposition of blocks of different formations and mixed breccia

10. Aeromagnetic map, Decaturville region ...

11. Gravity map, Decaturville region

12. Gravity map, central area of Decaturville structure 
FIGURE 13-18. Photograph:

13. Monolithologic breccia, Eminence Dolomite

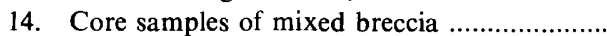

15. Core samples of mixed breccia showing alined grains in flow laminae and fragments drawn out or shaped by flowage

16. Mixed breccia at sulfide pit in center of structure

17. Sandstone from Lamotte Sandstone emplaced between block of Potosi Dolomite and mixed breccia in sulfide pit

18. Shatter-coned Derby and Doe Run Dolomites

19. Stereographic projection of shatter-cone striations

20. Photomicrograph showing rhombohedral fractures in quartz grain of sandstone

21. Photomicrograph of decorated planar feat ures in quartz grains from mixed breccia, spaced $9-60 \mu \mathrm{m}$ and oriented parallel to $\{0001\}$

22. Photomicrograph of mixed breccia, showing quartz grain with dominant planar features spaced 1-3 $\mu \mathrm{m}$ and oriented parallel to $\{1013\}$

23. Histograms showing frequency and orientation of quartz planar fractures

24. Photomicrograph of kink-banded muscovite grain surrounded by strained quartz in pegmatite

25. Cross section showing inferred shock-pressure envelope in undisrupted strata, movement of data points by disruption, and inferred crater positions

26. Map showing areas of volcanism and unusual structural disturbance near the 38th parallel

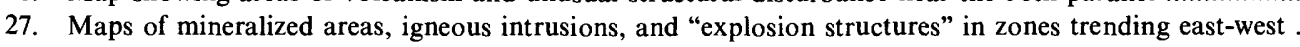

28. Schematic cross sections showing inferred time sequence of structural movements during cratering event 


\title{
GEOLOGY OF THE DECATURVILLE IMPACT STRUCTURE, MISSOURI
}

\author{
By T. W. Offield and H. A. Pohn
}

\begin{abstract}
ABSTRACI
The Decaturville structure of central Missouri is ascribed to meteorite or comet impact on the basis of structural style and presence of shock features. The intense deformation of rocks in a circular area $5.5 \mathrm{~km}$ across is in marked contrast to the surrounding flat-lying strata of the Ozark Plateau. A normal fault bounds the structure which consists of a central uplift and a surrounding structural depression. In the central uplift, Cambrian sandstone, dolomite, and shale normally at least $300 \mathrm{~m}$ deep are exposed and isolated blocks of Precambrian basement granite pegmatite and schist are $540 \mathrm{~m}$ above their normal position. Convoluted strata in the uplift have strike lengths 25-30 percent longer than the perimeters on which the strata lie, indicating that inward movement and crowding of beds accompanied the upward movement. The inward movement involved folding and thrusting and was succeeded by adjustments on steep faults with both upward and downward displacements of as much as $150 \mathrm{~m}$. The depressed zone around the uplift is characterized by thrusts inward and outward relative to its center and by steep faults that formed both before and after the thrusting.
\end{abstract}

Shock features include monolithologic and mixed breccias, shatter cones, planar features in quartz, and intense intragranular deformation. Monolithologic breccias, formed by successive dilation and crushing of individual beds without mixing of adjacent beds, are common throughout the structure. Shatter cones occur at the center of the structure in a circular area about $450 \mathrm{~m}$ across. The shatter-coned rocks form a capping layer over a megabreccia column containing blocks as much as several tens of meters in size. These blocks are from Cambrian formations that make up the bottom $240 \mathrm{~m}$ of the $540-\mathrm{m}$ disturbed sequence and are not in original stratigraphic order. A fine-grained matrix of mixed breccia around the megabreccia blocks contains quartz grains with close-spaced planar features, including some parallel to $\{1013\}$, probably indicating shock pressures as great as 60-100 kilobars. Intensity of shock effects in the structure decreases downward; the basement rocks do not contain positively identified shock features. The deepest point of shock-energy release is not well defined but was not deeper than about $360 \mathrm{~m}$ in the disturbed section.

Because the Decaturville structure is one of several features, volcanic or of uncertain explosive origin, that lie in general alinement across southern Illinois, Missouri, and Kansas, it commonly has been ascribed to origin by endogenetic explosion. A subterranean explosion, however, would result in dilation and outward dislocation rather than centripetal movement of beds in the central uplift and would not explain shock deformation at pressures far too great to be sustained beneath a few hundred meters of strata. Decrease of shock deformation downward also implies energy applied from above rather than below. In addition, the structure has many similarities to known impact structures and is unlike any proved endogenetic structures.

The structure is of considerable paleogeographic interest because in the depressed zone it contains the only known occurrences of the Silurian Bainbridge Limestone and the Ordovician Noix(?) Oolite,Leemon Formation, and Kimmswick Limestone in that part of Missouri. Exposures of
Cambrian formations found in the uplift are also unique in central Missouri. Blocks of units normally $189-540 \mathrm{~m}$ deep lie on the locally youngest formations in the ring depression and are interpreted as crater ejecta, or fallback, indicating that original ground surface is present in parts of the depression. On this basis, poststructure erosion in the area is estimated at no more than $50 \mathrm{~m}$. Because such a small amount of erosion could not have destroyed a crater estimated to be $3,300 \mathrm{~m}$ in diameter and $540 \mathrm{~m}$ deep, we believe that the crater was destroyed by the immediate inward movement of beds that formed the central uplift. This inward movement was a response to passage of the shock wave, and it produced the ring fault and structural depression as necessary concomitants to the development of the central uplift (volumes of the uplift and depression are virtually equal). As the crater closed, material spalling from the walls was trapped to form the megabreccia mass at the center of the structure. This explanation may apply to other astroblemes where erosion is not thought to be great but where a central peak is present without a topographic crater.

The age of the Decaturville impact structure is not definitely known but is almost certainly post-Pennsylvanian, and may be younger than Cretaceous.

\section{INTRODUCTION}

The Decaturville structure is located on the Ozark Plateau of central Missouri, along State Highway 5 about $13 \mathrm{~km}$ south of Camdenton and Lake of the Ozarks (fig. 1). The structure has about the same elevation and relief as the surrounding plateau; however, it is marked by a ring of low, wooded hills inside a nearly complete circle of low unwooded ground (fig. 2). The U.S. Geological Survey topographic maps of the Stoutland (1933) and Macks Creek (1934) 15-minute quadrangles with green forest overprint clearly show the circular pattern. Streams drain radially outward from the center of the area, a pattern in conspicuous contrast to the generally rectilinear, trellislike stream network of the surrounding countryside. The circular pattern of wooded and cleared ground and the radial drainage also are apparent in a high-altitude aerial photograph (fig. 3).

The circular area, $5.6-6.4 \mathrm{~km}$ in diameter, is one of intense deformation in fault contact with the little disturbed, flat-lying strata of the Ozark Plateau. The structure consists of a central uplift surrounded by a structurally depressed zone. The regional setting, style or type of structural deformation, and shock-metamorphic features of the Decaturville structure are characteristic of more than 60 similar, roughly circular features known around the world 


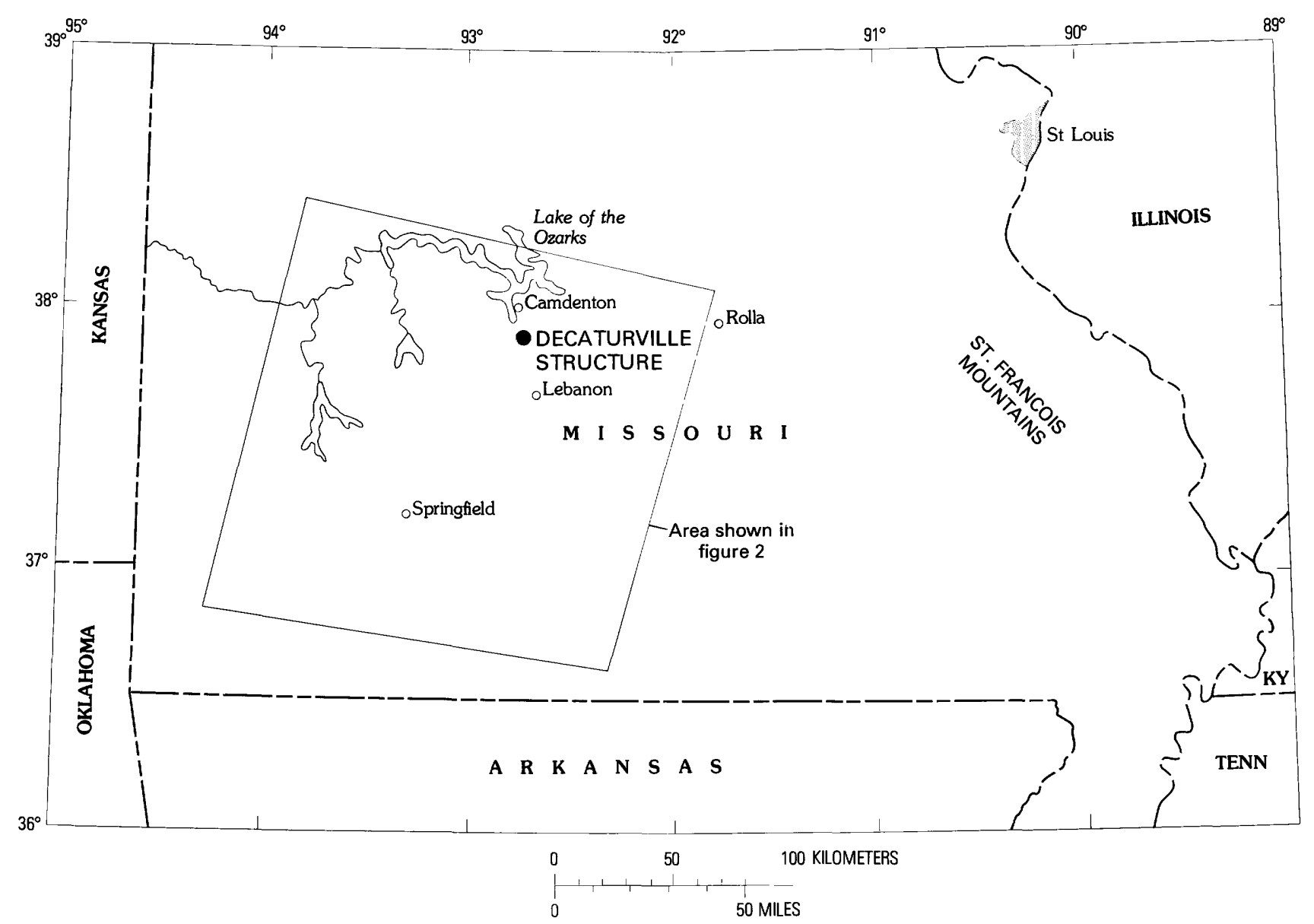

Figure 1.- Index map of southern Missouri, showing location of Decaturville structure, outline of area shown in figure 2, and features mentioned in text.

(15 in the United States), many originally thought to be produced by volcanism which caused an explosion but left no trace of volcanic activity. The name "cryptovolcanic" was applied to the group by Bucher in 1936, extending usage of the term applied by Branco and Fraas (1905) to the Steinheim structure in Germany. Boon and Albritton (1936) suggested that the structures might be of extraterrestrial (impact) origin. Dietz (1946) recommended the term "cryptoexplosion" as noncommittal with respect to impact or volcanic origin.

The detailed study of the Decaturville structure was done during 1968-70 as part of an investigation of possible lunar-crater analogs. Objectives of the study were to establish criteria (such as shock metamorphism and structural style) by which impact structures could be distinguished from endogenetic explosion structures, and to gain insight into the cratering process.

\section{PREVIOUS WORK}

Decaturville has been an area of continuing geologic interest since the report of Shumard $(1873$, p. 220), who noted that a few pounds of galena had been taken from pits some 600 feet $(183 \mathrm{~m})$ from an "igneous dyke of granite." Winslow (1894) referred to the Wheeler mine near a pegmatite dike surrounded by intensely disturbed rocks in an area more than 2 miles $(3.2 \mathrm{~km})$ wide; he presented a sketch map of structure around the mine and suggested a post-Pennsylvanian age for the intrusion and disturbance. In 1905, Shepard (p. 114-117) suggested two periods of uplift to explain the deformation and commented that the pegmatite area was surrounded by "an irregularly broken circle of low hills***making the whole area resemble somewhat the contour of an old crater." He also reported that the pegmatite was first discovered in float blocks and was excavated in 1869 by lead prospectors. Shepard (1905), Ruhl (1904), and Dake and Bridge (1927) ascribed the deformation to uplift accompanying intrusion of the pegmatite. Buehler and McQueen (1933) cited Dake's observation that the disturbed area measured approximately 5.5 miles $(8.8$ $\mathrm{km})$ east-west and 3.5 miles $(5.6 \mathrm{~km})$ north-south. Bucher (1936, p. 1071) also believed the pegmatite to be intrusive, dated the structure as latest Cambrian to earliest Ordovician, and categorized the structure as one of the "cryptovolcanic" group. 


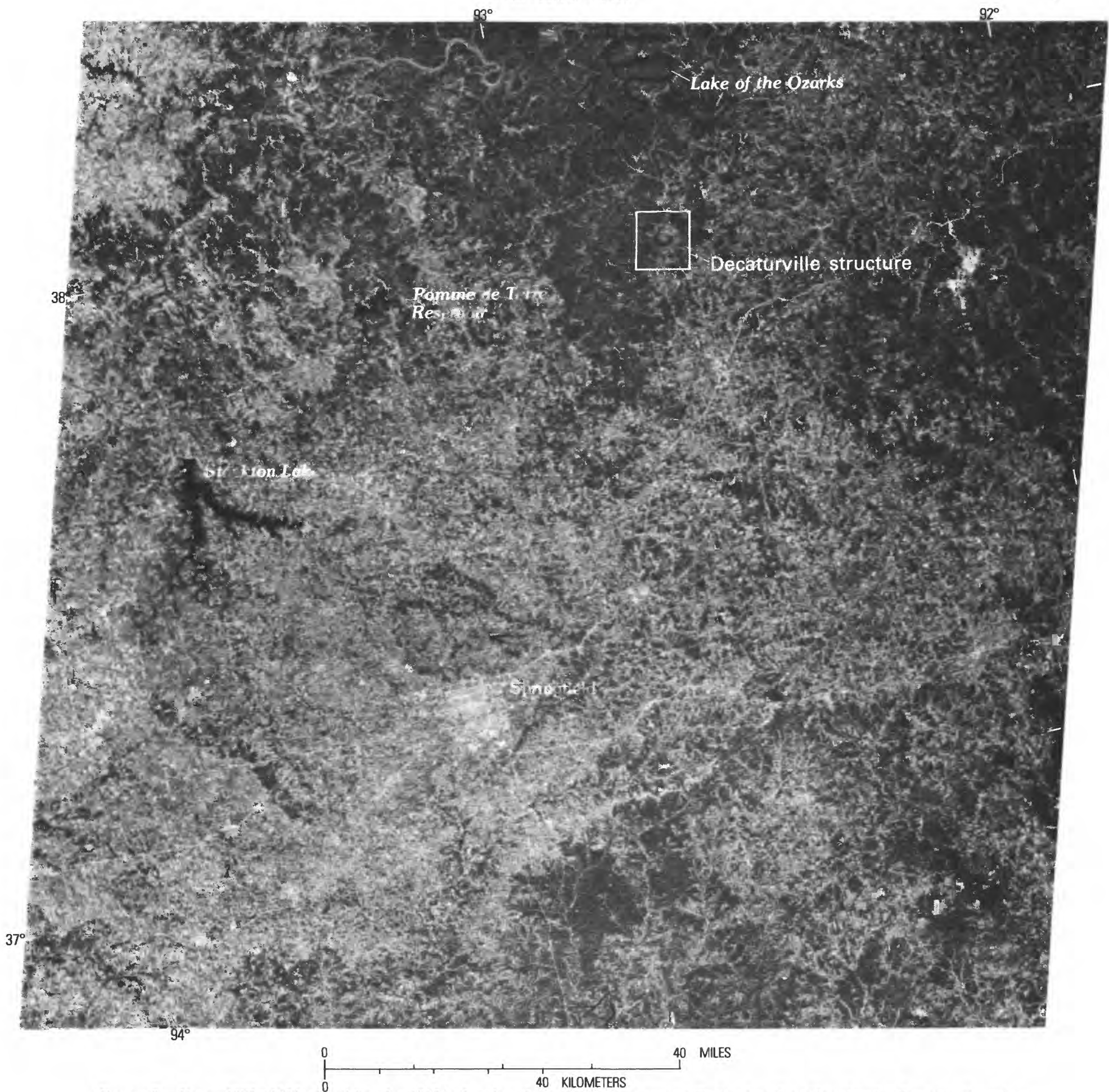

FIGURE 2.-Frame 1073-16224 taken 4 October 1972 by Landsat (formerly Earth Resources Technology Satellite) showing Decaturville region.

All these early authors reported certain stratigraphic identifications or relationships not borne out by the present study. Boon and Albritton (1936) noted the "cryptovolcanic" association, and suggested that these unusual features, including Decaturville, might be impact structures. Tarr, in 1938, and also in a discussion of Bucher's 1936 paper
(Bucher, p. 1083), expressed belief that the disturbance involved a buried hill of Precambrian granite. This opinion was shared by Tolman and Landes (1939) because of the lack of contact metamorphism and because the overlying strata probably were too thin to permit slow enough cooling of an intrusive to form a coarse-grained pegmatite. In 1962, 


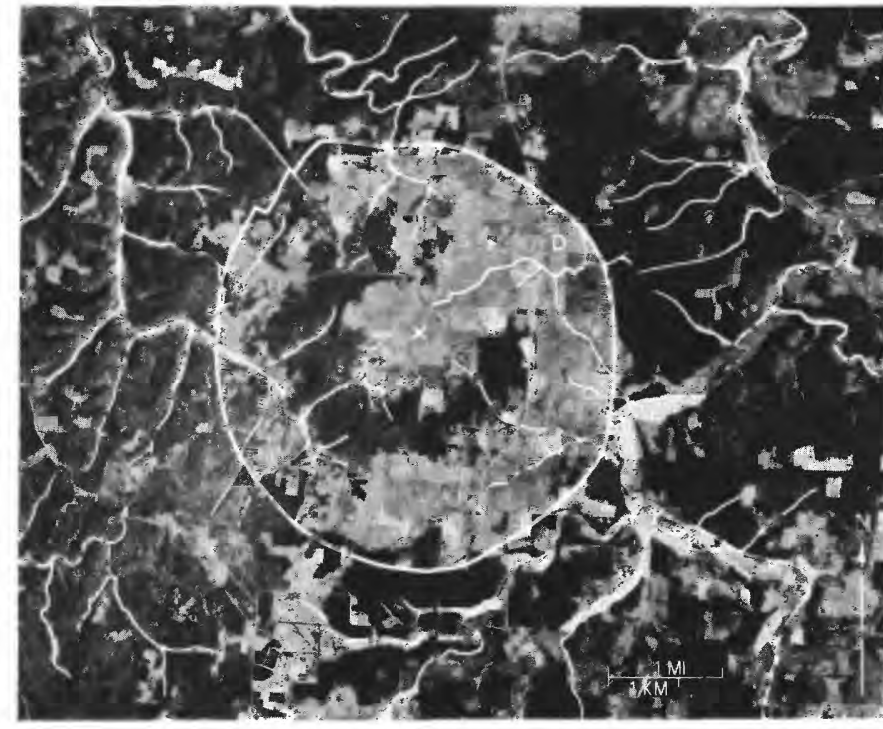

FIGURE 3.-High-altitude aerial photograph showing circular patterns and radial drainage of Decaturville structure; $x$ marks center of structure; $D$, village of Decaturville. U.S. Army photograph, June 1970.

radiometric age determinations by Tilton, Wetherill, and Davis confirmed a Precambrian age for the pegmatite exposed at the surface.

Kiilsgaard, Heyl, and Brock (1963) pointed out that the Decaturville disturbance and the very similar Crooked Creek structure $113 \mathrm{~km}$ to the east are probably located at intersections of regional tectonic lines, and they proposed subterranean gaseous explosions as the mechanism of disturbance. The idea was expanded by Snyder and Gerdemann (1965), who noted that the Decaturville, Crooked Creek, and Weaubleau disturbed areas, and five volcanic occurrences, some of which involved explosive processes, lie on an apparent east-west line that extends from southern Illinois to eastern Kansas. They postulated that volcanic gas explosions formed the Decaturville and Crooked Creek structures at intersections of an east-west zone of crustal weakness and local tectonic lines. These "alined" structures were the subject of a field trip in 1965 and described in the trip guidebook (Snyder and others, 1965). Other papers in this same period by Amstutz (1959, 1964a, 1964b; Krishnaswamy and Amstutz, 1960; Amstutz and Zimmerman, 1966; Zimmerman and Amstutz, 1965) ascribed the Decaturville structure variously to rejuvenation of ring dike or polygonal fractures "typical for the primordial crust of the earth," to diapirism, and to mud volcanism.

Shoemaker and Eggleton (1961) presented an impact origin for the structure, and Dietz later (1963) noted that shatter cones at Decaturville were indicative of intense shock and that therefore the structure probably was an impact feature.

Mineral exploration of the structure in the late 19th century reportedly consisted of four shafts, from 3.7-16.2 m deep, sunk by the property owner, Mr. Harry Wheeler.
About the end of World War II, some churn drilling and pitting was done in the center and at the outer edge by the St. Louis Smelting and Refining Co. and the Athletic Mining and Smelting Co. Since 1955, the central area has been owned or controlled by the Ozark Exploration Co. This company obtained more than $5,500 \mathrm{~m}$ of core from about 60 drill holes near the center of the uplift, and over a thousand meters more was taken in drilling the Gunter Sandstone Member of the Gasconade Dolomite, a sandstone bed that rings the uplift. Pits were opened in an area of sulfide-rich breccia (known as the "sulfide pit") and around the pegmatite. Many assays of sulfidic core samples also were obtained by the Ozark Exploration Co.

\section{ACKNOWLEDGMENTS}

The study was done in behalf of the National Aeronautics and Space Administration under contract 160-75-01-43-10. We are particularly grateful to $\mathrm{Mr}$. H. B. Hart, president of Ozark Exploration Co., for arranging access to much of the property on which the structure lies and for permitting use of drill core and privately held information without which this work would not have been complete. Consultations with $\mathrm{M}$. R. Dence, Dominion Observatory of Canada, and consultations in the field with D. J. Roddy and D. J. Milton, U.S. Geological Survey, were helpful in making comparisons with other similar structures. P. E. Gerdemann, St. Joseph Lead Co., provided information on local stratigraphy and subsurface data. We thank the staff of the Missouri Geological Survey, and especially Mrs. M. H. McCracken, for making available well-log and other stratigraphic information on central Missouri. Ground surveys of the gravity and magnetic pattern of the area were conducted by J. D. Hendricks, U.S. Geological Survey. We also thank R. W. Paul, who assisted in fieldwork (1968), and C. E. Nichols, who provided a detailed stratigraphic section of the Jefferson City Dolomite outside the structure. Fission-track studies bearing on the possible age of the structure were made by C. W. Naeser, U.S. Geological Survey. The topographic base map was prepared by J. L. Derick, G. M. Nakata, and Raymond Jordan, U.S. Geological Survey.

\section{STRATIGRAPHY}

The Decaturville structure is underlain by a sequence of rocks approximately $540 \mathrm{~m}$ thick that ranges in age from Precambrian to Silurian. The Upper Cambrian and Lower Ordovician sequence of Missouri apparently is complete from the Lamotte Sandstone through the Jefferson City Dolomite, and all the formations (with the possible exception of the Cambrian Bonneterre Dolomite) are exposed, at least in part, at the surface. The lithologies of the formations in the Decaturville stratigraphic sequence are shown in figure 4 . 

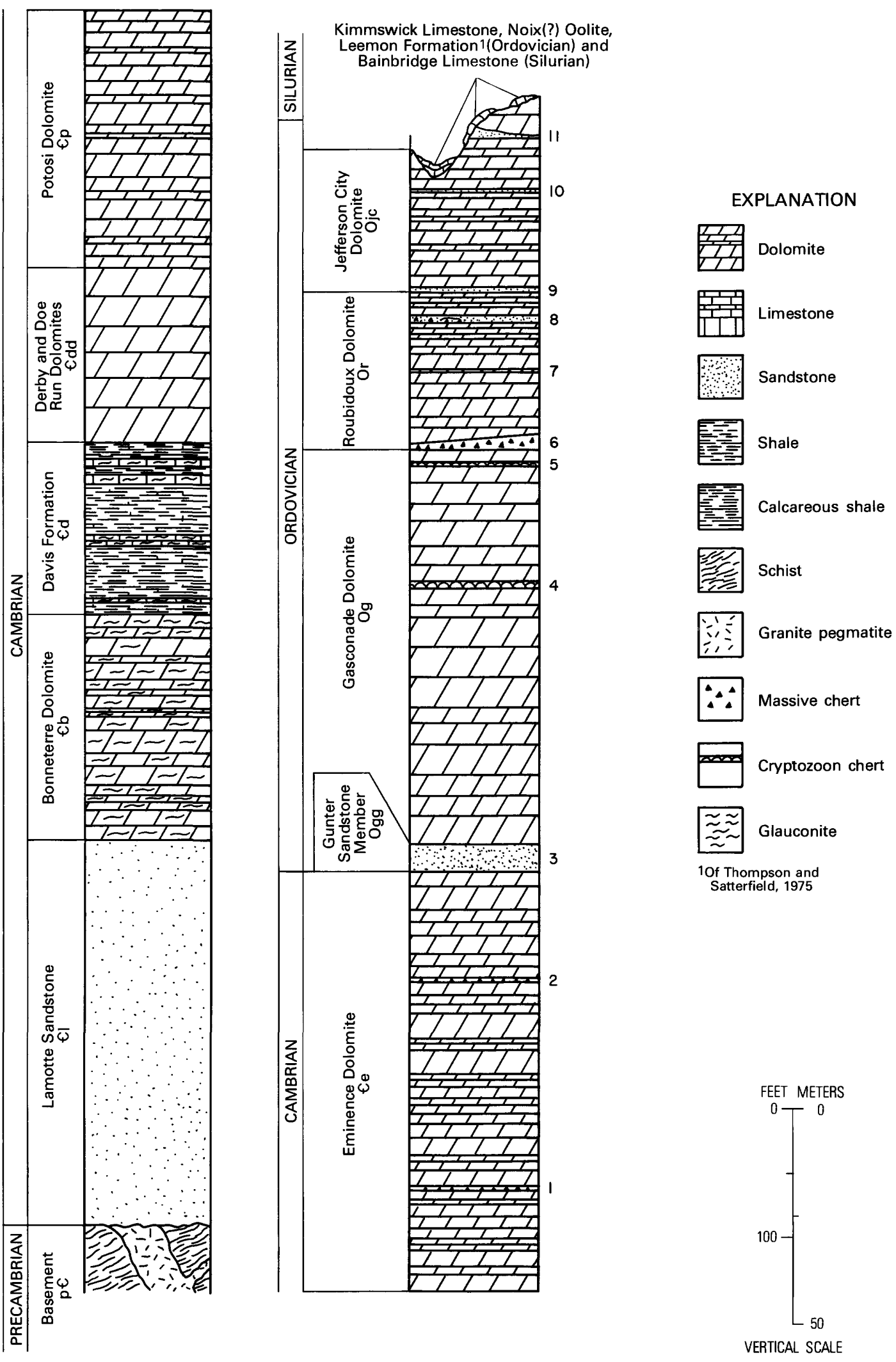

FIGURE 4.-Column showing lithologies and estimated thicknesses of Cambrian, Ordovician, and Silurian formations present in Decaturville structure; marker beds indicated by numbers. Base of section lower left; top of section upper right. 
Extensive core drilling at the center of the structure has recovered more than $5,500 \mathrm{~m}$ of core in 60 holes. Cores from the center of the structure reveal a chaotic mixture of rocks but all the formations from the top of the Precambrian basement through the Cambrian Potosi Dolomite have been recognized.

The difficulty of solving the complex structural relationships at Decaturville has been increased by the discontinuous nature of outcrops, by lateral variations in lithology of individual beds, and by low-angle thrust faults that make detailed measurements of thick stratigraphic sections all but impossible.

Several marker beds that were generally continuous or showed evidence of predictable lateral variation were used to solve these structural problems. Subsequent stratigraphic descriptions pay special attention to the lithology and color of these marker beds.

Less detailed descriptions of the intervening beds contribute to a general understanding of the gross lithologies of the formations.

\section{PRECAMBRIAN ROCKS}

Precambrian basement rocks, normally about $540 \mathrm{~m}$ below the surface, are represented in outcrop by a single block exposed near the center of the structure (map sector L-13, pl. 1). The block measures about 15 by $21 \mathrm{~m}$ in lateral extent and is continuous to a depth of $15 \mathrm{~m}$ in drill core. Most of this large block consists of granite pegmatite which displays a general pattern of lithologic zonation. In the poorly exposed center of the block, boulders lying on the surface indicate a quartz core a meter or two across. Around the core is a zone 3-6 m wide of coarse pegmatite containing quartz and microcline crystals as much as $5 \mathrm{~cm}$ long, intergrown to produce a graphic texture. This pegmatite locally contains as much as 5 percent muscovite. Outward from the coarse pegmatite is a much more disrupted zone of schistose and granulated micaceous pegmatite, containing accessory amounts of black tourmaline. The $\mathrm{Rb} / \mathrm{Sr}$ age of muscovite from the pegmatite was determined by Tilton, Wetherill, and Davis (1962) to be 1,445 m.y. A K ${ }^{40} / \mathrm{Ar}^{40}$ age for the same muscovite was 1,290 m.y., somewhat less, probably because the mica was slightly altered.

Muscovite schist at least $0.9 \mathrm{~m}$ thick is exposed in contact with the pegmatite in a trench on the northwest side of the pegmatite block. The schist contains accessory apatite and black tourmaline. Tourmaline crystals a re oriented to form a lineation that is deformed by pervasive rounded to kinklike crenulations typically $0.3 \mathrm{~cm}$ in amplitude. Along other margins the pegmatite is in contact with displaced blocks of the Potosi, Derby, Doe Run, Davis, and Lamotte Formations.

A few feet below the main pegmatite block, another $4.3 \mathrm{~m}$ of pegmatite was cut in a drill hole $31 \mathrm{~m}$ deep, and $1.8 \mathrm{~m}$ of schist was found. Other drill holes near the center of the structure cut a few small slivers of schist or pegmatite at various depths.

\section{CAMBRIAN SYSTEM}

\section{LAMOTTE SANDSTONE}

The outcrops of the Lamotte Sandstone in the structure are limited to one block $2 \mathrm{~m}$ long, to thin sand rinds that surround two blocks of Potosi Dolomite in the sulfide pit (map sector M-12, pl. 1), and to tightly cemented blocks adjacent to the pegmatite pod (map sector L-13). In addition, occurrences are numerous in drill cores. The thickest section is more than $37 \mathrm{~m}$ in a core that was started in Lamotte covered by soil. Unfortunately, the section shows no identifiable dip. Estimates made from drill holes nearest the structure (southeast of Lebanon, more than $32 \mathrm{~km}$ away) indicate a total thickness of $90 \mathrm{~m}$ for the formation.

Locally, the Lamotte is a tightly cemented bimodal sandstone, composed of coarse, light- to medium-gray, subrounded to rounded frosted quartz grains in an extremely fine grained nearly white matrix of quartz. Layering is marked by the distribution of the coarse grains. Some very fine grained parts of the Lamotte are seen in thin section to consist of angular quartz grains with about 25-30 percent feldspar. In core, the sandstone appears to be very clean; but in outcrop, the formation weathers yellow and shows some ferruginous cement.

In the eastern part of the State, where the Lamotte crops out, all the basal units are made up of a conglomerate of cobbles of Precambrian granite and schist in a sand matrix (Weller and St. Clair, 1928, p. 34-37; Dake, 1930). This particular lithologic character is not now seen in outcrop or in drill core on the structure; but in 1956 when the pegmatite pit was newly opened, T. E. Mullens (oral commun., 1974) observed several centimeters of conglomerate containing fist-sized pebbles of basement rock directly overlying the pegmatite. The conglomerate seems to grade laterally into schist, but the two rocks may be tectonically intermixed.

\section{BONNETERRE DOLOMITE}

No outcrops of unquestionable Bonneterre Dolomite have been identified, although it would seem reasonable to assume that some rock fragments in the mixed breccia in the sulfide pit are Bonneterre. In core, the Bonneterre has been identified as being a moderately glauconitic, medium- to fine-grained, light- to dove-gray dolomite that has a pale-olive-green cast when wet. The glauconite occurs as small pockets of pelletal material. Occasional thin shale partings are seen in the core sections. Small cavities lined with dolomite rhombs are characteristic.

Two drill holes at the sulfide pit penetrate a tilted block of Bonneterre. One core shows a continuous section of $43 \mathrm{~m}$ of Bonneterre, and although the formation is overlain by the Davis Formation and is underlain by Lamotte Sandstone, it 
is by no means definite that the section is not faulted. Three wells southeast of Lebanon show the total thickness of the Bonneterre to be $53 \mathrm{~m}$.

\section{DAVIS FORMATION}

The Davis Formation is the most easily identified formation, both in outcrop and in drill core. Parts of the formation are seen as huge blocks as well as fragments incorporated in the mixed breccia in the sulfide pit, and as a single small block beside the pegmatite pod. In core as in outcrop, the Davis is composed of interbedded light- to medium-gray, fine- to medium-grained limestone or limy dolomite and light-grayish-green limy siltstone and shale. The dolomite weathers pinkish tan and commonly contains lineations caused by alinement of millimeter-sized grains of glauconite. The shale and siltstone occur as beds from $0.3 \mathrm{~cm}$ to $15 \mathrm{~m}$ in thickness. A few angular grains of feldspar occur in some of the siltstone layers. The greatest thickness found in core section is $41 \mathrm{~m}$, and although the hole was started in the Davis Formation, it is felt that this core represents most of the formation. Thickness of the Davis in drill holes southeast of Lebanon is $40-43 \mathrm{~m}$.

\section{DERBY AND DOE RUN DOLOMITES}

The Derby and Doe Run Dolomites crop out as an ellipse 400 by $460 \mathrm{~m}$ at the center of the structure. These formations are extensively represented in drill cores, including one core from map sector $\mathrm{I}-19$, well outside the central outcrop area. From 30 to 40 percent of the materials in the cores from the center has been identified as belonging to the Derby and Doe Run.

Where the Derby and Doe Run crop out, they are white to tan, coarse-grained, massive dolomites that weather to a yellowish tan. Bedding is very rare in the cores and has only been tentatively identified in three outcrops; stylolites occur in a few core sections.

No attempt was made to map the Derby and the Doe Run separately, but the lower half of the map unit is composed of medium- to coarse-grained, white to yellowish- or pale-brownish-white dolomite. The upper or Doe Run half of the map unit as seen in core section is composed of medium-gray, fine- to medium-grained dolomite crystals in a very fine grained light-gray matrix. The occurrence of individual grains of glauconite is common to rare, but small pockets of clay and glauconite are common. In rare instances, samples contain a few quartz grains, some as nuclei of dolomite crystals.

The thickness of the Derby and Doe Run in the wells southeast of Lebanon is $40-43 \mathrm{~m}$. Because of the paucity of bedding at the structure, no estimate of the thickness is possible.

\section{POTOSI DOLOMITE}

The Potosi Dolomite is poorly exposed in an irregular annulus which surrounds the Derby and Doe Run
Dolomites at the center of the structure. The areas between outcrops are characterized by a typical deep-red to reddish-brown very clayey soil. The formation is a conspicuous part of the breccia in many core sections.

One of the most distinctive formations in the section at Decaturville, the Potosi is a poorly bedded, fine- to medium-crystalline, light- to medium-pinkish-brown dolomite. The color is distinctive, but the chief diagnostic feature of the Potosi is quartz druse found in outcrop. The druse consists of microscopic to macroscopic clear to tan crystals on botryoidal surfaces of white to gray quartz. Thin sections show the Potosi to contain minor amounts of detrital quartz and chert, and very sparse microcline. Freshly broken rock has a noticeable bituminous smell.

The Potosi has been logged in drill holes $13 \mathrm{~km}$ to the northwest and 8-16 km to the south as being $61 \pm 6 \mathrm{~m}$ thick.

\section{EMINENCE DOLOMITE}

The Eminence Dolomite is the oldest unit in the structure to exhibit exposures of virtually the whole formation. It typically supports abundant stands of cedar trees. The exposures of Eminence are, in general, good as well as widespread. Occurrences of Eminence in core are rare.

The lower half of the formation is composed of very light gray to slightly tannish gray, fine- to medium-crystalline dolomite and dolomite breccia in beds $1-10 \mathrm{~cm}$ thick. Most of the breccias consist of light-gray clasts in a yellowish-tan matrix. A single 8-cm bed of white porcelaneous chert (no. 1, fig. $4 ; \mathrm{pl} .1$ ) is present locally approximately in the middle of the lower half of the Eminence section.

The upper half of the Eminence is characterized by more massive and resistant outcrops than the lower half. It is composed of very light- to light-tannish-gray, fine to coarsely crystalline dolomite breccia and sparse unbrecciated dolomite in beds $0.15-2 \mathrm{~m}$ thick. As in the lower half of the Eminence, a single bed of white porcelaneous chert (no. 2, fig. 4; pl. 1) as thick as $0.9 \mathrm{~m}$ occurs in places approximately in the middle of the section.

Distinctive light-tan soils that are formed on both the upper and lower halves of the Eminence are composed of fine-grained dolomite sand.

The thickness of the Eminence in drill holes $16 \mathrm{~km}$ to the northwest and $16 \mathrm{~km}$ to the east is $99 \pm 5 \mathrm{~m}$.

\section{ORDOVICIAN SYSTEM}

\section{GASCONADE DOLOMITE}

\section{GUNTER SANDSTONE MEMBER}

The Gunter Sandstone Member is the lowermost of the key beds used for detailed mapping of the Decaturville structure (no. 3, fig. 4; pl. 1). This unit occupies a roughly triangular outcrop belt $610-1,220 \mathrm{~m}$ from the center of the structure. A huge isolated block of the sandstone also is found at the village of Decaturville, well outside the outcrop 
belt (sectors G-19, H-19, pl. 1). In outcrop, the Gunter commonly supports a lush growth of kelly-green moss, and where the sandstone is shallowly buried the unit is marked by a dense growth of poison ivy. The poison ivy is so closely tied to the sandy soil that in many places it is possible to follow the buried sands for one or two hundred meters between outcrops by walking out the poison ivy belt.

The Gunter is a quartz sandstone containing a bimodal distribution of rounded, frosted fine- and medium-sized grains. It weathers brown or buff and is clean white to slightly iron stained on fresh surfaces. The medium-sized sand grains are extremely pitted and have the appearance of miniature translucent golf balls. They make up 5-20 percent of the rock. In several places, notably in G-19 and I-11, the Gunter is highly fractured, with the fractures silicified enough to be slightly resistant and to weather in raised relief.

The thickness of the Gunter Sandstone Member varies from 3 to $8 \mathrm{~m}$ within the structure and from 2 to $12 \mathrm{~m}$ in drill holes and outcrop within a $32-\mathrm{km}$ radius of the structure.

\section{UPPER PART}

The upper part of the Gasconade crops out sparsely in a zone from the Gunter Sandstone Member to a distance of approximately $1.6 \mathrm{~km}$ from the center of the structure. The width of this zone is small relative to its thickness as compared to those relationships for most of the other formations in the structure.

The upper part of the formation consists principally of medium- to thick-bedded gunmetal-gray dolomite, medium to coarsely crystalline and saccharoidal in texture. Some beds are tectonically brecciated on a fine scale and are composed of typical Gasconade clasts in a tan- to whitish-gray matrix.

A bed of cryptozoon chert 0.3-0.9 m thick (no. 4, fig. 4; pl. 1) is approximately $20-30 \mathrm{~m}$ below the top of the Gasconade within the structure. It likely corresponds to the cryptozoon ledge described as the top of the lower part of the dolomite sequence of the Gasconade in the Lebanon quadrangle several kilometers to the south (Searight, 1955, p. 7). A second bed of cryptozoon chert, 0.3-0.6 m thick (no. 5, fig. 8; pl. 1), occurs approximately $3 \mathrm{~m}$ below the Gasconade-Roubidoux contact southeast of the structure. A thin dark-gray chert bed in the same position west is extremely porous and ropy; coral-like rounded masses of it are abundant in float.

Between the west edge of the area shown on plate 1 and Banks Branch $0.5 \mathrm{~km}$ farther west, several outcrops of sandstone as much as $3 \mathrm{~m}$ thick were found within the Gasconade. These sandstones do not resemble those seen in the Roubidoux. (See following section.) Moreover, they do not seem to be faulted into the Gasconade. They seem to be similar to the sandstone beds and lenses reported from the Gasconade in Miller County $56 \mathrm{~km}$ to the northeast (Ball and Smith, 1903, p. 37).

The thickness of the upper part of the Gasconade at the structure is estimated to be $93 \pm 2 \mathrm{~m}$ as determined from drill holes to the east, north, and south of the structure.

\section{ROUBIDOUX DOLOMITE}

Outcrops of Roubidoux Dolomite are common in a zone from the southwest to the northwest parts of the Decaturville structure, but are uncommon in the rest of the mapped area. In addition to lying in normal sequence in an annulus from 1,520 to $2,000 \mathrm{~m}$ from the center of the structure, the Roubidoux commonly occurs in fault slices as the formation nearest the ring fault on the west side.

Where bedrock is shallowly buried the residual soil is characterized by an abundance of sandstone and chert float, the chert commonly being present as blocks as much as $3 \mathrm{~m}$ on a side and 0.3-0.6 m thick. In many areas the Roubidoux Dolomite supports dense stands of scrub oak.

The base of the Roubidoux is in general represented by a single chert bed 1.5-3.4 m thick, typically a blocky sedimentary breccia but in places laminated and showing algal structures (no. 6, fig. 4). The $12-15 \mathrm{~m}$ of section above the basal chert is lithologically indistinguishable from the underlying Gasconade Dolomite. A second chert bed 0.3-0.6 $\mathrm{m}$ thick (no. 7) is present about $18 \mathrm{~m}$ above the base of the formation. In the section above the second chert the dolomite becomes successively thinner bedded, lighter gray, and more finely crystalline. Some beds or laminae contain numerous sand grains. A single sandstone bed $1.2 \mathrm{~m}$ thick (no. 8) occurs approximately $30 \mathrm{~m}$ above the base of the Roubidoux. In places on the west side of the structure this sandstone seems to be represented by a mixed sand and chert sedimentary breccia. In hand specimens the fine to medium quartz grains are subangular to subrounded and most are slightly frosted. The individual grains are weakly cemented by iron oxide which gives the sandstone a reddish-tan cast.

The upper approximately $6 \mathrm{~m}$ of the formation is composed of thin-bedded $(1-8 \mathrm{~cm})$, aphanitic, tan marly dolomite (locally termed "cotton rock") interbedded with beds of tectonically brecciated medium-gray dolomite 8-15 $\mathrm{cm}$ thick. Green shale partings also occur at places in the upper part of the Roubidoux.

The total thickness of the Roubidoux Dolomite on the structure varies from 31 to $37 \mathrm{~m}$, although our choice of the formation top for mapping purposes may add about $4 \mathrm{~m}$ to the unit, relative to other mapped areas. (See following section.) Outside the structure, drill holes and mapping show that the formation is $29-38 \mathrm{~m}$ thick.

\section{JEFFERSON CITY DOLOMITE}

The outer zone, ranging in width from 610 to $1,220 \mathrm{~m}$ from the Roubidoux Dolomite to the ring fault, is underlain mostly by Jefferson City Dolomite, the youngest formation of Early Ordovician age present. Exposures of the Jefferson City are excellent on the west side of the structure. The belt of Jefferson City is the widest in proportion to formation thickness of any of the formations in the structure. 
Although the contact of the Roubidoux with the Jefferson City has been widely accepted to be the well-known "buhr-stone" chert marker bed and is mapped that way by $\mathrm{C}$. E. Nichols (1973) in an area just south of the structure, we have seen this contact at only one place on the structure. Nichols mapped a bed of sandstone $1.5 \mathrm{~m}$ thick occurring 1.8 $\mathrm{m}$ below the "buhr-stone" chert, and we are confident that this is the same bed that we have mapped as the $1.2-\mathrm{m}$ sandstone bed $6 \mathrm{~m}$ below the marker that we have selected as the base of the Jefferson City. That marker bed (no. 9, fig. 4; pl. 1), chosen for mapping convenience because of its numerous outcrops and distinctive character, is a platy sandstone, commonly mud cracked and ropy, composed of uniformly fine grained, subangular, clear grains. This sandstone varies in thickness from $8 \mathrm{~cm}$ to $0.3 \mathrm{~m}$, is moderately well cemented with iron oxide, and in general has a reddish cast.

The section for $23 \mathrm{~m}$ above the basal sandstone is a mixture of thin to medium beds of light- to medium-gray-brown, medium-crystalline dolomites, tan, aphanitic marly dolomites ("cotton rock"), and thin- to thick-bedded dolomite breccias. The conspicuous marker sequence of thick-bedded dolomite called "quarry ledge" and mapped some $11 \mathrm{~m}$ above the base of the formation elsewhere in the region was not positively identified anywhere in the ring zone. Possible occurrences were noted in sectors L-6, G-8, and F-15. Thin beds $(2.5-7.6 \mathrm{~cm})$ of hackly chert breccia and thin dolomite beds containing algal structures occur in a few places. Large ovate nodules of brown chert appear in float.

Approximately $23 \mathrm{~m}$ above the basal sandstone is a second sandstone bed (no. 10) composed of clean, fine-grained, angular, clear to slightly frosted quartz. At places, the sandstone grades laterally into a sandy chert bed or into a zone $15 \mathrm{~cm}$ to $0.3 \mathrm{~m}$ thick that is composed of alternating 2.5 $\mathrm{cm}$ beds of aphanitic, white-weathering, whitish-tan dolomite and pink, very fine grained sandstone that is made up of subrounded and slightly frosted grains and covered with black lichen. The differential weathering combined with the alternating light and dark zones results in a banded appearance rather like that of varved glacial clays.

The approximately $14 \mathrm{~m}$ of section between the second or middle sandstone bed and the third sandstone bed (no. 11) of the Jefferson City is mostly composed of thin-bedded, aphanitic, tan dolomite and dark-grayish- to chocolate-brown dolomite and dolomite breccia. Beds become increasingly more massive upward in the section, and the unit just below the upper sandstone is a bed of pale-reddish-purple cryptozoon dolomite 1.8-2.4 m thick.

The third or upper sandstone bed (no. 11) is the most highly variable in both texture and thickness of all the marker sandstone beds in the section. The thickness varies from 0.6 to $3 \mathrm{~m}$ (and at map locality $\mathrm{H}-7$ more than $12 \mathrm{~m}$ ). Lithologically, the fine-grained sandstone varies from dominantly subangular and glassy grains with fewer rounded-to-subrounded frosted and clear grains to mostly subrounded frosted grains mixed with highly comminuted glassy grains.

As much as $6 \mathrm{~m}$ of section is preserved just above the upper sandstone bed. This $6 \mathrm{~m}$ is predominantly thin bedded dolomite breccia and dolomite beds, overlain by a series of massive beds 0.6-0.9 $\mathrm{m}$ thick of grayish-tan medium-crystalline dolomite and brecciated dolomite.

On the east side of the structure, many of the outcrops in the ring zone are isolated exposures of sandstone. Massive white sandstone, especially where near limestone outcrops, can reasonably be identified as the upper sandstone of the Jefferson City, and the basal sandstone is typical and readily identifiable where it occurs. Many of the other sandstone outcrops, however, have a bimodal grain-size distribution not like the distribution in any of the sandstone beds mapped in the Jefferson City on the west side. Numerous large frosted quartz grains or white chert grains are scattered through a fine-grained, angular, clear quartz matrix. These sandstone beds also do not resemble any units below the Jefferson City. They are considered tentatively to be equivalent to the middle sandstone bed of the west side and are mapped as such; but it is possible that some of the outcrops may be Roubidoux sandstone in lithology slightly different than previously observed, and they thus may indicate unmapped fault blocks.

\section{KIMMSWICK LIMESTONE}

Numerous small patches of limestone occur atop the Jefferson City Dolomite in the depressed ring zone around the structure; these are assigned with reasonable certainty on the basis of fossil content to the Kimmswick Limestone, which is of Middle Ordovician age. The limestone is thin bedded, light to medium gray, and generally aphanitic, but at places fine or medium crystalline. It typically weathers light gray with a slight bluish cast. Numerous outcrops are brecciated and contain coarsely crystalline white calcite. Resistant fossil material is evident on weathered surfaces of many of the limestone outcrops. The limestone fauna identified to date (collection E6-4; R. J. Ross, written commun., 1971) consists of brachiopods Paucicrura sp., Rostricellula? sp.,Sowerbyella sp., Zygospira sp., Furcitella? sp., and conodonts (identified by L. A. Wilson) Acontiodus alveolaris Stauffer, Cordylodus sp., Amorphognathus sp., Drepanodus homocurvatus Lindstrom, Polyplacognathus sp., Oistodus inclinatus Branson and Mehl, Ozarkodina cf. O. concinna Stauffer, Panderodus panderi (Stauffer), Panderodus compressus (Branson and Mehl), Prioniodina sp., Sagittodontus sp., and Trichonodella flexa Rhodes.

In a few places, the thin-bedded limestone rests conformably on a thicker bedded aphanitic to fine crystalline limestone that seems to be much less fossiliferous. The lower part of the limestone section possibly is Plattin Limestone.

Exposed thickness of the limestone beds nowhere exceeds $4 \mathrm{~m}$ in the Decaturville structure, although in places 
limestone outcrops occur as much as $9 \mathrm{~m}$ below hill crests. This may be explained by structural displacements or by hills having an irregular erosion surface on the Jefferson City and being partly plastered with limestone, but the possibility also exists that the hilltops are underlain by more of the limestone or even by unexposed younger formations.

\section{NOIX(?) OOLITE}

One small patch of a very distinctive limestone (the southeasternmost of a group of five limestone patches in sector $\mathbf{M - 5}$ ). has been identified as Late Ordovician in age. The limestone is thin bedded, medium gray, and weathers light brownish gray on a bas-relief surface showing the rock to consist mostly of oolites and fossil hash. It occurs within a few feet laterally of Leemon Formation of Thompson and Satterfield (1975) of Late Ordovician age. The unusual lithologic character of the limestone matches that of the Noix Oolite which elsewhere underlies the Leemon Formation. The Noix and Leemon are part of the Edgewood Group of Thompson and Satterfield (1975, p. 77).

The limestone "contains most of the elements of the faunule described from the Thebes Sandstone" (collection E2-2; J. W. Huddle, written commun., 1971, revised by J. Repetski, 1975):

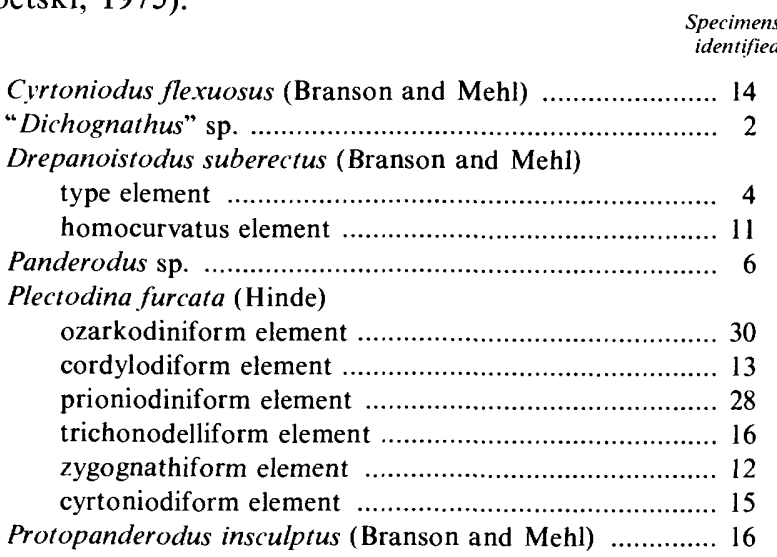

\section{LEEMON FORMATION}

Next to the Upper Ordovician limestone (Noix (?) Oolite) in sector M-5 are four outcrops of the Upper Ordovician Leemon Formation (newly defined by Thompson and Satterfield, 1975, as part of their Edgewood Group), a brownish-red to purple limestone, partly coarsely conglomeratic and partly somewhat shaly. The Leemon contains fossils that may range from Late Ordovician to Early Silurian age: Dalmanella edgewoodensis, a primitive clorindid of the genus, Brevilamnulella, and a rostrospiroid (collection E2-1; A. J. Boucot, written commun., 1971). A coral fragment, identified by W. A. Oliver, Jr. (written commun., 1971) as cf. Pycnolithus sp., is less diagnostic but indicates Late Ordovician to Middle Silurian age.

Similar limestone just south of a fault in the northwestern part of locality E-7 probably is Leemon also. The color is more like that typical of the Bainbridge Limestone, but the fauna is of Leemon age.

\section{SILURIAN SYSTEM}

\section{BAINBRIDGE LIMESTONE}

Thin-bedded cream or tan limestone with a greenish cast similar to part of the Bainbridge Limestone (Ball, 1939) occurs in two outcrops surrounded by outcrops of massive dolomite in sectors L-4 and M-4. Fragmental fossil material from this limestone has been tentatively identified as Middle Silurian (R. W. Paul, written commun., 1969), which is the age of the Bainbridge. Similar limestone forms the northernmost of three limestone outcrops in the center of sector U-10.

Another three outcrops of fossiliferous limestone, light dove gray, fine to medium crystalline, and weathering pinkish brown, is found in a stream bed on the line between sectors U-9 and U-10 and probably represents another part of the Bainbridge. It contains a fragmentary strongly trilobate pentamerinid brachiopod with characteristics believed to indicate Middle Silurian (Wenlock-Ludlow) age (A. J. Boucot, written commun., 1971). Boucot comments, "The Bainbridge Limestone is the nearest named unit that this material could be assigned to, but shells of this type have not previously been reported from the Bainbridge (dolomites in the Mid-Continent do have them)." This limestone also contained an indeterminate stromatoporoid. Two localities in F-8 also appear to be Bainbridge Limestone.

A sixth locality, not seen by us, was reported from the northeastern part of the ring zone, in a highway construction drill hole made when State Route 5 was moved a short distance (noted in Snyder and Gerdemann, 1965, p. 485).

It should be noted that all the limestone outcrops shown on the map, except those specifically described here as Noix(?), Leemon or Bainbridge, very much resemble lithologically the limestone beds paleontologically identified as of Kimmswick age. However, very few of the limestone outcrops were examined paleontologically; therefore, some of them may be unrecognized Silurian limestone or possibly Middle and Upper Ordovician limestones not previously mentioned. Because of the paleogeographic importance of the limestone stratigraphic assignments, a specific study of all the limestone outcrops mapped is highly desirable.

\section{REGIONAL PALEOGEOGRAPHIC IMPLICATIONS}

The Decaturville structure provides interesting paleogeographic information because it exposes formations otherwise seen only on the flanks of the St. Francois Mountains $113 \mathrm{~km}$ to the east and because it preserves remnants of other formations that elsewhere are missing across central Missouri. The Upper Cambrian-Lower Ordovician sequence is different from that described in eastern 
Missouri only in relatively minor ways (Koenig, 1967). No conglomerate or arkose is seen in the exposed or cored Lamotte Sandstone, although the basal part may include such phases. Edgewise conglomerate beds were not found in the Davis Formation, nor were sandstone beds. The Derby and Doe Run differ considerably from those formations in described eastern Missouri sections; they are massive to the point of being without bedding, entirely dolomite without any siltstone or shale, and white or mottled two-tone gray. In the Eminence Dolomite, no quartz druse or fossils were found, though these are common elsewhere. The Gunter Member and the upper part of the Gasconade, Roubidoux, and the Jefferson City rocks are relatively similar to those in these formations in the surrounding region. A maximum of $43 \mathrm{~m}$ of Jefferson City Dolomite was present in the area when the Middle Ordovician Kimmswick Limestone was deposited. The Kimmswick seems principally to have been laid down in lows or on slopes of an erosion surface with about $15 \mathrm{~m}$ of relief. It is considerably thinner than where it crops out in eastern Missouri. No rocks of the intervening section (including the Middle Ordovician St. Peter Sandstone) were found, and it is not known if they ever covered the area.

A similar unrecorded interval existed after the Kimmswick until latest Ordovician time when the Noix(?) Oolite and the Leemon Formation were deposited. Inasmuch as the Sexton Creek Limestone of Savage (1909) has not been identified in the area, the Middle Silurian Bainbridge Limestone is assumed to have been deposited disconformably upon the Leemon Formation. Whether these units were continuous or filled only topographic lows is not known, but the Upper Ordovician to Lower Silurian seas and Middle Silurian sea clearly covered this part of the Ozark dome.

\section{STRUCTURE}

The Decaturville structure is a sharply fault bounded, roughly elliptical area of intense and unusual deformation, set within the broad expanse of nearly flat lying Paleozoic sedimentary rocks of the Ozark Plateau. The major axis of the ellipse trends northwest and measures $6.3 \mathrm{~km}$; the minor axis is $5.5 \mathrm{~km}$ long. Inside the fault boundary, a structurally depressed ring zone about $1.6 \mathrm{~km}$ wide surrounds a central domelike uplift about $2.4 \mathrm{~km}$ across. Rocks preserved in the ring depression include Ordovician and Silurian limestones, outliers of two formations which have westward pinchouts in eastern Missouri, 135 and $277 \mathrm{~km}$ from Decaturville. The central uplift is capped by a formation $305 \mathrm{~m}$ above normal stratigraphic position, and isolated blocks of other units have been lifted as much as $540 \mathrm{~m}$. Decaturville affords the westernmost exposure of these formations after they dip beneath younger rocks on the flank of the St. Francois Mountains $145 \mathrm{~km}$ to the east. The disturbed area is characterized by complex folds and faults and by brecciation of unusual type.

\section{DEFORMATION OUTSIDE THE STRUCTURE}

The structure lies along the crestal zone of a regional upwarp, as can be seen in the Geologic Map of Missouri (McCracken, 1961) and in the structure contours on the base of the Gasconade Dolomite (fig. 5). These contour data indicate that the Gasconade in the vicinity of Decaturville has regional dips of less than $2 \mathrm{~m}$ per $\mathrm{km}$ east and west from the axis of the upwarp. Eleven kilometers northwest along the axial strike from Decaturville, the Eminence Dolomite and perhaps some Potosi Dolomite are exposed near Camdenton in what is called the Proctor anticline. These formations are partly truncated on the west limb of the anticline by the Red Arrow fault. The fault does not apparently continue toward Decaturville, but a small fault that offsets the structure's ring boundary lies along a direct projection of the Red Arrow fault and has the same sense of displacement. The regional upwarp persists another $24 \mathrm{~km}$ northwest of the Ozarks. No direct relationship between the Decaturville structure and this regional fold is apparent. Another slight regional tilt is observed from elevations of the base of the Roubidoux Dolomite outside the structure. The Roubidoux seems to dip northward fairly uniformly across the mapped area, at about $4 \mathrm{~m}$ per $\mathrm{km}$. A slight eastward component of dip on the Roubidoux base amounts to about $2 \mathrm{~m}$ per $\mathrm{km}$ from one side of the structure to the other.

Most bed dips outside the structure are very low, but isolated outcrops show dips as steep as $32^{\circ}$, particularly 4.8-6.4 km away to the south (near Eldridge) and to the north (along County Highway K). The dipping beds do not define folds, and outcrops are too sparse for tracing of possible structural lines. Because most outcrops show flat-lying beds between the structure and these dipping beds, and because a zone of disturbance was not found at this distance all around the structure, we do not believe that the tilted rocks are related to the Decaturville structure. More likely they are evidence of faults related to the deformation episode marked by the Red Arrow fault.

An orthogonal drainage pattern outside the structure is typical of much of central and western Missouri and reflects pervasive joint sets trending northeast and northwest. That the axes of the elliptical structure also trend in these directions is probably not coincidence. The drainage pattern and jointing are completely disrupted at the ring boundary of the Decaturville structure, and little evidence would indicate that the joint pattern influenced deformation within the structure or that it subsequently was reimposed across the disturbed area.

About $1.6 \mathrm{~km}$ west of the structure, and just off the boundaries of the geologic map (pl. 1), a north-trending straight segment of Banks Branch marks a fault of unknown but probably small displacement. Small crossfaults are associated with the east side of this fault, but they cannot be traced eastward far enough to intersect the ring boundary. Nearby, and in the mapped area (sector N-2), sandstone, 


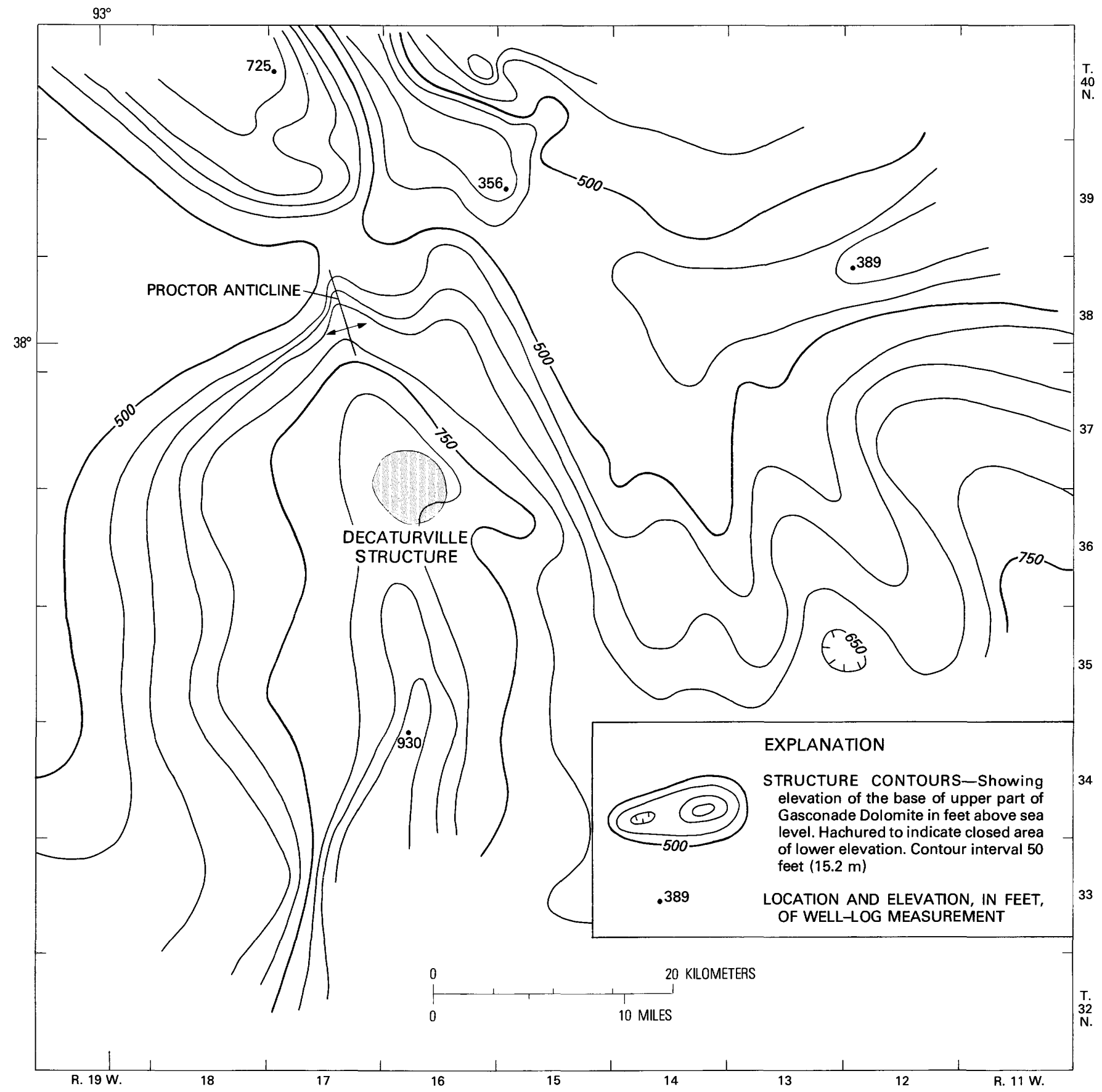

FIGURE 5.-Structure contour map on the base of the upper part of the Gasconade Dolomite. Well-log information from Missouri Geological Survey.

probably Roubidoux but possibly Gasconade, occurs along a fault in the Gasconade.

A few small folds were seen short distances beyond the structure. Low-amplitude undulations a few feet wide occur in thin-bedded sandstone and chert of the Roubidoux in poor roadside exposures at the south edge of the mapped area (State Route 5, sector Z-18) and just off the southeast corner of the area of plate 1 on County Highway W (near center of sec. 15, T. 36 N., R. 16 W.). One fairly sharp monoclinal flexure, showing asymmetric rotation outward from the structure, was noted in a cliff exposure of Roubidoux Dolomite along a streamcut at sector G-23. Axes of these features are oriented crudely circumferential with respect to the Decaturville structure.

The small faults and folds described above cannot be related specifically to the structure, but the close proximity 
and type of deformation-particularly the folds-suggest that these features were products of the main disturbance. In three other places, the relationship is clear: small faults cut the ring fault that bounds the structure (sectors D-7, D-12, G-5). Gentle dips along the line of the crossfault in D-7 indicate that deformation extends no more than $183 \mathrm{~m}$ beyond the ring fault.

Broad-scale warping of the plateau sequence just outside the ring fault can be inferred from the isolated outcrops of marker beds. It is not clear how much of the apparent warping just outside the fault was produced when the structure was formed and how much might be due to earlier regional deformation. Elevations of the base of the Jefferson City Dolomite in the zone outside the ring fault indicate that formations south and north of the structure are respectively about $31 \mathrm{~m}$ and $76 \mathrm{~m}$ below the positions expected from the regional structure contours shown in figure 5. The northward deepening matches the plunge of the regional structure, but either that anticlinal plunge culminated in a low north of the Decaturville structure and then slightly reversed northward toward Camdenton or the Decaturville disturbance produced significant downwarp outside the ring boundary. The probable original dip of strata across the area was on the order of $1^{\circ}$, and the disturbance can be inferred to have caused elevation changes in formations of $31 \mathrm{~m}$ at the maximum, from one side of the structure to the other. The structurally induced dips outside the structure, therefore, probably were typically $1^{\circ}$ to $2^{\circ}$.

\section{RING-FAULT BOUNDARY}

A normal ring fault, with downthrown side toward the center, surrounds the structure and forms the boundary around the area of most intense deformation. As can be seen from outcrop distribution shown on plate 1, this fault can only be inferred along much of its length; in places, the boundary could be a flexure rather than a fault. However, the likelihood of a continuous ring fault is indicated by the abundance of Roubidoux float which in general ends rather abruptly just outside the inferred fault line, by the very appreciable stratigraphic displacement over short distances, and by the general lack of dip in beds outside the line sufficient to account for the displacement across the boundary. The fault is known to be broken by crossfaults in three places on the north and northwest. Probably many other crossfaults have not yet been detected; these might alter the ring-fault trace now shown as a combination of inferred straight and somewhat scalloped segments. We believe, however, that changes in float and breaks in topographic slope permit the general line of the ring fault to be drawn to within $\pm 61 \mathrm{~m}$ of the actual location even in areas of sparsest outcrops.

Displacement on the ring fault can be estimated fairly closely in many places. Generally, Jefferson City Dolomite is downdropped against Roubidoux Dolomite, but in places offset is entirely within the Roubidoux; in only three places of low topography is Gasconade Dolomite exposed against the fault on the footwall. The displacement ranges from 20 to $128 \mathrm{~m}$ and varies considerably in short distances. Because of unknown amounts of drag on outside beds and uncertainties in contact elevations and formation thicknesses, the estimates of displacement are considered accurate to about 6 $\mathrm{m}$. Figure 6 shows generalized amounts of stratigraphic displacement in the structure. On the north side, the ring fault has dropped blocks down 61-92 m. In the northwest, displacements are 61-107 m. An outcrop block in sectors D-7 and E-7 (pl. 1) is down $107 \mathrm{~m}$ at the north end and $82 \mathrm{~m}$ at the south end. The western sector of the fault shows the maximum known range of displacements, from less than 20 $\mathrm{m}$ to more than $122 \mathrm{~m}$, the large variations over small distances owing to the presence of small fault-bounded blocks that dropped independently of each other. At the south edge of L-3, uppermost Jefferson City is juxtaposed against Gasconade, and displacement is $107 \mathrm{~m}$. In another fault block just to the north, Roubidoux lies against Roubidoux along the ring fault, and displacement is no more than $20 \mathrm{~m}$. At one place on the south edge (sector V-12), displacement of $60 \mathrm{~m}$ is believed probable. In the southeast and northeast, reliable estimates cannot be made. In two map sectors on the east boundary, N-22 and O-22, displacements are 76 and $95 \mathrm{~m}$.

Larger and smaller displacements alternate irregularly around the perimeter. The pattern is clear on the north and west sides where outcrop data provide good control, and it seems on the basis of sparse data also to be clear on the east and south sides. A wavelike sequence of highs and lows marked by displacement is consonant with the type of movements recorded by complex structural features of the central uplift, to be discussed in a subsequent section entitled "Central uplift."

Good outcrops just outside the fault area are sparse, but drag on the footwall strata seems commonly to extend no more than $30-60 \mathrm{~m}$ beyond the ring boundary. An exception is seen in sector D-7 where dips of $8^{\circ}$ are seen about $180 \mathrm{~m}$ outside the fault boundary, but these may relate to a fault that cuts the ring fault. In sector L-3, where fault displacement is $107 \mathrm{~m}$, beds are dragged down about $2 \mathrm{~m}$; a resulting tilt is not seen more than $15 \mathrm{~m}$ beyond the fault. In a few places at short distances beyond the ring fault, Roubidoux sandstone has been highly fractured, and the fracture network so silicified that it is resistant and stands out in relief on outcrop surfaces.

The dip of the fault is known from direct evidence only in one place, M-3, where the fault has the maximum known displacement. At M-3, an exploratory hole drilled about 150 $m$ inside the fault line by the St. Louis Smelting and Refining Co. went through a normal downdropped sequence to $90 \mathrm{~m}$, then through a stratigraphically jumbled zone to $150 \mathrm{~m}$, and then crossed into the normal footwall sequence. The wide 


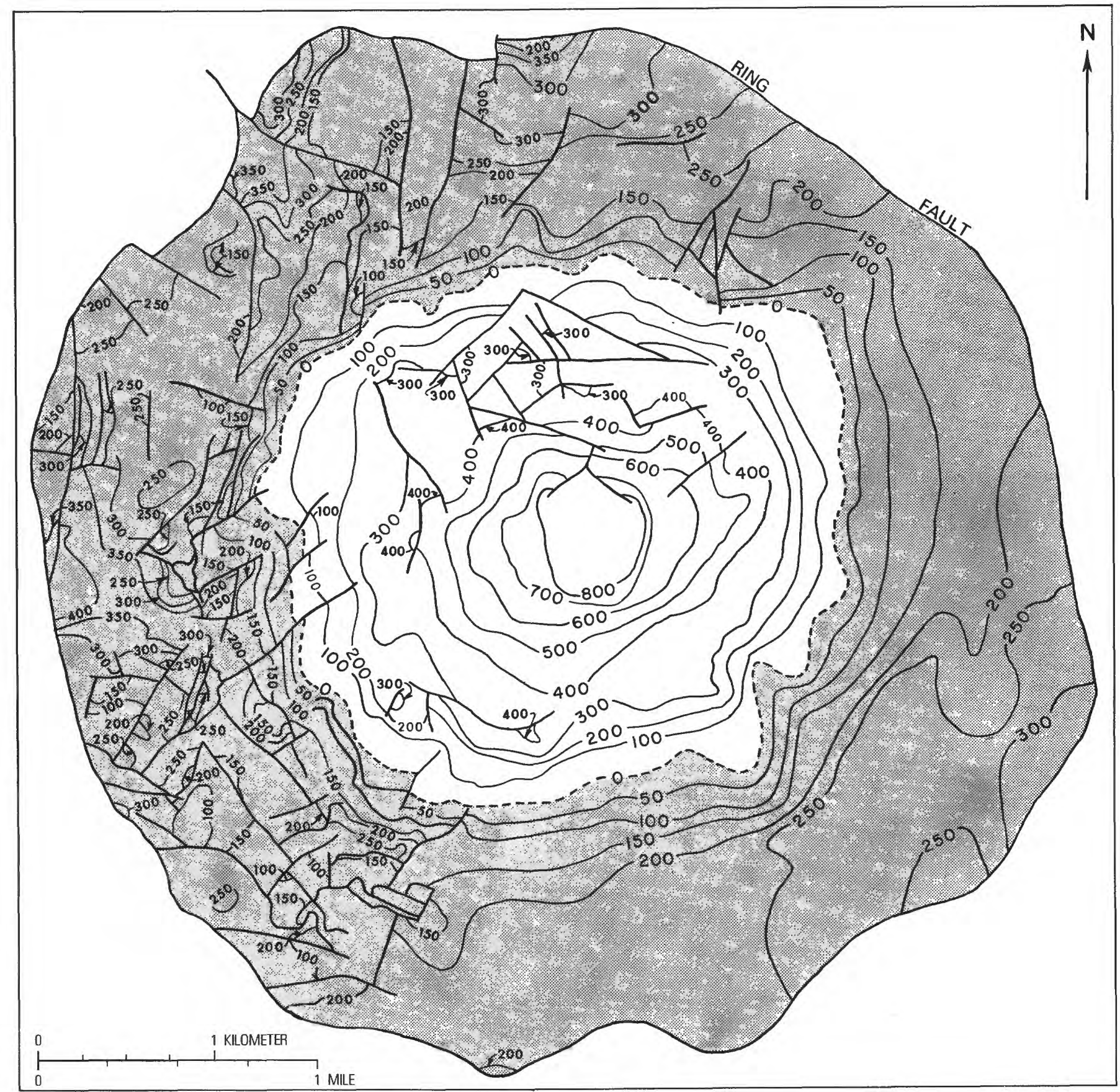

\section{EXPLANATION}

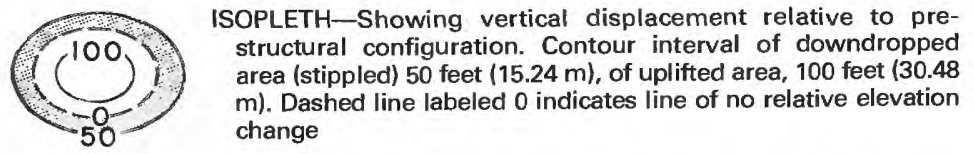

FIGURE 6.-Map of isopleths showing pattern of vertical displacements in Decaturville structure relative to prestructure configuration. Heavy solid lines, faults.

broken zone probably reflects complications from a fault $\mid$ fault is clearly evident at $150 \mathrm{~m}$. This gives the fault an between the hole site and the ring fault, but the main ring $\mid$ average dip of $45^{\circ}$ from the surface to a depth of $150 \mathrm{~m}$. A 
similar dip is suggested in L-3 just to the north by a large slab of fault breccia that dips $45^{\circ} \mathrm{E}$. This dip does not fit much of the fault trace shown on plate 1 . Most of the trace across the gentle topography suggests a steeply dipping fault at the surface. The curving fault trace is drawn as a smooth, continuous line, which may be misleading because in places the fault may be mislocated by perhaps $60-90 \mathrm{~m}$, and may actually be broken by many small concealed faults. It is believed that most of the fault is steep at the present ground surface, and in profile curves inward below ground to form a continuous bowl-like boundary surface around the entire Decaturville structure. We surmise that the fault dips $60^{\circ}-75^{\circ}$ just below surface and about $30^{\circ} 150-200$ meters lower to give the observed average dip of $45^{\circ}$.

Crossfaults that offset the ring fault by 140,79 , and $107 \mathrm{~m}$, are mapped in G-5, E-7, and D-12, respectively. Inasmuch as these faults have displaced beds outside the ring fault little, if any, they are regarded as tear faults that have horizontal displacement. They probably formed simultaneously with the ring fault; and beds inside the ring fault, being more free to move in a different stress environment, are vertically displaced different amounts on opposite sides of the crossfaults. In E-8, for example, Jefferson City marker beds indicate $60 \mathrm{~m}$ of downthrow on the ring fault on the north side of the tear fault, and $107 \mathrm{~m}$ on the south side, in the present position of the blocks. If the apparent lateral displacement is removed, the difference in vertical displacements on opposite sides of the fault is even greater.

\section{DEPRESSED ZONE}

Inside the ring fault lies a $1 \frac{1}{2}-\mathrm{km}$-wide belt of mostly Jefferson City beds, extremely complexly deformed and structurally depressed as much as $128 \mathrm{~m}$ relative to their normal position outside the structure. Figure 6 , contoured to show lines of equal vertical displacement throughout the whole structure, indicates that the depressed zone on the north and west is variously monoclinal, synformal, and antiformal in general cross section. It has a warped monoclinal slope out to the ring fault on the east and south. The depressed zone ends inward at a hinge line, generally within the Roubidoux outcrop belt, which marks the beginning of the central uplift.

Roubidoux in normal stratigraphic sequence is exposed by erosion in relative structural highs within the depressed zone, but more commonly it is exposed in windows through thrust plates of Jefferson City or in thrust plates overlying Jefferson City rocks. Complex interrelated folds, steep faults, and particularly thrust faults can be mapped or reasonably inferred throughout the zone in the western half of the structure. The rest of the zone has poor outcrops and may be of equally complex structure, but because only the top $23 \mathrm{~m}$ of the rock section generally is recognized in outcrop, we believe that fairly gentle, broad undulations, and small faults and folds characterize this part. In the southern and eastern areas of poor outcrop, small folds typically are asymmetric, with the steeper limb toward the center of the structure; the few inferred faults apparently are steep.

For the western sector, outcrop data are good enough to permit construction of block diagrams, shown on plate 2 , which provide a means to add inferred structural details that we feel are necessary to explain observed surface complexities. Because they represent various styles of deformation that are characteristic of different sectors of the depressed zone, their settings, structures, and movement sequences are described in some detail.

Block $A$ displays a shinglelike arrangement of 10 thrust plates. Age relations among the faults are not entirely clear, but faults $A$ and $B$ apparently formed early with northward displacement (clockwise relative to the center of the structure). The other, later thrust faults all involved displacement northeastward toward the center, commonly raising the Roubidoux to a slight structural high in the depressed ring zone. Lateral displacements on the faults range from about 30 to $90 \mathrm{~m}$, as shown in the displacement of fault $A$ by fault $D$; and stratigraphic throw is on the order of 6 to $30 \mathrm{~m}$. Small faults are numerous and probably formed as local surfaces of adjustment during thrusting. No steep faults were mapped in the block area. Bed dips are gentle to moderate and the general configuration suggests gentle, circumferentially oriented folds associated with, or broken by, the thrusts. One radial fold, overturned northward, is delineated by the sandstone on thrust plate $J$. Pavement exposures of coarse breccia, believed to mark the sole of plate $B$, are seen in two places.

Block $B$ shows gentle folds, circumferential to the center of the structure, that probably formed and were broken by steep faults before the inward thrust pushed at the south corner of the block. That thrust was overridden by a later thrust which apparently moved outward relative to the center of the structure and southward, and the folds probably were warped in axial trend, plunge, and symmetry by that movement. The late thrust block itself was broken by a fault that has a curving trace. Repetition of the sandstone marker bed suggests that this fault was a surface of slip which allowed part of the late thrust block to lag behind the leading edge of the thrust mass in its upward and southward movement.

Block $C$ is a transparent representation of generally circumferential but crosswarped folds and faults in the middle marker sandstone bed (marker no. 10) of the Jefferson City. The folds vary considerably in shape and symmetry, perhaps in part because of block rotations along the faults that break the folds. Near the east end of the diagramed area the sandstones in two outcrop lines separated by a fault are overturned in opposite directions; these may have been connected above the present surface as parts of a mushroomlike box fold, or the steep fault shown 
may actually be an outward thrust that caused the pronounced westward overturning of the fold in the outer block. The folds and faults were overridden by a thrust plate of Roubidoux apparently directed toward the northwest.

Block $D$ portrays a particularly well exposed structure and a clear sequence of deformation phases. Circumferential folds, one of which is slightly overturned outward, formed first. Steep faults broke the folds to produce a horst-and-graben pattern. A small thrust seems to have formed after the folds and before the steep faults, but the main thrust movement clearly occurred after the normal faults and involved displacement of the entire mass toward the center of the structure. Pavement outliers of coarse breccia in front of the thrust-plate edges show that the plates originally extended at least short distances farther east ward.

Block $E$ displays a gentle dome partly overridden by thrusts. The dome was broken by one steep fault; then inferred inward and outward movements probably involving mostly bedding-plane slip occurred in the gently dipping section on opposite sides of the dome. Fault intersections or truncations indicate that inward thrusting preceded outward thrusting, as in block $B$. The change from inward to outward movement is an important facet of our interpretation of the total-movement picture given in a later section. Outward slip apparently was the dominant movement and is expressed by four intricate thrust sheets on the side of the dome toward the center of the structure. Coarse breccias mark the thrust soles at the leading edges or in windows through the plates.

Block $F$ shows the main ring fault and is characterized by imbricate thrusts in a gently warped eastward-dipping section. Eight outward thrusts can be inferred from available exposures. Deletion and repetition of marker beds varies in the block. The upper sandstone of the Jefferson City Dolomite (marker no. 11) is repeated at the north end, but does not appear in the exposed section at the south end where the thrusts instead repeat the Kimmswick Limestone. Inasmuch as the section below the Kimmswick in two of the plates in this block diagram is thick enough to include the upper sandstone of the Jefferson City, its absence suggests that still other thrusts, not mapped, may be present. The outermost thrust is truncated against the ring fault which is believed to predate the thrust. One steep fault at the south end of the block cuts three thrust plates and itself is cut by a fault that probably changes northward from a reverse fault to a thrust.

Block $G$ also shows a series of imbricate thrusts involving outward movement of plates. Of particular interest is the outermost thrust, represented by the upper sandstone of the Roubidoux (no. 8) which is partly eroded and shows the overridden section. The sandstone evidently was a well-lubricated material that flowed in part during its outward translation by thrusting or sliding; at one place it is $12 \mathrm{~m}$ thick instead of the normal $1.2 \mathrm{~m}$. A small outlier of the sandstone shows the former minimum extent of the thrust plate. The section is virtually unfolded; one high-angle reverse fault was mapped and appears to have formed before the thrusts.

Block $H$ shows a transparent representation of a very gently folded sequence broken by two outward-directed thrusts. The salient feature is local structure caused by the thrusts in the middle and northern segments of the block. Progressive overturning of the basal sandstone of the Jefferson City indicates the effect of either push or drag by the thrusts that must have extended over that part of the sandstone. The drag folding of beds just beneath one of the thrusts is virtually completely exposed in the area of the northern block segment.

In summary, the structural features displayed in the diagramed blocks and elsewhere on the west side permit some generalizations concerning a sequence of deformation phases in that part of the depressed zone. Circumferential folds occur in seven of the eight blocks and radial folds (excluding small crosswarps) in only one block. Steep faults were mapped in four of the eight blocks; in five instances in these blocks they occur with folds which they postdate. In three of the four blocks that contain both steep faults and thrusts, the steep faults are earlier than the thrusts. If we look at the entire west side, it seems clear that two phases of block faulting occurred: One associated with an early phase of folding and before thrusting, and another as a late, postthrusting period involving vertical structual adjustments along relatively long faults. Outward thrusts occur in seven of the eight blocks and inward thrusts in four blocks; in two of three blocks where the outward and inward displacements occur together, inward movement appears to have taken place earlier than outward. Except on the southwest, thrusts inferred to be inward are uncommon, and outward thrusts are dominant.

On the north side, the configuration of marker beds indicates fairly open folds around axes oriented both circumferentially and radially with respect to the center of the structure. Folds with radial axes seem more common in this area than elsewhere, and they probably slightly postdate circumferential folds. One inward thrust is inferred, but the area is dominated by late block faults along subradial and circumferential lines. To the east and south, no large vertical or horizontal dislocations are suggested by the marker beds seen in sparse outcrops, but many small faults undoubtedly are present. Dips indicate that gentle principally circumferential folds are the dominant type of structural feature in that part of the depressed zone.

\section{EXOTIC BLOCKS IN THE DEPRESSED ZONE}

Three unusual rock occurrences in the depressed zone on the northeast, near the village of Decaturville (G-19, H-19), are believed to have special significance. At the road intersection in the village is an area of outcrop of highly fractured sandstone some 55 by $180 \mathrm{~m}$. Continuity between outcrops is confirmed by drill data. This sandstone is 
identified as Gunter Sandstone Member of the Gasconade Dolomite because its bimodal grainsize, coarse, pitted, golf-ball-like grains in the large-size fraction, and its unusual grain fracture or cleavage are exactly like those of the Gunter along the main outcrop belt farther into the structure. The sandstone bears no resemblance to any other Paleozoic sandstone that conceivably might once have been present in the area. Available drill cores show that the sandstone extends $27 \mathrm{~m}$ below the surface and lies upon Kimmswick Limestone in normal sequence above the Jefferson City Dolomite. The sandstone dips $70^{\circ}$ at the surface, and according to the drill data probably dips about $45^{\circ}$ overall. The underlying rocks are horizontal. Normal thickness for the Gunter is no more than $8 \mathrm{~m}$, so at least a doubling of thickness by flowing, faulting, and perhaps folding is indicated here. 1t is clear that at this locality a great tilted block of Gunter sits 171-180 $\mathrm{m}$ above its normal stratigraphic position and upon distorted beds at the top of the local stratigraphic section.

A second unusual occurrence involves coarse flakes of mica, presumably from a block of displaced Precambrian rock, found in a fresh grave in the Decaturville cemetery (sector G-20) by Mr. H. B. Hart. The find was confirmed by Snyder and Gerdemann (1965). This material lies along the ring fault and, like the sandstone, seems from its general position to be lying on top of the normal stratigraphic sequence. Precambrian rock in this occurrence is about 530 $m$ above its normal position.

The third occurrence is known only from drill cores of a hole put down just south of the village of Decaturville in a borrow pit in sector 1-19. Cores were obtained showing about $15 \mathrm{~m}$ of Derby and Doe Run Dolomites just below the surface. The base of the Derby was not penetrated but inasmuch as both formations here are $305 \mathrm{~m}$ above normal position, the Derby is assumed to be a block resting on Jefferson City Dolomite at the top of the local sequence.

Blocks like these, markedly above normal position, have been noted in other cryptoexplosion structures and in fact are rather a hallmark of this type of structure. At Sierra Madera, Tex., for example (Wilshire and others, 1972), blocks of shatter-coned Permian rock occur along faults in Cretaceous rock at the edge of the structure. These rocks are about $210-300 \mathrm{~m}$ above normal position and $3-4 \mathrm{~km}$ laterally outside the envelope of shatter coming in the uplift.

The implication of the exotic blocks as to the nature of the Decaturville and similar structures will be discussed in another section.

\section{CENTRAL UPLIFT}

The zero-displacement line on figure 6 marks the hinge line between the depressed zone and the central uplift. It occurs stratigraphically generally within the lower half of the Roubidoux Dolomite. The hinge line is very irregular, but roughly circular; the diameter of the uplift is about 10 percent greater in the northeast-southwest direction than in other directions $(3,350$ versus $3,050 \mathrm{~m})$.

Except for areas of block faulting, upward displacement increases in a fairly regular fashion toward the center of the structure (fig. 6); and successively older formations are exposed, as in a normal domical structure. Thus the Gunter Member is raised $90-120 \mathrm{~m}$, and the Derby and Doe Run at the center have been uplifted about $280-305 \mathrm{~m}$.

A zero-displacement line can be located approximately for each formation in reasonable cross sections, and the volumes of material inside and outside of a zero-displacement surface can be compared. Using average figures obtained for displacement on eight profiles across the structure, we calculate the total volume of uplifted material to be about 7.4-7.6 $\times 10^{8} \mathrm{~m}^{3}$, and the volume of material in the depressed zone to be about 7.4-7.9 $\times 10^{8} \mathrm{~m}^{3}$. Despite the approximations involved, the agreement of the two volumes is strikingly close.

If the well-exposed Eminence Dolomite is representative, formations on the uplift are intricately deformed on a small scale. However, the formations as whole units apparently have relatively gentle dips off the dome. Comparisons of formation thickness to width of outcrop belt indicate that the Gasconade Dolomite has dips that average $10^{\circ}-30^{\circ}$ outward, the Eminence $10^{\circ}-15^{\circ}$, the Potosi $20^{\circ}-60^{\circ}$, and the Derby and Doe Run $5^{\circ}-10^{\circ}$. The Derby and Doe Run Dolomites are intensely deformed and shatter coned, but they must be nearly flat lying in order to cover the central area which is 490 to $610 \mathrm{~m}$ across; they are only $43 \mathrm{~m}$ thick, and their base is nowhere exposed in the area. Calculated steeper formational dips for the Potosi Dolomite ringing this area may indicate an unusual structural discontinuity, to be discussed in another section, or they may simply indicate that the unit is thinner than supposed in his area.

The Gunter Sandstone Member is the only thin marker bed (no. 3) useful for detecting structural offsets in the whole uplift sequence. lts outcrop line is conspicuously lobate and defines numerous gentle folds around axes radial to the center. On the south side of the uplift, several shallow basins are outlined by the Gunter. At about the Gunter outcrop line, a system of apparently steep faults nearly rings the center of the structure. On the east side of the dome the center is displaced upward along these faults, and on the west side it is displaced downward. Outside this fault line, in most places where outcrops permit mapping, block faulting has raised Eminence and Gunter commonly as much as $90-120 \mathrm{~m}$ within the Gasconade. Two isolated blocks within Gasconade in a complex of block faults on the north side (1-13) consist of uppermost Roubidoux beds downdropped $120-135 \mathrm{~m}$. The large block faults postdate the folding of the Gunter and seem to represent a late phase of major vertical structural adjustment. Block $I$ of plate 2 shows folds in the Gunter which vary from broad, open warps to a tight fold overturned outward and which are cut by steep faults with scissor, hingelike, and simple vertical displacements.

One area of thrusts has been mapped within this general 
zone, as illustrated in block $J$ of plate 2. Deformation is very complex, but apparently involved three thrust sheets, partly broken into schuppen during thrusting, and later steeply dipping faults along which small-scale block movements occurred. The thrusts brought Gasconade inward over Eminence along a surface marked by conspicuous breccia, and Gunter inward in two slices over the upper part of Gasconade. A synclinal thrust block outlined by the Gunter Sandstone Member lies separated by erosion from its root thrust just to the west. The inward thrusts and the lobate Gunter line are believed to indicate an important phase of inward movement as the uplift formed. The Gunter lobate configuration also could have been produced by simple radial folding, but the lack of similar folds in beds inside and outside the Gunter suggests that uneven inward movement was more significant in producing the pattern. Lateral translation of beds also is suggested by the departure of the Gunter line from the general circularity seen in other contacts. The Gunter outcrop belt forms a rough somewhat triangular northeast-trending ellipse, with irregular wings produced by block faulting on the northwest and southeast. This ellipticity is more conspicuous than the 10 percent extension of the zero-displacement line of figure 6 noted previously, and is shown in that figure particularly by the $120-, 150-$, and $180-\mathrm{m}$ uplift contours. The northeasttrending major axis of the Gunter ellipse measures roughly $2,440 \mathrm{~m}$, compared to the $1,950 \mathrm{~m}$ for the northwest-trending axis. The uplift ellipse is oriented perpendicular to the ellipse defined by the ring fault that bound the structure.

The total length of Gunter segments (pl. 1) is about 30 percent longer than the perimeter of the ellipse or triangle on which the segments lie. This implies a shortening of the perimeter of the Gunter at its original prestructure stratigraphic level by 30 percent, as a result of inward and upward movement during formation of the central uplift. Similar configurations have been reported from cryptoexplosion structures at Sierra Madera, Tex., Wells Creek Basin, Tenn., Gosses Bluff, Australia, and Vredefort, South Africa (Wilshire and Howard, 1968). As the Gunter typically is thinner within the uplift than it is outside the Decaturville structure, some of the apparent lengthening of it along its present perimeter may be due to thinning rather than to crowding of material into a smaller area. Nevertheless, a minimum of 20 percent shortening of perimeter by inward movement is indicated.

Inside the elliptical Gunter zone, most deformation involves small open basins and canoelike folds on a scale of ten to a hundred meters. Many of these small structures apparently are laterally dislocated short distances and are slightly rotated. Numerous small thrusts are suspected but few could be mapped with certainty; lack of marker beds makes movement directions indeterminate. Across the Eminence belt a few steep faults extend (pl. 1); however, these were mapped mostly along lines of bed truncation and breccia lenses rather than on the basis of known displace- ment. A rather unusual type of map of the southeastern area of Eminence outcrop was presented by Zimmerman and Amstutz (1965, fig. 4). Their interpretation involved several different periods of movement and different stress fields; and they reported cemented faults cut by later faults as indication of time separation of the fault periods. We examined the same area but could not find the features they showed; our interpretation of the structure there is not nearly as complex as theirs, although folds clearly have various orientations and are broken by thrusts and steeper faults. One out-of-place block was found within the Eminence belt-a small silver of Potosi raised along a steep fault in M-11.

The Potosi and Derby and Doe Run at the center of the uplift are poorly exposed and so massively bedded that in general structure within them could not be determined. As mentioned previously it is thought that the Derby and Doe Run, in particular, are nearly flat lying as a whole. It is clear from drill cores, however, that at least part of the central area is characterized by extreme and unusual brecciation and by movement of large blocks which mixed formations on a scale of 200 meters.

Near the geometric center of the structure is the outcrop of pegmatite (L-13). A drill hole (C-2 in fig. 7) through the pegmatite penetrated $15.2 \mathrm{~m}$ of pegmatite, then $1.8 \mathrm{~m}$ of slightly conglomeratic sandstone (presumably Lamotte), 4.3 $\mathrm{m}$ of pegmatite and schist, and then $140 \mathrm{~m}$ of mixed breccia with a few blocks of Potosi. Trenching and scraping around the pegmatite has shown the basement block to be about 15 by $20 \mathrm{~m}$ in extent. A sheath of muscovite schist perhaps as much as $1.8 \mathrm{~m}$ thick is exposed on the north side, beyond which is a jumble of blocks of Lamotte Sandstone, Davis Formation, and Derby and Doe Run Dolomites (fig. 8). On the south and west the pegmatite is bounded by juxtaposed blocks of Davis, Derby and Doe Run, Potosi, and Lamotte. The mixed formations occur on scales of small chips to individual blocks as much as $6 \mathrm{~m}$ across.

Another outcrop $120 \mathrm{~m}$ southwest of the pegmatite outcrop shows a block of shatter-coned Potosi within the Derby and Doe Run country rock. About $360 \mathrm{~m}$ farther to the southwest is a large trench called the "sulfide pit" by the Ozark Exploration Co. This trench provides fresh exposures of shattered Potosi, mixed breccia (some of which contains sulfides), and upfaulted blocks of Davis (fig. 9). The trench and surrounding drill holes show the Davis to cover an area of about 90 by $90 \mathrm{~m}$. It is well bedded and nearly horizontal in the open cut but has steeper dips in some of the drill holes. One hole shows an apparently complete section of Davis (41 $\mathrm{m})$, but data from other holes suggest that most of the Davis may be somewhat thinner $(27-30 \mathrm{~m})$. If Bonneterre in the drill holes is not faulted, it shows similarly smaller thicknesses than expected from data outside the structure. This may indicate tectonic thinning on the order of 25-30 percent of original stratigraphic thickness of at least some strata at places within the generally thickened section in the central uplift. One drill hole (C-34 in fig. 7) near the large 
Davis block started in Eminence and others (C-43, 52, 54) in Derby and Doe Run, indicating the presence of other blocks out of place within the sulfide-pit area. Outside the pit area, however, red soil, sparse outcrops, and a few drill holes show Potosi at the surface where it should be in its annulus around the center.

Surface exposures and drill-hole data (figs. 7,9) in the area of the sulfide pit reveal a fairly simple picture of blocks of upraised Davis and Derby and Doe Run and, in at least one place, downfaulted Eminence. In general, drill holes show normal stratigraphic sequences in the raised or dropped blocks. The mechanism of upfaulting is not clear, but movements must have been violent and must have been generated from below this stratigraphic level, because fine-scale mixed breccia involving rocks as deep as the Lamotte occurs as a matrix around some blocks in the sulfide pit.

A much more complex and remarkable configuration is revealed in 30 drill holes from an area around the pegmatite; the area drilled is about 270 by $360 \mathrm{~m}$ and extends southwest from the pegmatite toward the sulfide pit (fig. 7). Of the 30 holes (27 shown in fig. $7 \mathrm{~B}$ ), one was started in Precambrian pegmatite, one in Lamotte Sandstone, one in Bonneterre Dolomite, and two in Potosi Dolomite. Other out-of-place blocks undoubtedly exist at the surface, but the remaining 25 holes started in Derby and Doe Run, a fact which together with stream-bed outcrops, shows that these dolomites cover most of the central area in normal stratigraphic position. Below these capping dolomite units, however, the drill holes reveal a chaotic jumble of blocks, some with thicknesses as much as $60 \mathrm{~m}$ in core, totally out of sequence as to formation, and, in part, with a matrix of mixed breccia. This jumble of blocks fits the term "megabreccia" (Eggleton and Shoemaker, 1961) which commonly has been used for central zones of impact and cryptoexplosion structures. Long blocks in the megabreccia commonly seem to be on end, pointing inward and upward in an acicular pattern.

The mixed breccia around the blocks exhibits evidence of flow and shock deformation; it is described in the section on shock features. In three holes near the pegmatite, the mixed breccia is not just a matrix but makes up most of the 162-241 $\mathrm{m}$ penetrated in each hole. Small slivers of basement rock were cut in holes $15-37 \mathrm{~m}$ from hole C-2 which started in the pegmatite. Lamotte, the next deeper unit, was seen generally in minor amounts from the surface to a depth of $180 \mathrm{~m}$ in seven holes. Hole C-8, near the center of the structure, cut 37 $m$ of Lamotte at the surface. In hole C-8, Lamotte is 180-200 $\mathrm{m}$ above its normal position relative to the Derby and Doe Run cap unit, but is lifted more than $440 \mathrm{~m}$ above its normal elevation. Bonneterre was only tentatively identified but is believed to be present in cores from eight holes. Six holes southwest of the pegmatite cut partial sections of Davis; this is a much lower frequency of occurrence than would be expected for the unit directly below the Derby and Doe Run which blanket the surface. Derby and Doe Run are scattered throughout the jumble cut by most of the drill holes and occur at least as deep as the deepest core. Potosi, positively identified in five holes and tentatively in nine others, occurs in slivers and blocks down as much as $210 \mathrm{~m}$ relative to its outcrop position above the present elevation of the Derby and Doe Run cap layer. Various Potosi blocks range in structural uplift from 60 to $210 \mathrm{~m}$ above their prestructure elevations. No formations above the Potosi were recognized in the central area drill cores, although some gray dolomite tentatively assigned to the upper half of Derby and Doe Run might possibly be Eminence.

The extreme subsurface complexity shown by cores would be difficult to overstate. From just below the Derby and Doe Run to as deep as $320 \mathrm{~m}$ from the surface, it is rare to be able to connect, even tentatively, formations cut in adjacent drill holes even spaced as closely as $15 \mathrm{~m}$. Inasmuch as the holes are limited to a small area, the lateral extent of this megabreccia is not well defined. Analogous intense block brecciation and jumbling of formations, however, are found in holes $275 \mathrm{~m}$ from the pegmatite but not at $425 \mathrm{~m}$, in the southwest direction. To the northeast, megabreccia is not present $360 \mathrm{~m}$ from the pegmatite. Northwest and southeast of the pegmatite, the area of megabrecciation extends more than $120 \mathrm{~m}$. Thus, this type of brecciation apparently characterizes a zone perhaps as much as $610 \mathrm{~m}$ long and at least $270 \mathrm{~m}$ wide.

Depth of the megabreccia mass or lens is greater than 320 $\mathrm{m}$, as judged from the one hole that went that deep. Certainly the basement and overlying Lamotte were disrupted, but the cores show such a minuscule amount of basement rock and such a small amount of Lamotte relative to its presumed 90-m thickness as to suggest less mixing with other units than that undergone by higher formations. If the stratigraphic pile were undisturbed, then basement would lie about $200 \mathrm{~m}$ deep at the center of the uplift. In fact, except for isolated blocks torn loose and lifted, not only does the basement lie below $320 \mathrm{~m}$, but so does the Lamotte. This gives a minimum figure of $410 \mathrm{~m}$ below surface for basement rocks; the lack of Lamotte in the deep hole suggests that it may occur at least 30-60 m deeper, making basement depth likely to be $440-470$ $\mathrm{m}$. Normally, basement in the surrounding plateau is 490-520 m below the elevation at the center of the structure, so little general uplift of the basement surface under the structure seems indicated.

Intensity of formation-mixing within the megabreccia mass is greatest at its apparent center; only there do the blocks of basement occur, and only there is fine-scale mixed breccia the dominant lithology rather than a sparse filling around large blocks. The general pattern seen in the megabreccia suggests that it is of limited lateral extent and is confined under the capping stratum of the uplift center, that it dominantly involved formations above the Lamotte but none higher than Potosi, and that it decreases somewhat in intensity of block dislocation outward from a central focus of disruption. 


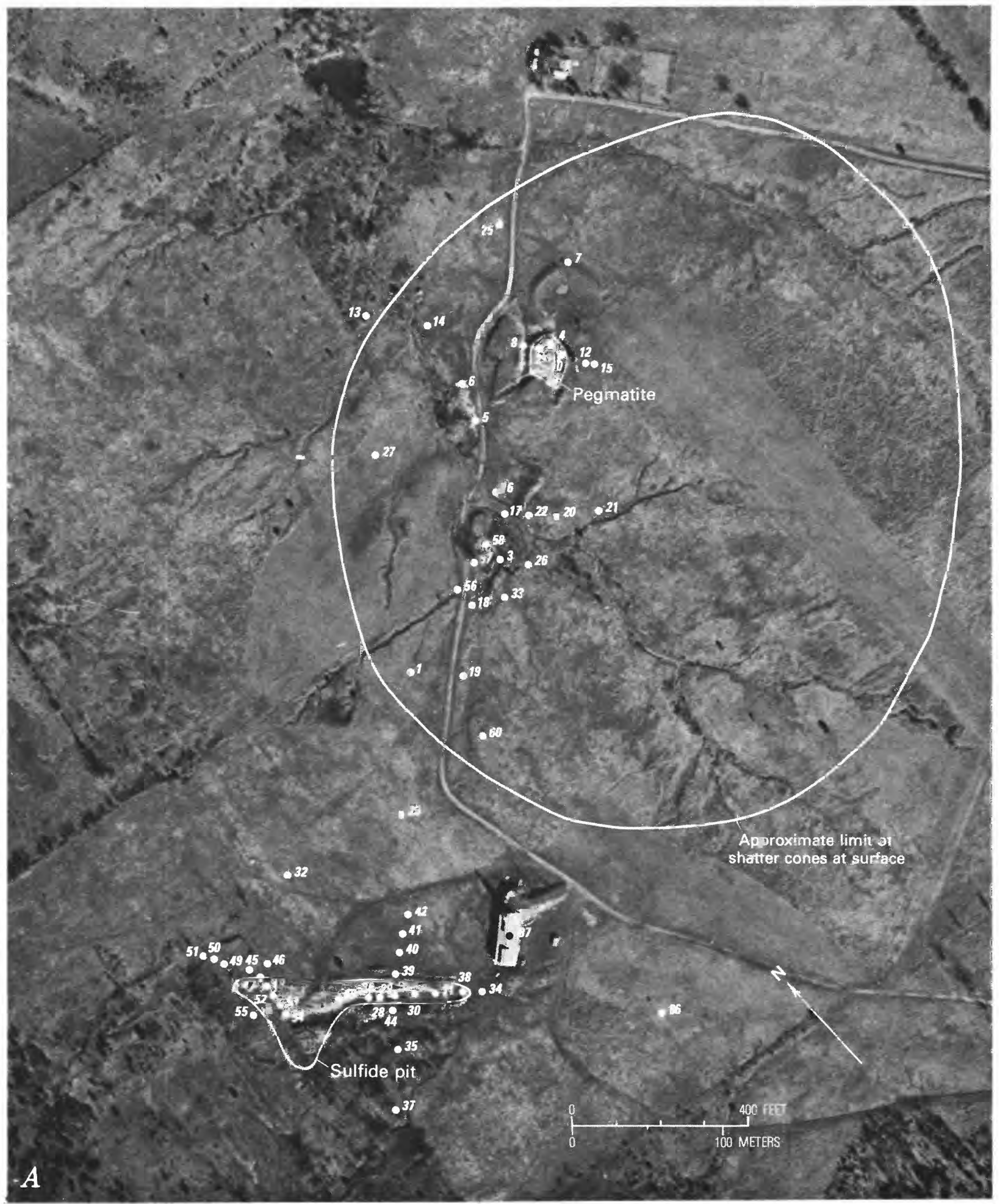

FIGURE 7 (above and facing page).--Numbered drill-hole sections and locations at center of Decaturville structure. $A$, photograph showing drill holes. $B$, drill-hole sections in pegmatite area. $C$, drill-hole sections in sulfide-pit area. 
STRUCTURE
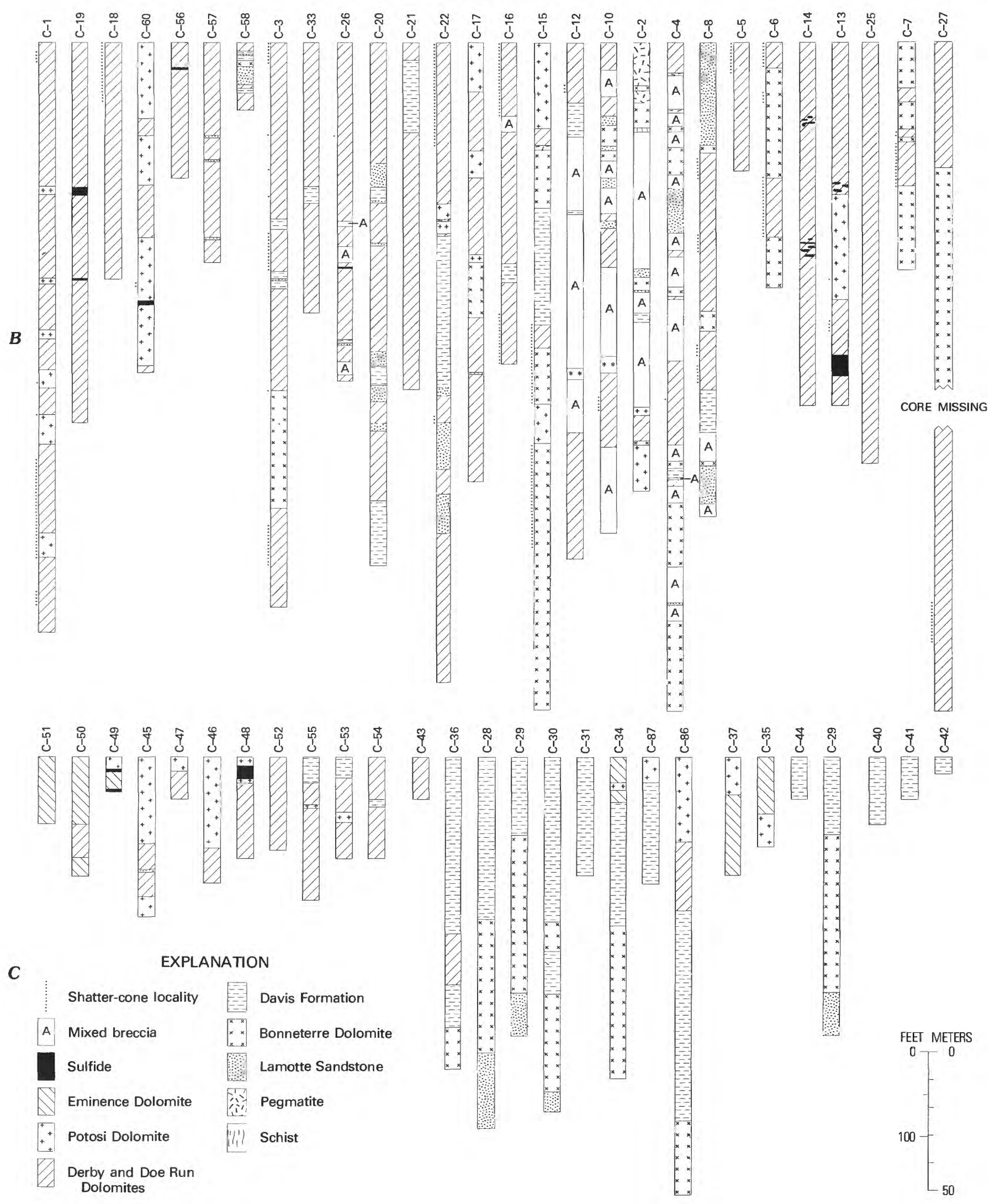


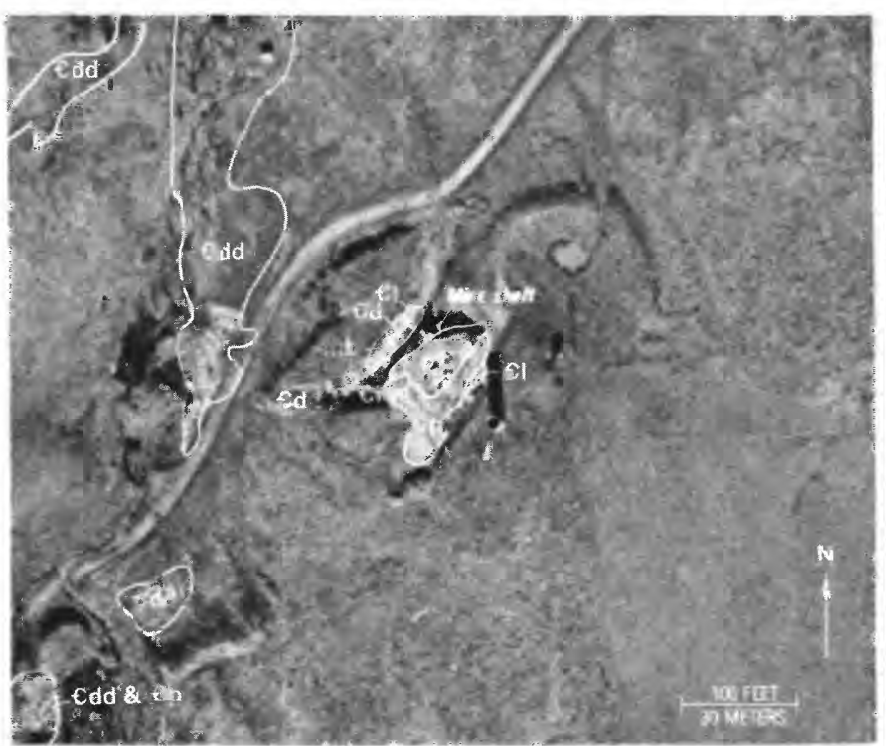

Figure 8.-Pegmatite area (sector L-13), showing juxtaposition of blocks of different formations at center of structure; $\mathbf{p} \mathcal{E}$. Precambrian pegmatite and schist; $€ \mathbf{I}$, Lamotte Sandstone; $€ d$, Davis Formation; $€ d d$, Derby and Doe Run Dolomites; $€$ p. Potosi Dolomite; mb, mixed breccia.

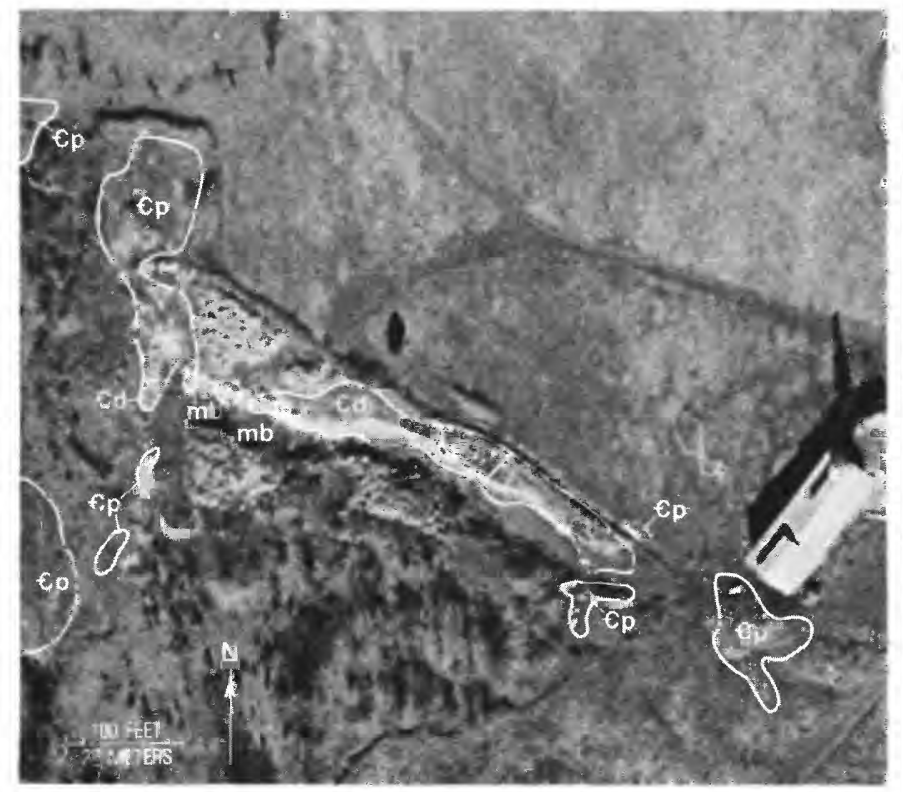

FIGURE 9.-Sulfide pit (sector M-12) showing juxtaposition of blocks of different formations; $\boldsymbol{\epsilon d}$, Davis Formation; $\boldsymbol{\epsilon}_{p}$, Potosi Dolomite; $\mathrm{mb}$, sulfidic mixed breccia.

\section{GEOPHYSICAL DATA}

The magnetic map of Missouri (Missouri Div. Geol. Survey, 1943), compiled from ground-based readings on 3.2$\mathrm{km}$ centers at a 100-gamma contour interval, depicts regional lithologic and structural trends in the Precambrian basement. Linear alinements trending northwest, and to a lesser extent northeast, dominate the pattern. More detailed aeromagnetic maps are available for the Decaturville area and make an interesting comparison with the local geology (fig. 10). The Decaturville structure is centered $4.8 \mathrm{~km}$ west of a conspicuous northwest-trending linear magnetic high, which is continuous to the Camdenton area where it corresponds closely to the Proctor anticline. A steep gradient on the west edge of the high underlies the position of the Red Arrow fault near Camdenton and is continuous to the southeast beyond Decaturville. It passes to the northeast of the Decaturville structure, approximately tangent to the ring fault. This suggests that the Red Arrow fault does not intersect the ring fault on the north side, as a simple projection of its surface trace would indicate.

A similar and more conspicuous high $10 \mathrm{~km}$ farther east is seen on the State magnetic map. It extends for at least 105 $\mathrm{km}$ to the northwest but does not seem to correspond to surface geologic features. The two highs end or are interrupted by an east-west break in the magnetic pattern; this break is subtle but may extend west from some $5-8 \mathrm{~km}$ south of the Decaturville structure all the way to the Kansas border. Eastward it is not continuous but may be represented by minor breaks in a sharp high southwest of the Crooked Creek structure and across the tight magnetic pattern of the St. Francois Mountains.

The aeromagnetic map of Stoutland quadrangle (fig. 10) shows a northwest-trending elliptical 100-gamma low, about $1,520 \mathrm{~m}$ long and perhaps $1,220 \mathrm{~m}$ wide, centered about 180 $m$ south of the center of the Decaturville structure. No evidence in outcrop or drill core indicates the presence of impact melt breccia like that which was found to have thermo-remanent magnetism that caused lows at the Gosses Bluff astrobleme in Australia (Milton and others, 1972). A probable explanation for the Decaturville low is that the basement was disrupted sufficiently by fracture and brecciation when the structure formed so that it now has no coherent remanent magnetic field. This was suggested by Beals, Innes, and Rottenberg (1963) to be the reason for magnetic lows at various Canadian impact structures. It may be, however, that even with the coincidence of location no special explanation for the low at Decaturville is necessary, because the magnetic maps show small circular or elliptical features to be common in the Stoutland and Macks Creek quadrangles. These may relate to the presence of small masses of granitic rock scattered within a schist area, as is indicated from basement rocks exposed in the Decaturville area.

Magnetometer ground traverses across the central highly broken zone of the Decaturville structure revealed no discrete small anomalies that might indicate either meteoritic or volcanic material within the breccia envelope or underlying basement.

Gravity measurements were made by J. D. Hendricks, U.S. Geological Survey, at about $1.6-\mathrm{km}$ intervals along roads in the area to produce a regional map. Terrain correction was not considered necessary because of the low relief in the area, particularly around the structure itself. 


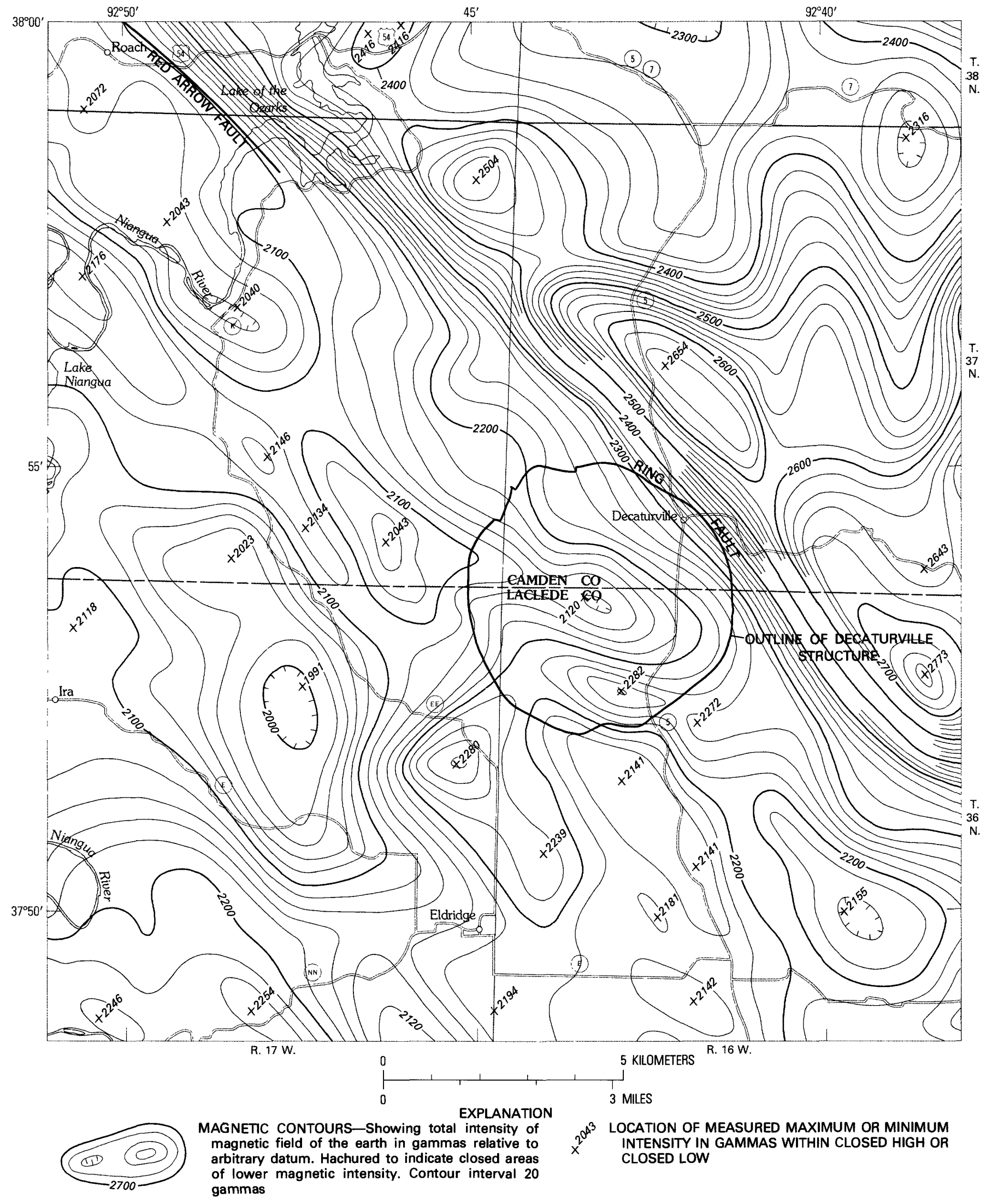

Figure 10.-Aeromagnetic map of Decaturville region showing outline of structure (modified from Missouri Div. Geol. Survey, 1:62,500, Macks Creek and Stoutland aeromagnetic quadrangle maps, 1962). 


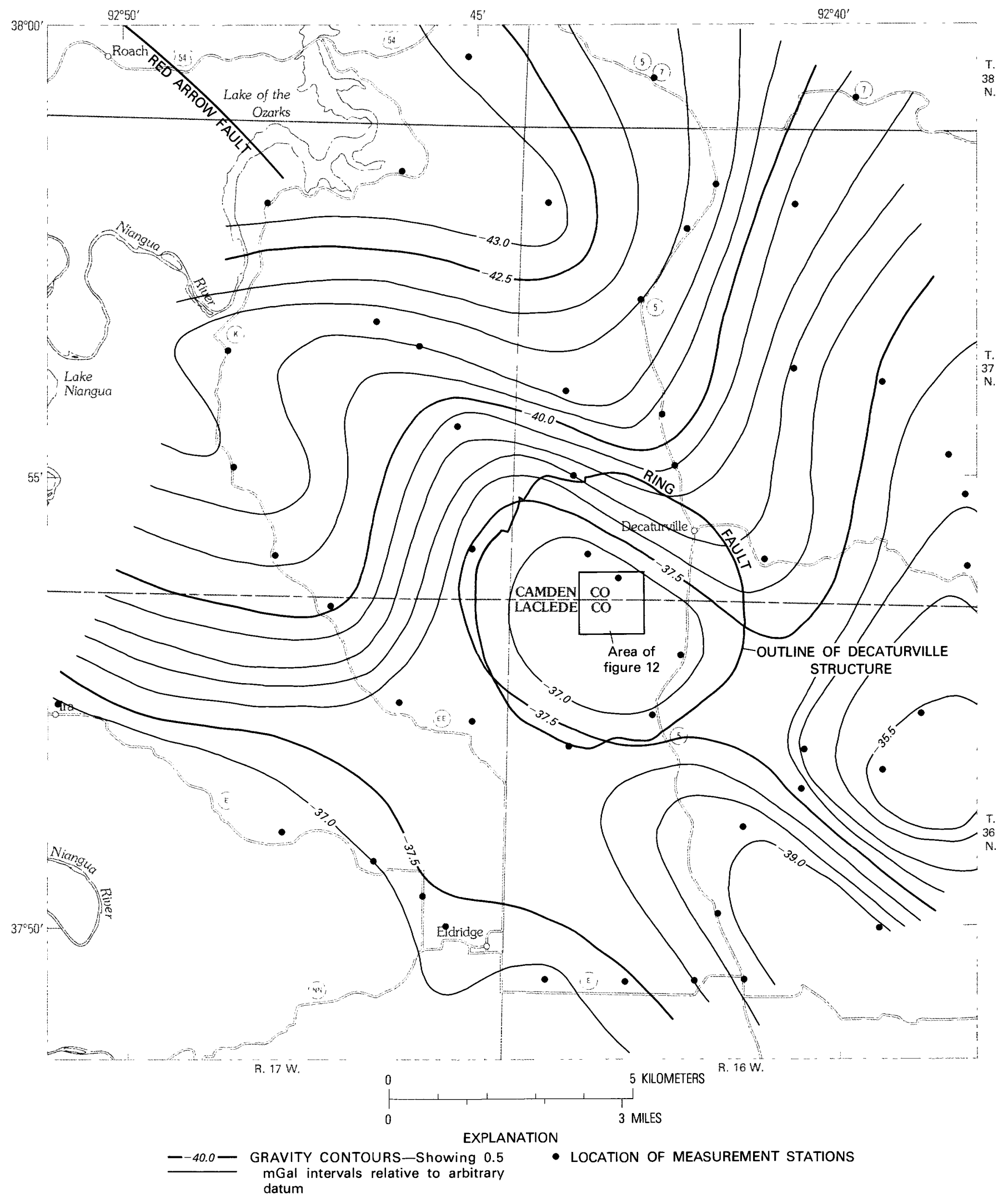

FIGURE 11.-Gravity map, Decaturville region; prepared by J. D. Hendricks, U.S. Geological Survey. Not terrain corrected. 


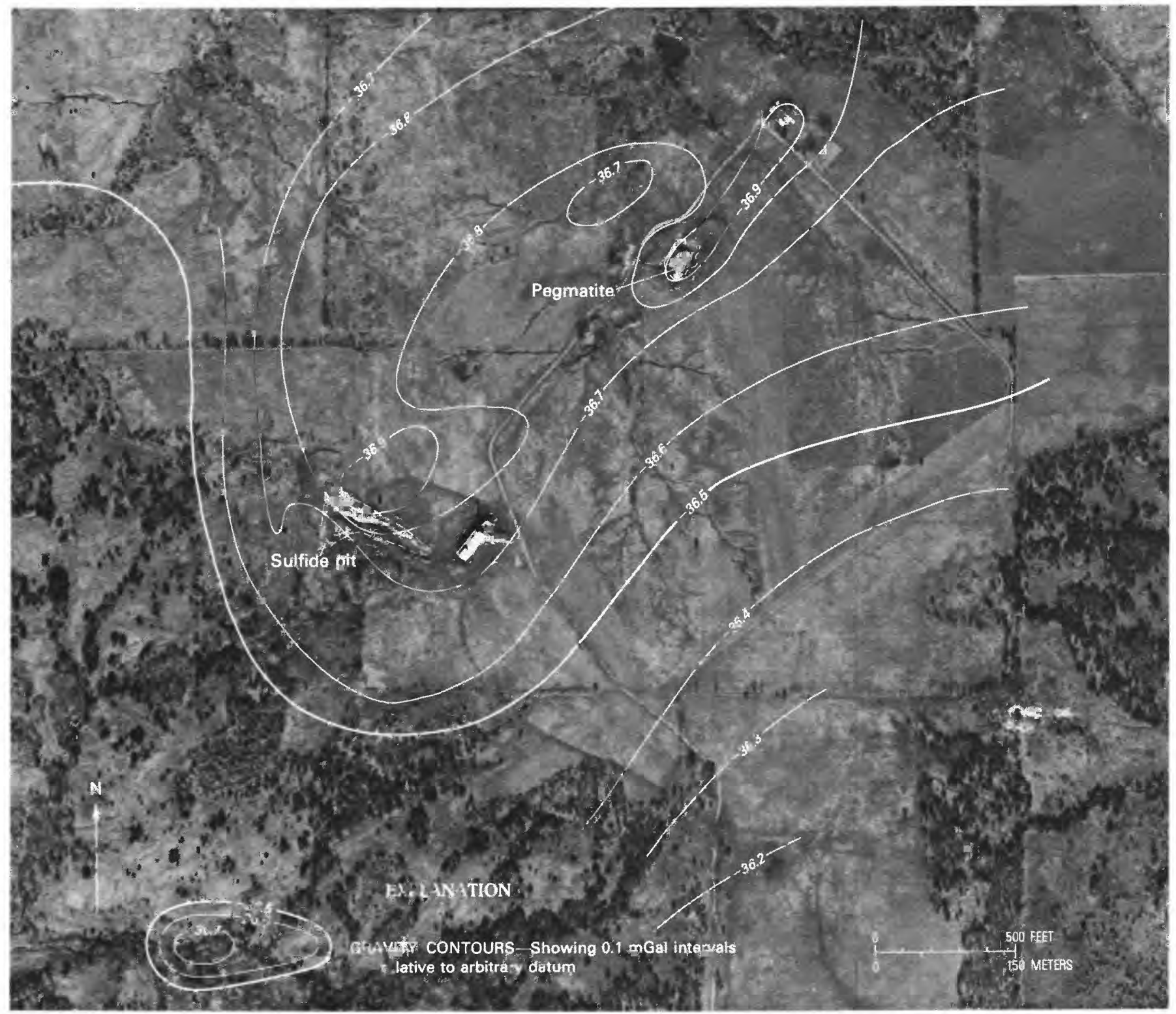

FIGURE 12.-Gravity map, central a rea of Decaturville structure; prepared by J. D. Hendricks, U. S. Geological Survey. Not terrain corrected.

Figure 11 shows two gentle gravity highs from which a regional gradient extends northward to lower values. The Decaturville structure partly coincides with one of the highs but does not seem to influence the transition from the high to the regional slope, and therefore may have little to do with the presence of the $1-\mathrm{mGal}$ high. Inasmuch as most of the rocks in the stratigraphic section have fairly similar densities, vertical dislocations of the section associated with the structure should not produce much of a gravity effect. If anything, the brecciation and fracturing of much of the rock inside the ring fault might be expected to cause a slight relative gravity low across the structure.

Such an effect is in fact seen in a more detailed map of the center of the structure (fig. 12), which shows an elongate gravity low exactly where outcrops and drill core show brecciation to be far greater than anywhere else in the structure. The central zone contains large quantities of polymict breccia having densities of $2.1-2.4 \mathrm{gm} / \mathrm{cm}^{3}$, as compared with the brecciated but more nearly normal dolomites, shale, and sandstone (densities $2.5-2.9 \mathrm{gm} / \mathrm{cm}^{3}$ ) of the surrounding area. Not enough data exist to permit modeling of the size and overall density of the breccia lens to compare with the observed gravity low. However, the shape and the location of the gravity low likely are valuable clues to the configuration of the breccia envelope. It is interesting to note that the gravity low has the same shape and trend as the larger oval of uplifted material defined by outcrops of the Gunter Sandstone Member. Within the generally low central zone, the two lowest areas are in places (particularly the sulfide pit) where exposures and drill cores indicate the 
maximum known amount of sulfidic breccia fillings. Gravity lows in those places suggest a lack of large sulfide concentrations in the subsurface. The significance of a $0.1-\mathrm{mGal}$ positive anomaly located north of the pegmatite area is not known.

\section{SHOCK-RELATED DEFORMATION \\ FEATURES}

The Decaturville structure contains several types of deformation features not normal for most structurally disturbed areas. These include monolithologic and mixed brecciation, rock granulation and small-scale rhombohedral rock cleavage, shatter cones, and intragranular planar features in quartz, dolomite, calcite, and mica, all believed to indicate extremely intense deformation.

\section{MONOLITHOLOGIC BRECCIAS}

Breccias consisting of clasts and mylonitic matrix derived from single beds occur throughout the structure in most of the fine- to medium-grained carbonate rocks. They are particularly well developed in the Eminence Dolomite and the finer grained beds of the Roubidoux and Jefferson City Dolomites. Less common in the Gasconade Dolomite, they occur principally in the fine-grained dolomites rather than in the more abundant medium-grained saccharoidal dolomites. The one example of monolithologic breccia outside the structure was found in fine-grained Gasconade Dolomite a few feet beyond the ring fault. Pure fine-grained dolomites of the Jefferson City are brecciated, but the tan marly dolomites are not. Limestone beds above the Jefferson City are locally coarsely brecciated. The Potosi Dolomite contains some brecciated beds of this type but more commonly displays an unusual close-spaced irregularly rhombic cleavage which gives the beds a shattered appearance. Derby and Doe Run Dolomites also show this type of cleavage or intense granulation rather than a clast and matrix breccia development. Monolithologic breccias are nearly absent from rocks of the Davis Formation and Bonneterre Dolomite, and are not found in any of the sandstones throughout the stratigraphic section. Gunter Sandstone Member in places is highly fractured but not visibly brecciated; it is however intensely granulated. Snyder and Gerdemann (1965, p. 484) reported that "grain size analysis of the disaggregated sandstone shows far more -200 mesh material than is normal for this or other lower Paleozoic sandstones in Missouri."

Intensity of brecciation in Eminence beds near the center of the structure does not seem appreciably greater than in Jefferson City or Roubidoux beds in the outer depressed zone, suggesting that the brecciation is not related to distance from the center of general disruption. It should be emphasized that monolithologic breccias are not associated with faults; their occurrence and character clearly indicate that they result from shattering and dilation of individual beds. Even in sequences of beds less than $2.5 \mathrm{~cm}$ thick, each
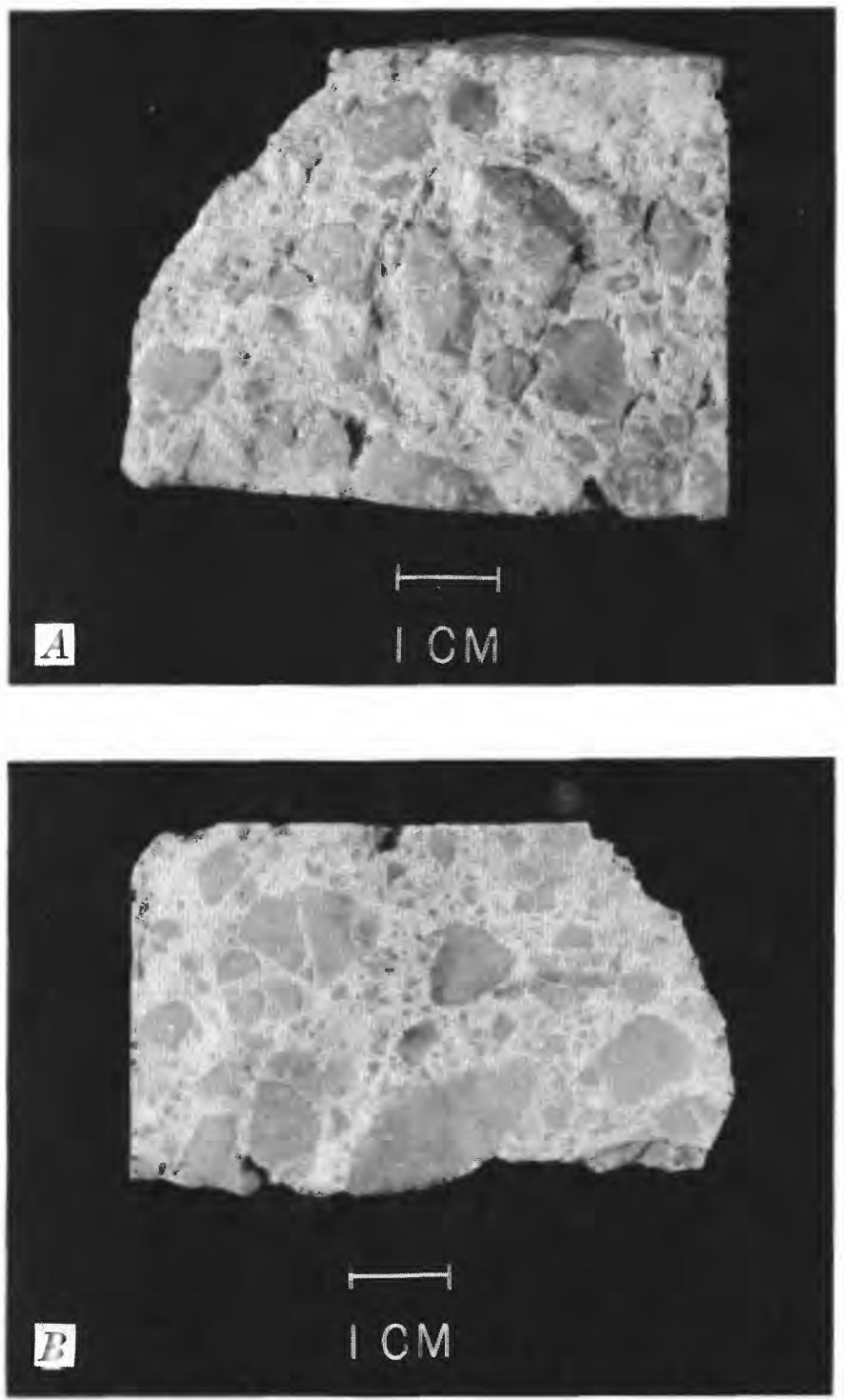

FIGURE 13.-Monolithologic breccia, Eminence Dolomite. $A$, weathered surface, fragments in bas relief. $B$, sawed surface showing fragment-matrix relationships.

brecciated bed maintains perfect stratigraphic coherence; there is no mixing with adjacent beds. In formations such as the Jefferson City a 7.6-cm bed of clean gray dolomite typically will be thoroughly brecciated, whereas the $2.5-\mathrm{cm}$ beds of tan marly dolomite above and below it will show no brecciation whatever.

In detail, monolithologic breccias are made up of angular to subrounded fragments that are of normal color for the dolomite unit in which they occur, generally less than $2.5 \mathrm{~cm}$ across, and surrounded by a white, cream, or tan matrix. Breccia character is especially clear on sawed surfaces, but fragments are commonly more resistant than the matrix, and weathered outcrop surfaces provide excellent displays of the breccias (fig. 13). The lowest intensity of brecciation produces fragments separated by hairline cracks that are filled with extremely fine grained mylonitic material. With 
more extensive development, to the point of having a greater percentage of matrix than fragments, the fragments become internally fractured and the matrix becomes a poorly sorted mixture of very small fragments, individual carbonate grains, and mylonite. Fragment-matrix boundaries typically are sharp and clean in thin section, showing little evidence of plucking or fraying of the fragments to produce the matrix. Many fragments apparently underwent rotation, and some alinement of grains near the borders of fragments suggests flow of the matrix; but the lack of mixing of adjacent beds shows that any movement must have been very small. The shattering and dilation that produce the fragmentation probably are followed by both flowage and crushing recompaction to produce the mylonitic matrix.

The monolithologic breccias at Decaturville are virtually identical to those described for the Sierra Madera, Tex., impact structure by Wilshire and others (1971), as well as those for other impact structures in carbonate rocks, such as Flynn Creek, Tenn. (Roddy, 1968a), and Wells Creek, Tenn. (Wilson and others, 1968).

\section{MIXED BRECCIAS}

The megabreccia at the center of the structure consists of blocks ranging in largest dimension from one-third to twenty meters, which represent formations from the basement to the Potosi Dolomite. Finer grained mixed breccia consisting of fragments of the same range of formations forms a matrix around many of these blocks. In drill holes C-2, 4, 10, and 12 at the center (fig. 7), mixed breccia makes up most of the 760 $\mathrm{m}$ of cored material. The breccia is composed of fragments in the complete range of sizes from clay to cobbles. Fragments of chalky Derby and Doe Run are markedly predominant, though easily recognized glauconitic pieces of Davis are common also (fig. 14). The other formations are poorly represented. Bonneterre, for instance, has not been positively identified in the fragments, but this probably is a problem of lack of recognition of it as small fragments, because Bonneterre is at least sparsely present in the megabreccia blocks. Typically the fragments are white to pale gray (or green and gray for the Davis) and the matrix is light to medium gray; the two-tone color pattern is very conspicuous.

Fragments are very irregular in shape: some are angular with extremely sharp corners; some are very rounded. Some are broken or are plucked at the edges, with the darker fine-grained matrix material separating the pieces of the original single fragment. The matrix is composed of very tiny fragments and of individual grains, part of them microcrystalline. Individual grains are mostly dolomite, but glauconite is common, and quartz may constitute as much as 10 percent of some thin-sectioned samples. A very few of the quartz grains display planar features indicative of various intensities of shock. Shatter-cone segments are present in a few fragments of Potosi and Derby and Doe Run within the breccia.

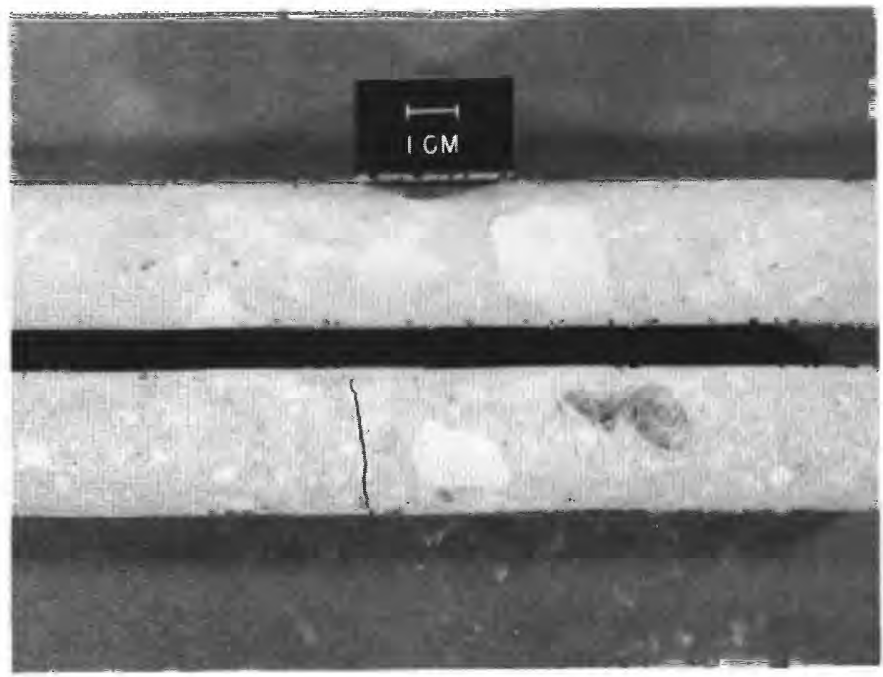

FIGURE 14.-Core samples of mixed breccia with white fragments of Derby and Doe Run Dolomites and dark (dark-green) fragments of Davis Formation in a light-gray matrix of comminuted material from several rock units. Top sample from hole $\mathrm{C}-2,132 \mathrm{~m}$; bottom sample from hole C-10, $52 \mathrm{~m}$.

Some zones within the core sections of mixed breccia are notable because of their flowage features. The matrix is finely banded and clearly shows folds and swirls and the characteristic of wrapping around intricately sculpted edges of fragments (fig. 15). In places, dolomite fragments surrounded by flow-banded material themselves seem to have been drawn out plastically to become irregular

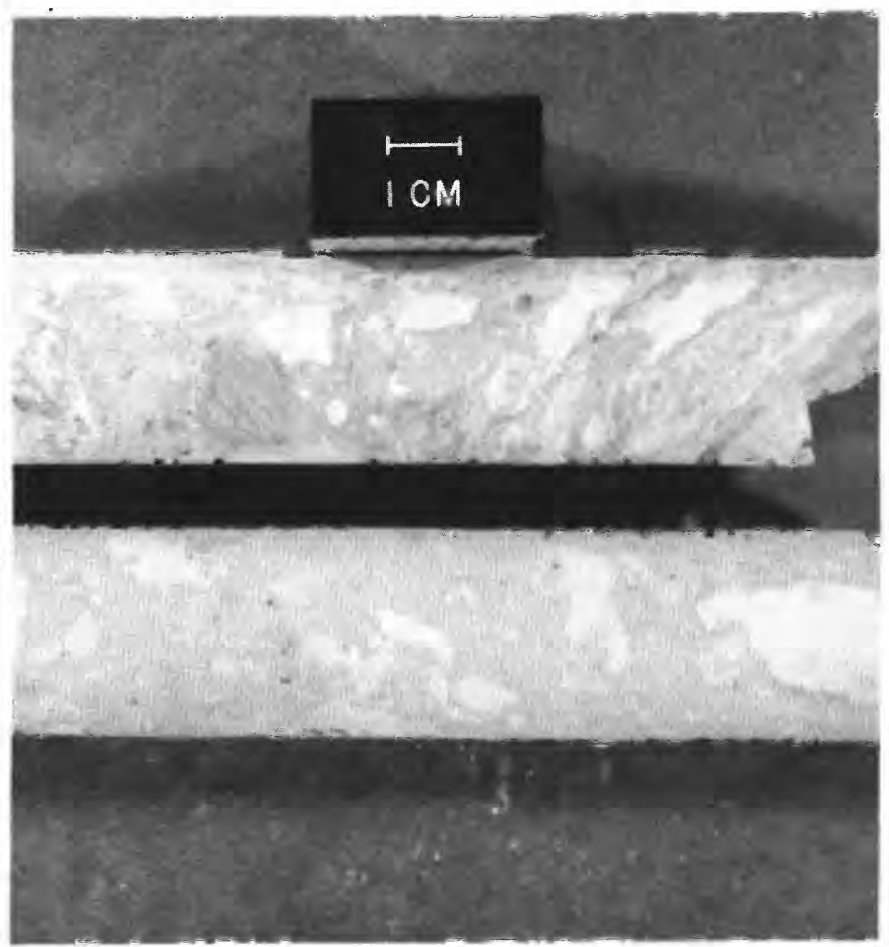

FIGURE 15.-Core samples of mixed breccia showing alined grains in flow laminae and fragments drawn out or shaped by flowage. Top sample from hole C-26, $65 \mathrm{~m}$; bottom sample from hole C-2, $130 \mathrm{~m}$. 

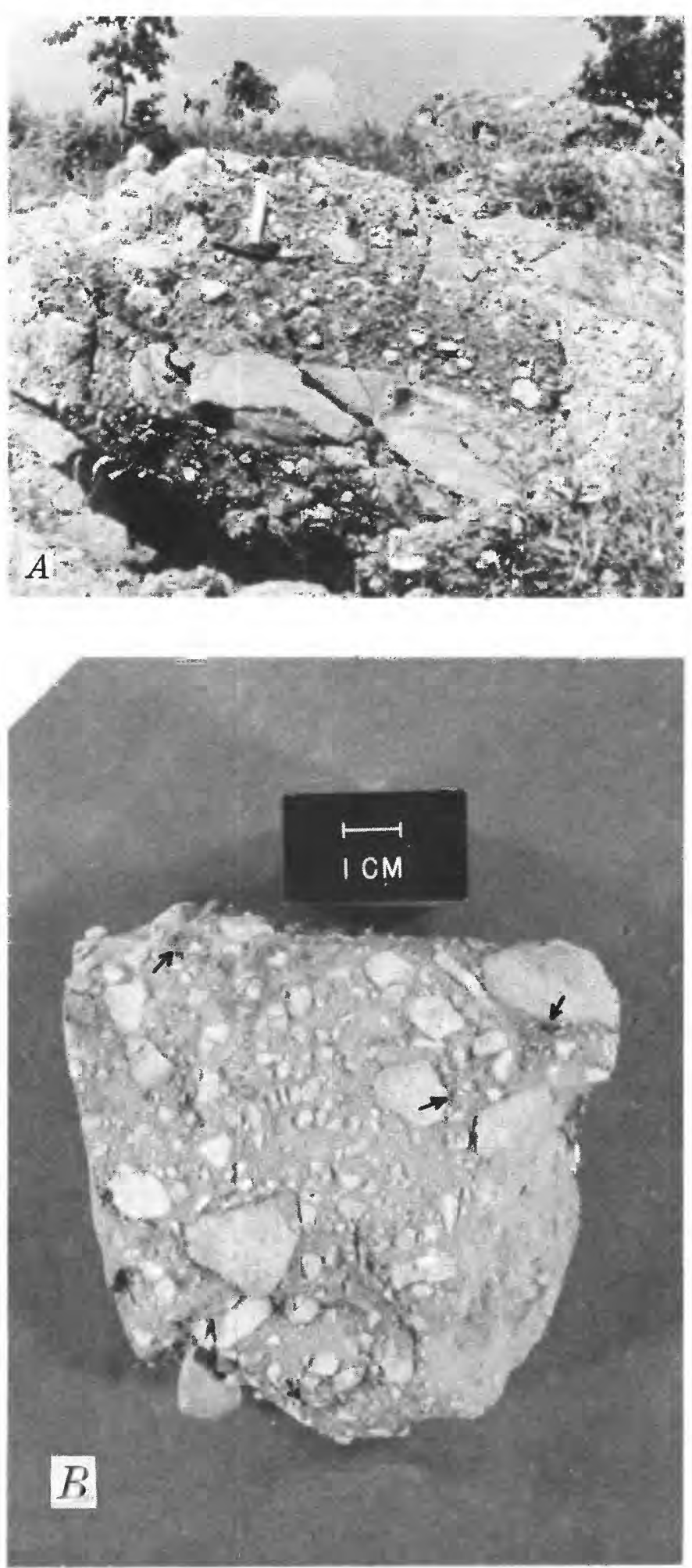

Figure 16. - Mixed breccia at center of structure. A, exposure in sulfide pit (hammer for scale). Large block is Lamotte Sandstone in which the dark areas are discolored by sulfidization. Smaller angular fragments mostly dolomite from the Potosi and Derby and Doe Run Dolomites. $B$, hand specimen of mixed breccia with medium-dark-gray sulfidic matrix, light fragments of Derby and Doe Run Dolomites, and dark fragments of iron sulfide (arrows). schlieren with ragged flamelike ends.

At the center of the structure, a few zones as much as several inches thick in certain cores are conspicuously medium to dark gray. These contain as much as 10 percent sulfide fragments, which are mostly marcasite, with minor chalcopyrite, and traces of galena and sphalerite (fig. 16). They seem to be the same material as the rest of the breccia except for the sulfides. In the sulfide pit, most of the mixed breccia exposed is this type of dark material, with sulfides in numerous small grains as well as fragments as much as $8 \mathrm{~cm}$ across. The sulfide is incorporated in the breccia like other rock fragments, although overgrowths on a few fragments suggest minor deposition or redistribution of iron sulfide after the breccia was emplaced. Numerous fragments are botryoidal or concentrically banded, with sharp broken edges clearly showing that they did not crystallize in the breccia (Zimmerman and Amstutz, 1972). Mixed breccia is rare in core from drill holes at or near the sulfide pit, but this paucity is probably because such material had been removed from the core before we made our examination. This explanation may also apply to the apparent paucity of sulfide material in cores from the center.

Sulfide-rich mixed breccia at the sulfide pit fills openings between large blocks of shattered Potosi, the normal country rock at that position. It also partly surrounds large upfaulted blocks of Davis. The Davis blocks are perhaps $60 \mathrm{~m}$ vertically up out of place, and indicate relatively large scale jostling of the local units. Granular material such as the mixed breccia was probably capable of moving greater distances than blocks, and of flowing or being injected into openings. An extreme example of granular flow is seen in the sulfide pit where Lamotte Sandstone has flowed along the contacts of two blocks of Potosi and the surrounding mixed breccia to form a laminated rind around the blocks (fig. 17).

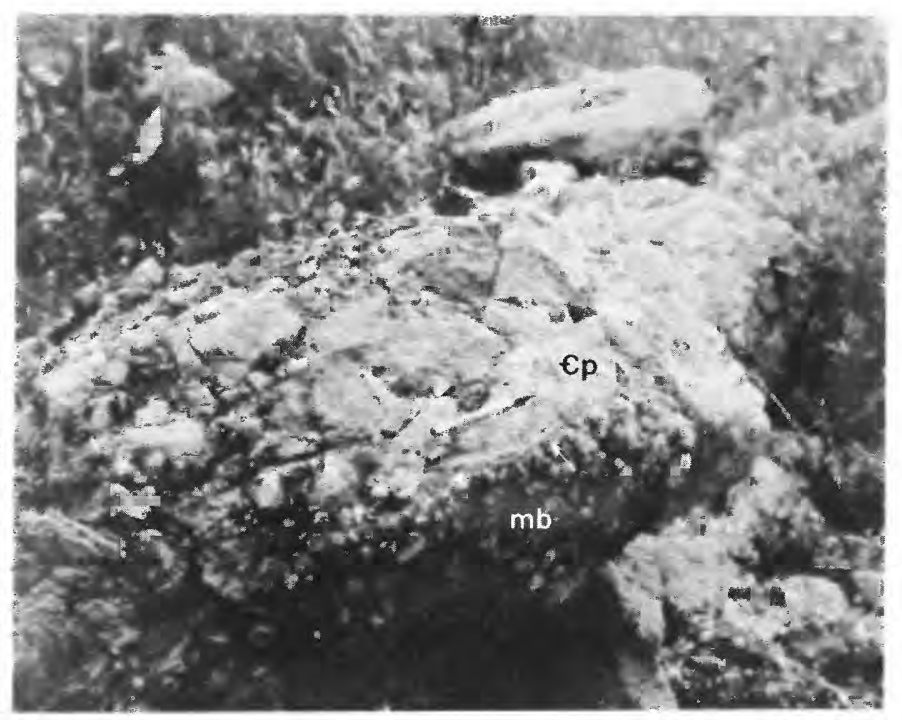

Figure 17.-Sandstone from Lamotte Sandstone (arrows) emplaced by flow between block of Potosi Dolomite $(\epsilon p)$ and mixed breccia $(m b)$ in sulfide pit. Pen for scale. 
This sandstone must have come from at least $150 \mathrm{~m}$ stratigraphically below its present position.

Fragments in the breccias at the sulfide pit are primarily Potosi, Derby and Doe Run, and Davis. Some fragments have the texture of Derby and Doe Run but are mottled light and dark gray instead of white. These may be from the Eminence but are not typical of the Eminence. They have very small amounts of an extremely fine grained sulfide mineral that might be enough to give either Eminence or Derby and Doe Run an unusual color. This, together with the abundance of sulfide fragments, suggests that sulfide deposition favored the locality of the present sulfide pit over other parts of the area before formation of the structure.

Mixed breccia different from the type seen in the central zone is shown in many places on the geologic map, but it apparently formed mainly by crushing, or in part by the filling of dilatant zones, along faults. It consists of angular to somewhat rounded fragments of the various lithologies available from adjacent formations in a very fine grained matrix of dolomite that weathers white to buff. For example, these breccias in the Jefferson City Dolomite contain fragments of gray dolomite, tan "cotton rock", and chert; breccias in the Gasconade Dolomite contain fragments of chert with algal banding distinctive of the Gasconade. The matrix and some of the fragments show crushing but no indication of unusual crystal deformation such as might have been produced by shock in this type of breccia. The breccia is found along the traces of several thrust faults, forming pavement exposures that extend (for example, in map sectors $\mathrm{N}-10, \mathrm{O}-7$ ) well beyond the present edge of the upper plate and give some clue to the pre-erosion extent of the plate which overlay the thrust-sole breccia. Along steeper faults, the breccia is seen in erosion-resistant wall-like outcrops. Alined outcrops of breccia were used to infer faults in several places.

\section{SHATTER CONES}

Distinctive striated fracture surfaces in the form of cones or segments of cones have been reported from about 20 of the more than 60 known cryptoexplosion structures. At several structures, such as Sierra Madera, Tex. (Wilshire and others, 1972), Gosses Bluff, Australia (Milton and others, 1972), the Ries Basin, Germany (M. V. Engelhardt, oral commun., 1971), Brent, Canada (Dence, 1968), Nicholson Lake, Canada (Dence and others, 1968), and Sudbury, Ontario (Bray and others, 1966), shatter cones occur in association with clearcut petrographic evidence of shock deformation. Shatter cones have formed in quartz diorite at shock pressures of about $30 \mathrm{~kb}$ (kilobars) produced during chemical-explosion cratering experiments (Roddy and Davis, 1969). They have not been found in volcanic explosion environments or tectonically deformed rocks. Dietz as early as 1959 suggested that shatter cones indicate meteorite impact origin for the host structure, and no persuasive evidence to the contrary has yet been produced.

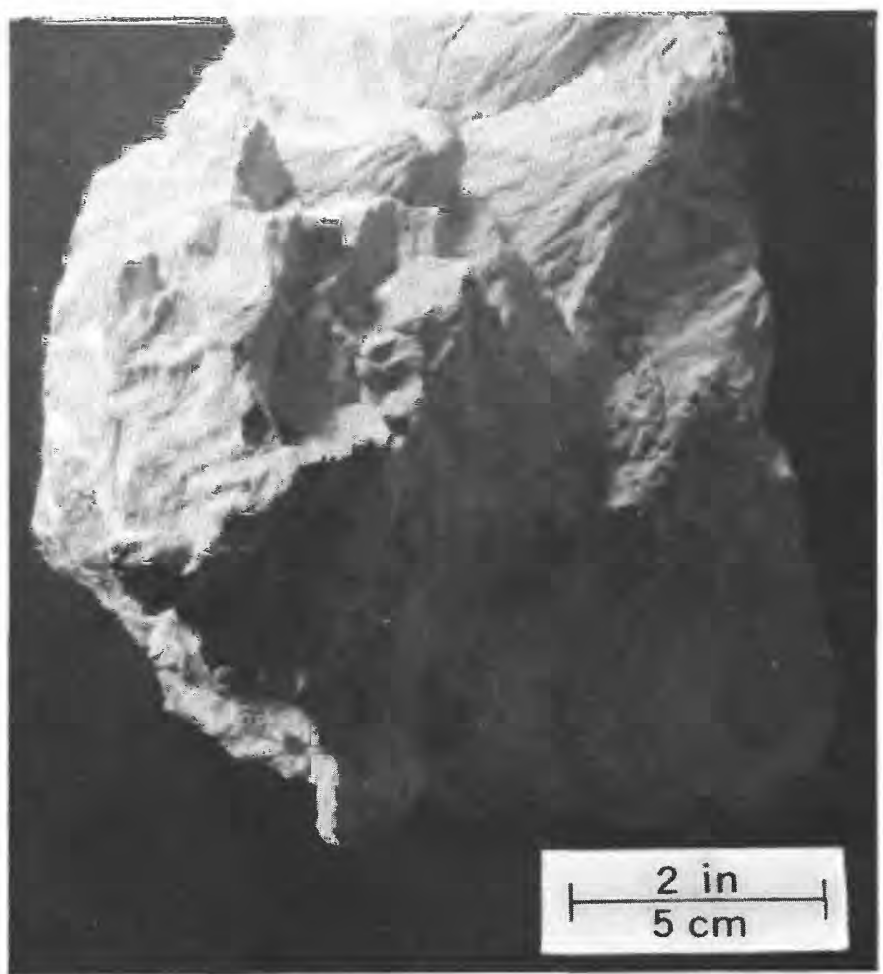

Figure 18.- Shatter-coned Derby and Doe Run Dolomites from near the pegmatite pit.

At Decaturville, well-formed shatter cones (fig. 18) are common in outcrops of the Derby and Doe Run in a roughly elliptical area measuring about 420 by $480 \mathrm{~m}$. (See pl. 1.) They do not occur at the present surface in identical dolomite of the Derby and Doe Run where the dolomite extends outside that ellipse in the central area. Cones are not found in the surrounding outcrop belt of Potosi but are present in displaced blocks of Potosi within the Derby and Doe Run area at the center of the structure. Fragments and blocks of Derby and Doe Run and Potosi display cone segments in many drill cores. The deepest occurrence noted is in a Derby and Doe Run block at $250 \mathrm{~m}$ in drill hole C-27, at the north limit of shatter cones in outcrop. Cones typically are $2.5-5 \mathrm{~cm}$ high, but cones as high as $25 \mathrm{~cm}$ have been found in mining pits near the pegmatite outcrop. Double cones pointing in opposite directions from a common base, or single cones pointing opposite to the general mass of cones in an outcrop are not common, but seem more abundant at Decaturville than they are reported to be at other structures.

The formation of shatter cones is believed by Johnson and Talbot (1964) to occur where rock inhomogeneities focus compressive stresses induced by passage of a shock-wave front. Another theoretical study (Gash, 1971, p. 34) suggests that cones should form beneath the shock source and that "very high amplitude shock sources are required" in order to provide the necessary tensile stresses. Gash estimated that well-formed cones in a rock with tensile strength of 100 bars would require a minimum source stress of 20-40 kb. Cone 
axes in theory should be oriented perpendicular to an expanding, generally hemispherical wave front, in effect definıng radii trom the shock center. Hargraves (1961), and later Manton in more detail (1965), at the Vredefort Ring, South Africa, showed that striations of apparently randomly oriented cone segments in a single outcrop plot stereographically to define the projection of a cone pointing toward the center of the structure. Shatter cones form before the major structural deformations that produce the circular structures, so use of cone axes to define the shock center requires sufficient information to reconstruct the position of shatter-coned beds before the disturbance. This has been done successfully not only at V redefort, but also at Sudbury (Bray, and others, 1966) and Sierra Madera (Howard and Offield, 1968). At these structures, if beds are replaced in their original position, shatter cones point inward and upward to an inferred focus of shock-wave energy release. Shatter cones in a thick stratigraphic section at Gosses Bluff permit similar determination of focus; high beds give a different focus than lower beds, the difference being a measure of greater inward movement of the lower beds as the central uplift formed (Milton and others, 1972).

At Decaturville, striations on cones and cone segments were measured and plotted stereographically at eight localities to determine cone-axis orientations. Despite the intensive post-shatter coning disruption suffered by the

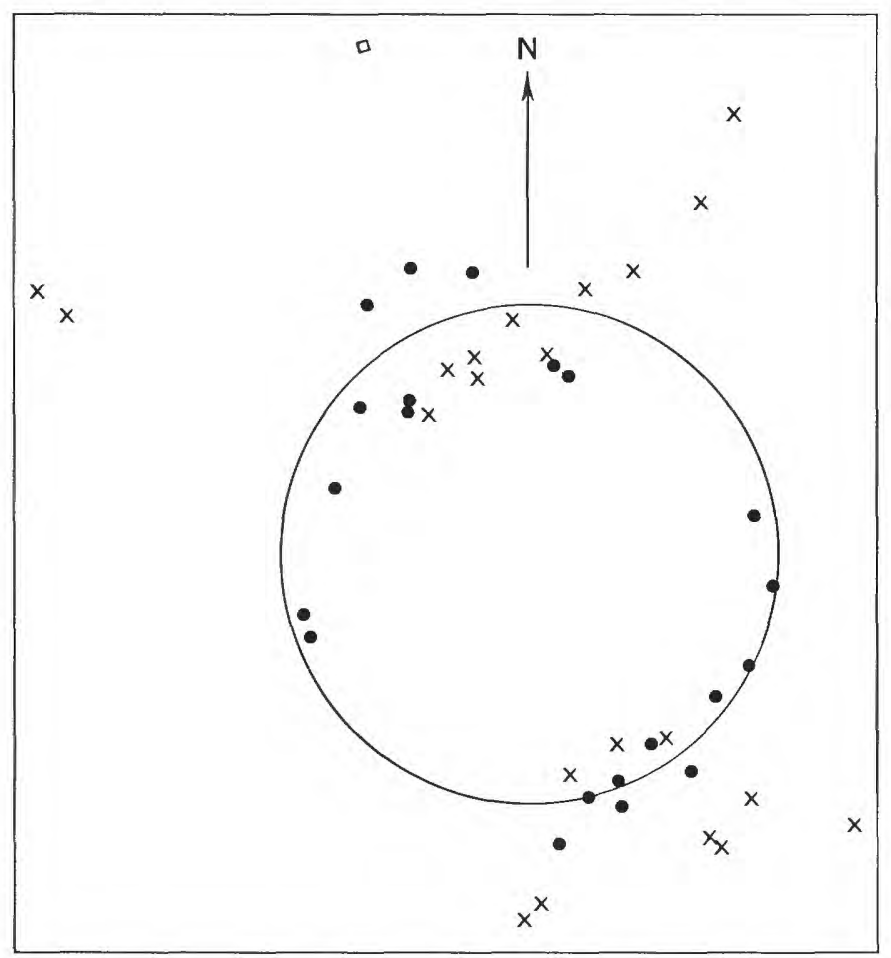

FIGURE 19.-Stereographic projection of shatter-cone striations defining cone with $92^{\circ}$ apical angle (rotated to vertical). Of 21 measurements, one lies more than $\pm 10^{\circ}$ from mean circle. Azimuth and plunge of striations measured in situ $(x)$ and rotated to define cone with vertical axis (.); axis of cone in situ shown by small open square.
Derby and Doe Run Dolomites, six of the eight plots showed that striations on diversely oriented cone segments gave excellent conical projection (fig. 19). A total of 120 striations were used in the 6 plots, and all but 12 fell with a $\pm 10^{\circ}$ variation in apical angle from the mean cone projection. Apical angles ranged from $79^{\circ}$ to $92^{\circ}$, with a mean of $86^{\circ}$.

Unfortunately, the orientation of the shatter cones is uncertain because bedding in the Derby and Doe Run is virtually impossible to define. Three localities display surfaces which may be bedding, and rotation of these to horizontal was done by stereographic projection. Cones in these beds then pointed in and down to a focus within the Davis. If the Derby and Doe Run beds have moved inward, as will be argued in the section on origin of the structure, then the downward-pointing cones in their original positions farther out would have defined an even deeper shock focus, probably within the Bonneterre. This is not in accord with the distribution of shock features discussed in the remainder of this section. We therefore believe that bedding in the shatter-coned rocks has not been correctly identified and that these cones cannot be used to determine the stratigraphic level at which the energy release was focused.

\section{PLANAR ELEMENTS IN QUARTZ}

Quartz develops distinctive intragranular features as a result of deformation under high transient pressures, such as occur during passage of a shock wave. Data from shock experiments and observed deformation features around nuclear-explosion sites show a definite progress in development of planar elements in quartz as intensity of shock deformation increases. At Decaturville, planar elements in quartz include open "cleavage" fractures, closely spaced parallel planes called "planar features," and possible deformation lamellae (permanent strain zones produced by slip and indicative of high shock pressures).

Rhombohedral cleavage is common in individual quartz grains of the Gunter Sandstone Member, including the large exotic block of Gunter at the village of Decaturville. The cleavage planes are open, clean fractures that typically appear in a rectilinear network of traces spaced $40-100 \mu \mathrm{m}$ (micrometers) (fig. 20). They may occur in nearly every grain in a thin section or in only a few. Cleavage is not found in quartz grains from formations that crop out outside the ring of Gunter. Nor has it been observed in the quartz that occurs as isolated grains or small clusters of grains in the carbonate formations below the Gunter.

Rhombohedral cleavage does occur in some grains in blocks of Lamotte Sandstone, not as abundantly as in the Gunter but with finer spacing $(4-8 \mu \mathrm{m})$. The Lamotte, however, has a few grains that show well-developed basal cleavage $\{0001\}$, a cleavage not seen in the Gunter Sandstone Member. This cleavage is marked by dark traces about 3-5 $\mu \mathrm{m}$ wide and spaced at $9-60 \mu \mathrm{m}$ (of the type shown in quartz grains of unidentified stratigraphic position in fig. 21). Inasmuch as basal cleavage requires more bonds broken per 


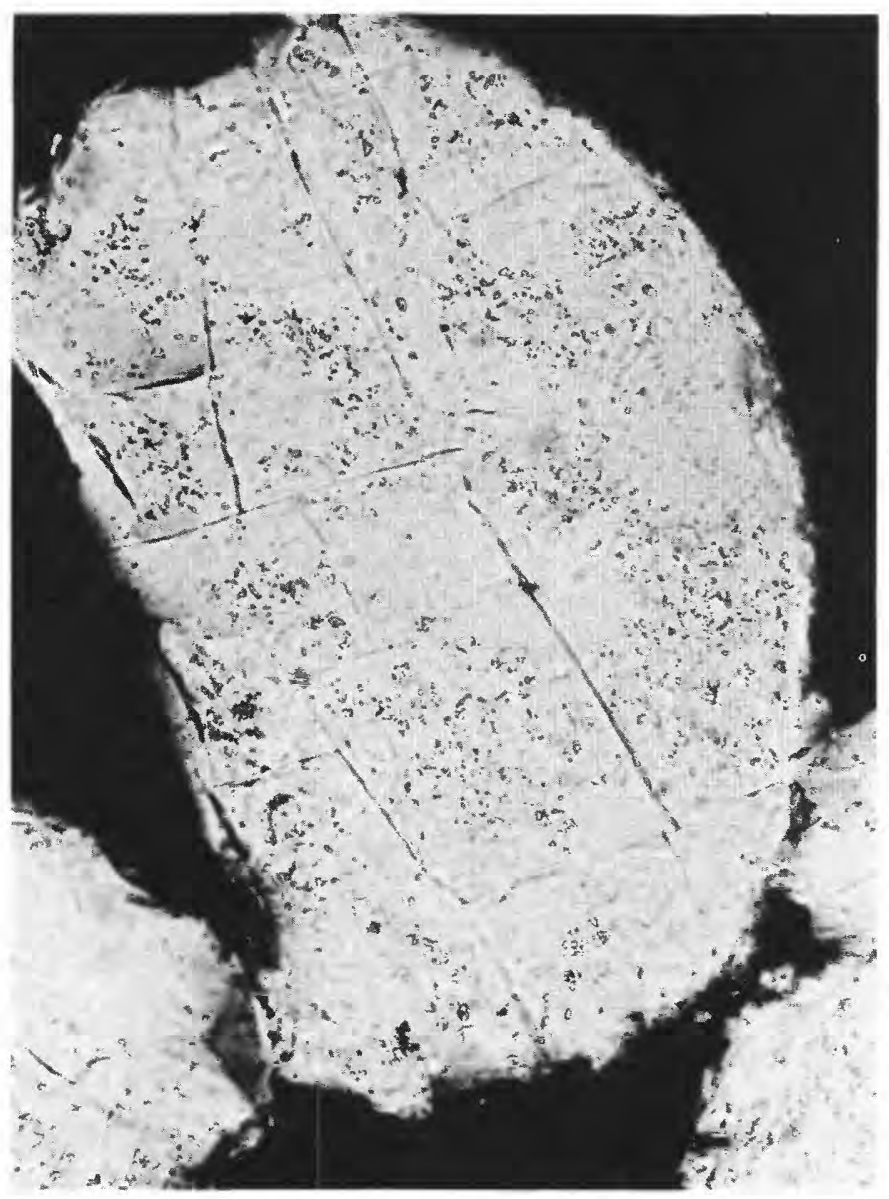

FIGURE 20.-Photomicrograph $(120 \mathrm{X})$ showing widely spaced rhombohedral fractures in quartz grain of Gunter Sandstone Member of the Gasconade Dolomite.

unit area than does rhombohedral cleavage (Fairbairn, 1939), the presence of basal cleavage and the much closer spacing of rhombohedral cleavage in the Lamotte suggest higher strain than was experienced by the Gunter along the present outcrop ring. Small lateral displacements or faults as defined by Carter (1968, p. 457) mark both types of cleavage in the Lamotte grains, but they are not numerous. In fact, grains with any kind of planar fractures in the Lamotte probably make up no more than $2-3$ percent of the 17 thin sections examined. Moreover, it is interesting that only Lamotte samples taken at the center of the structure show cleavage in the quartz; samples from the sulfide pit $490 \mathrm{~m}$ away show marked granular flowage on megascopic scale but the grains do not have cleavage. Even at the center, cleavage development is extremely variable. One Lamotte sample from a block in the wall of the pegmatite pit contains nearly twice as many grains with cleavage as all other samples combined, and it shows basal cleavage as common as rhombohedral cleavage in nearly all the fractured grains. Neither the pegmatite nor the schist below the Lamotte shows fracturing of quartz; some grains show unusual curving or chevronlike strain extinction bands, but complex- ly sutured boundaries are undisturbed and cleavage is absent.

Quartz grains make up a few percent of the matrix in the mixed breccia at the center of the structure. One to two percent of these show closely spaced rhombohedral and basal cleavages, about equally abundant and well developed. In a very few grains, planar elements both parallel and perpendicular to the $c$-axis are spaced only about $1-3 \mu \mathrm{m}$ apart. Other elements in some grains, equally rare and closely spaced, are crystallographically oriented parallel to $\{10 \overline{1} 3\}$. (fig. 22). These closely spaced planes are conspicuous in bright-field illumination and are visible independent of direction of light vibration. They are reasonably good examples of what Carter (1968) defined as "planar features," but are much less common and are in fewer sets per grain than are reported in studies of several other probably impact structures (for example, Robertson and others, 1968; Short and Bunch, 1968; Chao, 1967). Even rarer are grains containing planar elements parallel to $\{0001\}$ and $\{10 \overline{1} 3\}$ and marked by abundant tiny cavities or inclusions. These are only moderately visible in bright-field illumination but are seen equally well in plane and polarized light; their visibility

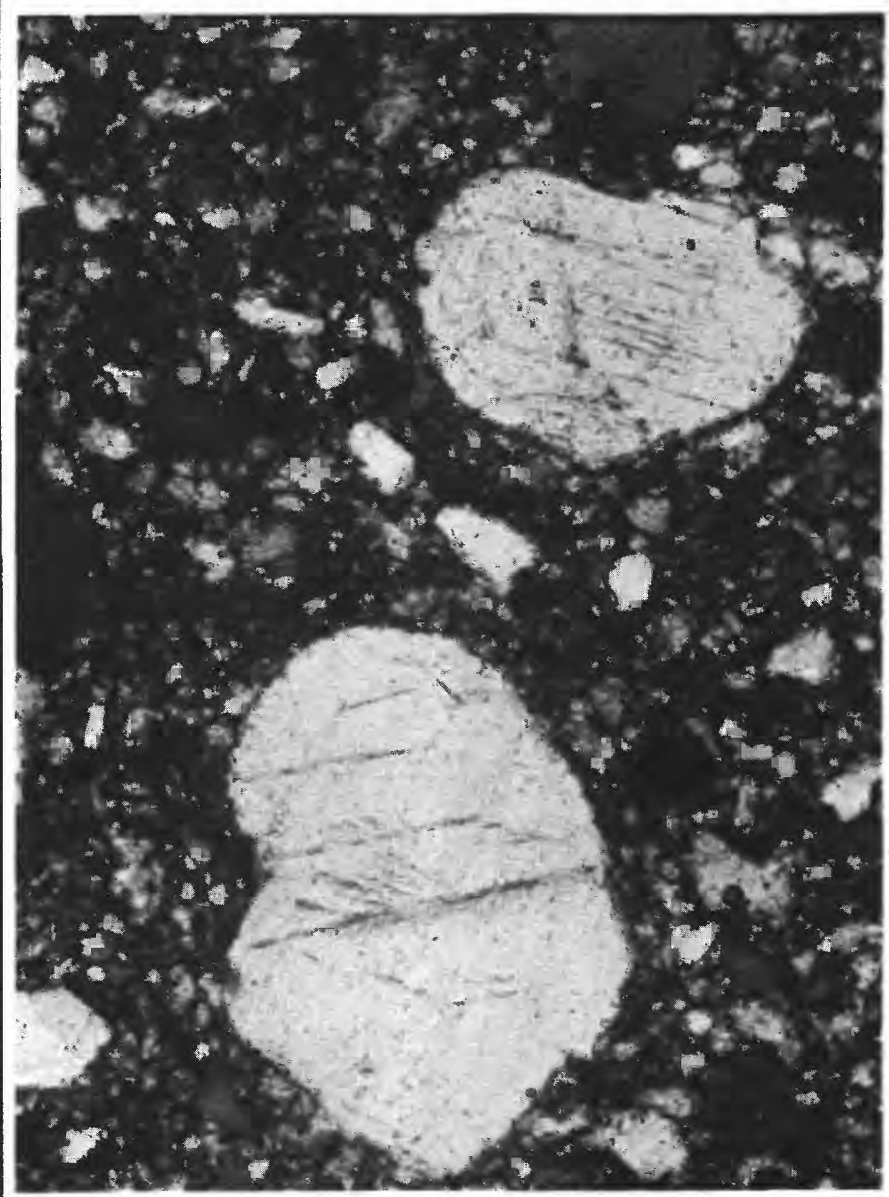

Figure 21.-Photomicrograph (120X) of mixed breccia. Two large quartz grains in a carbonate matrix have prominent decorated planar features spaced $9-60 \mu \mathrm{m}$ and oriented parallel to $\{0001\}$. Polarized light. 
varies with the direction of light vibration. These rare features seem to be rather poorly developed examples of what Carter (1968) has called deformation lamellae; they connote intragranular flow. As with the Lamotte, only mixed breccias from the center of the structure contain quartz grains that have the described planar elements. Virtually identical mixed breccia from the sulfide pit does not contain such grains.

The stratigraphic origin of the quartz grains in the mixed breccia is not certain. Many of the grains are large and rounded and on that basis alone might have come from the Lamotte, Gunter, or perhaps the Davis. No fragments from higher than the Potosi have been identified in the mixed breccia; thus it does not seem likely that sand grains from a formation as high as the Gunter would be present. The Lamotte breccia fragments that were examined contain grains having basal and rhombohedral cleavage and a few microfaults, but the grains do not have planar features and in particular they do not show planes parallel to $\{10 \uparrow 3\}$. The few quartz grains that do have $\{10 \overline{1} 3\}$ planar features were

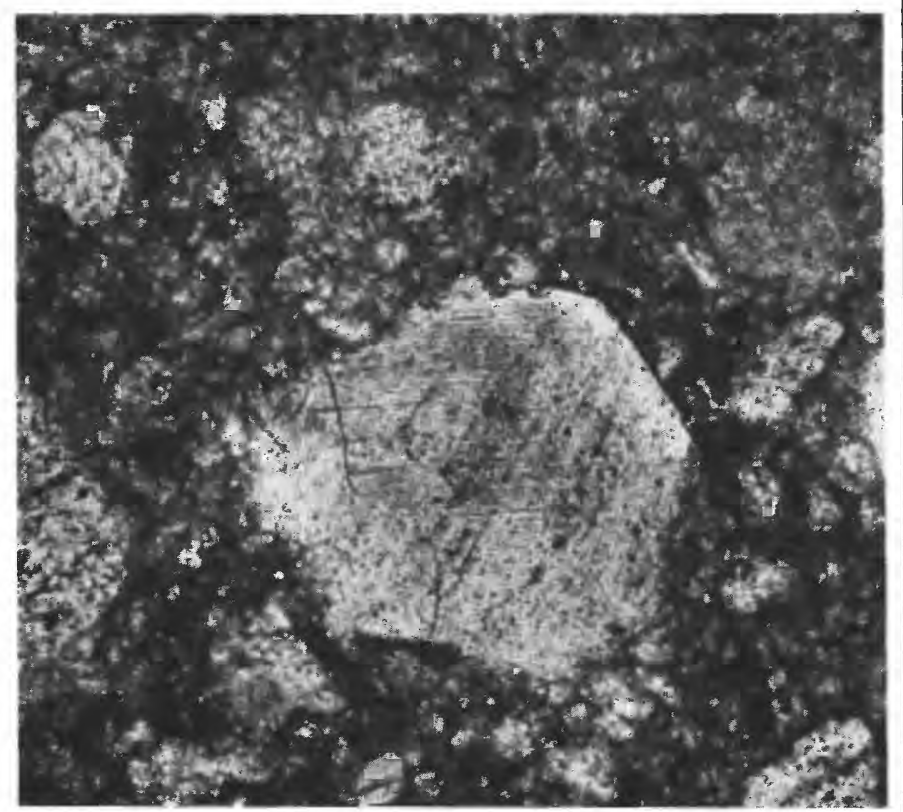

FIGURE 22.-Photomicrograph (200X) of mixed breccia, showing quartz grain with dominant planar features spaced $1-3 \mu \mathrm{m}$ and oriented parallel to $\{10$ T3 $\}$. Plane light.

mostly found in clusters of small angular grains within a single small core sample of mixed breccia. These grains are typical of grains in clusters or laminae in the silty portions of the Davis, although they could possibly be derived from any formation below the Eminence. We suspect that the grains having planar features are in fact from the Davis, because, as mentioned, they are not likely to have come from either the Gunter or the Lamotte, and other intervening formations generally lack quartz.

The problem of representative sampling is considerable in trying to assure that grains were seen which indicated the maximum shock-pressure levels attained. Quartz grains probably make up less than 5 percent of the examined mixed breccia samples. In samples showing the highest levels of shock found for both the breccia and the Lamotte, only 1 grain in 50 or 100 may contain planar features.

The meaning of planar elements in quartz rests largely on statistical arguments in which type and orientation of planes are compared with like data obtained from static and dynamic deformation experiments and from proved impact structures. Figure 23 compares a histogram of frequency and orientation of the planar fractures observed in rocks of the Decaturville structure, with histograms from Meteor Crater, Ariz., from other impact structures, and from shock experiments. Planar elements at Decaturville are similar to those from Meteor Crater and Middlesboro, Ky.; the Decaturville histogram is deficient in the $\{1013\}$ orientation relative to those from Sierra Madera, Tex., Clearwater Lake, Quebec, or from rocks experimentally shocked at 250-300 kb (kilobar) pressures; and the planar elements at Decaturville differ in every category from elements in tectonites or rocks deformed statically at low confining pressure and much lower strain rates. The high frequency of basal elements shown in the histogram of Decaturville samples occurs because cleavage, planar features, and (probable) deformation lamellae are plotted together. Clearly, most of the components measured were cleavage.

The cited experiments and field studies permit little doubt that the types of planar elements in quartz observed at Decaturville were produced by high transient pressures associated with passage of shock waves. Reasonable estimates of the shock pressures involved at Decaturville can be made by comparison with results obtained from experiments. Studies of granodiorite at the Hardhat nuclear explosion site showed that sets of "cleavage" fractures in quartz began to develop at pressures of about $50 \mathrm{~kb}$ (Short, 1966). A similar pressure can be inferred from laboratory results of Horz (1968). The lowest pressure levels he described were about $50 \mathrm{~kb}$, at which level cleavages developed but only sparsely as compared to those formed at higher pressures. At 52 and $54 \mathrm{~kb}$, with the quartz oriented differently with respect to the shock-wave direction, Horz produced cleavages dominantly on rhombohedral planes, but also parallel and perpendicular to the $c$-axis. In a third orientation, and at $109 \mathrm{~kb}$, basal cleavage became much more conspicuous. It is reasonable to assume that the lowest level of cleavage development (other than the simple rhombohedral fracturing in the Gunter) observed at Decaturville required on the order of $50 \mathrm{~kb}$. The presence of microfaults associated with cleavages is a further indication that pressures on the order of $40 \mathrm{~kb}$ were experienced by part of the Lamotte (Christie and others, 1964; Carter, 1968).

Planar features and deformation lamellae have been shown to require considerably greater pressures. Carter $(1968$, p. 470) estimated that basal slip requires a stress difference at $76 \mathrm{~kb}$ at $300^{\circ} \mathrm{C}$, and Horz (1968) found in 

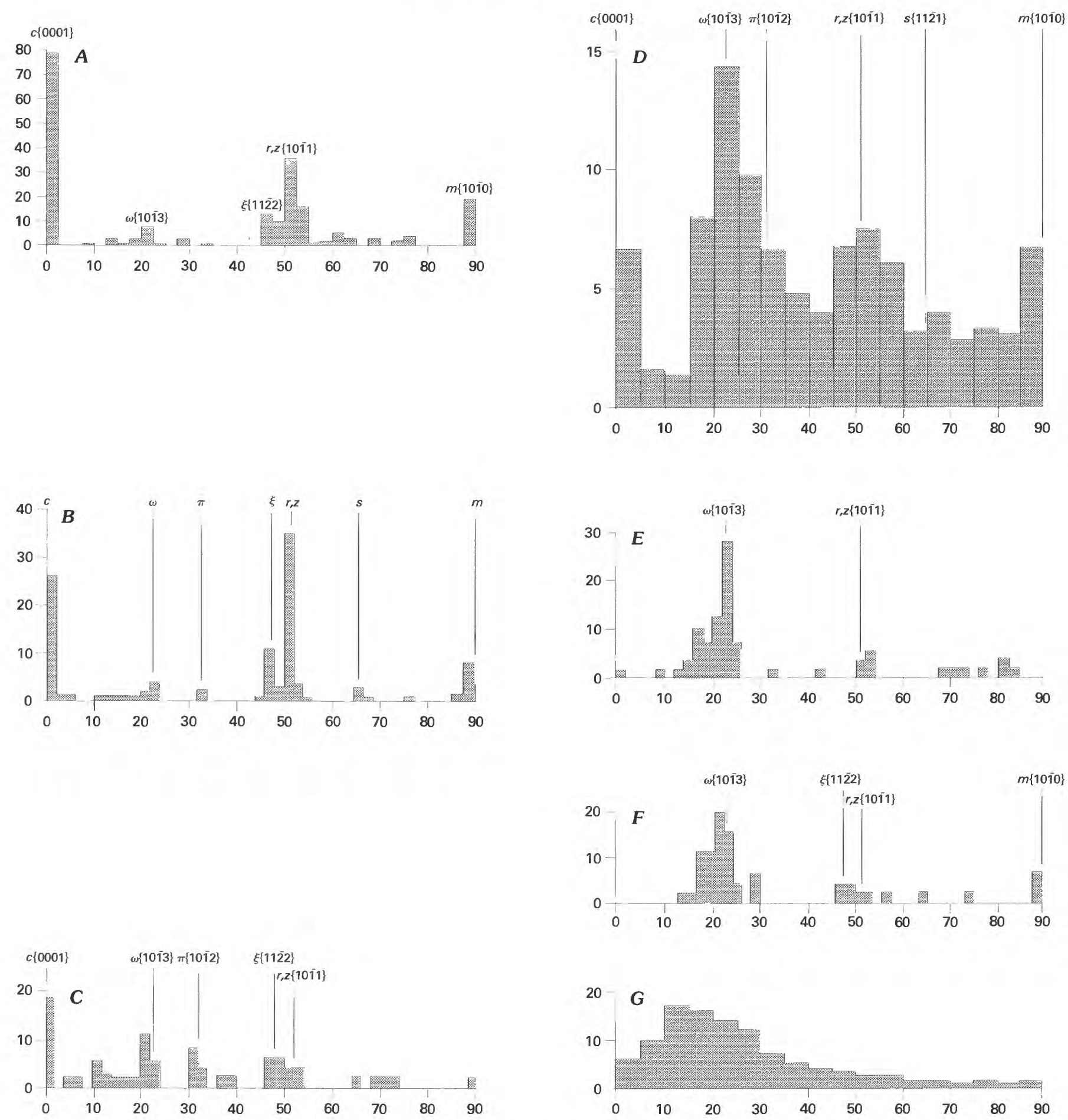

Figure 23.- Histograms showing frequency and orientation of quartz planar fractures. $A$, Decaturville, 100 grains from Lamotte Sandstone and mixed breccia; $B$, Meteor Crater, Ariz. (Bunch, 1968); C, Middlesboro, Ky. (Bunch, 1968); D, Sierra Madera, Tex. (Wilshire and others, 1972); E, Clearwater Lake. Quebec (Bunch, 1968); $F$, Shock experiment. 250-300 kb (Bunch, 1968); $G$, Tectonites; (Carter and Friedman 1965). Vertical axis, frequency (percent); horizontal axis, angle between $c$ axis and pole to planar element set (degrees).

experiments on single crystals that pressure between 100 and $\mid$ We have no good evidence on temperatures associated with $120 \mathrm{~kb}$ was required to form planar features parallel to \begin{tabular}{l|l}
$\{10 T 3\}$ and $\{1001\}$. The lower the temperature, the greater the & has been found and complete thermal annealing of fission \\
pressure required to produce the observed planar features. & tracks in the basement rocks probably did not occur.
\end{tabular} the shock event at Decaturville, except that no melt phase 
Annealing of tracks in apatite depends on the duration of the thermal event, but if we assume that raised temperatures prevailed for less than a year, basement temperature probably did not exceed $150^{\circ} \mathrm{C}$ (Naeser and Faul, 1969). Ahrens and Gregson (1964) calculated that in sandstone the temperatures associated with various pressures are $229^{\circ} \mathrm{C}$ at $25.4 \mathrm{~kb}, 336^{\circ} \mathrm{C}$ at $52.8 \mathrm{~kb}$ and $720^{\circ} \mathrm{C}$ at $104.5 \mathrm{~kb}$. These data suggest that pressures in the basement rocks probably were less than $20 \mathrm{~kb}$ and that transient temperatures in the most highly shocked part of the Lamotte (presumably the upper part) probably were around $300^{\circ}-350^{\circ} \mathrm{C}$. The quartz containing planar features parallel to $\{0001\}$ and $\{10 \overline{1} 3\}$ probably came from strata above the Lamotte and thus may have developed planar features at somewhat less than the $100 \mathrm{~kb}$ used in experiments. It seems reasonable to suppose that these features record pressures between 70 and $100 \mathrm{~kb}$.

The wide-spaced cleavage seen in the Gunter does not necessarily indicate shock pressures, but it is unusual for rocks deformed under normal tectonic conditions. Such large, open fractures may indicate that the Gunter, less confined than deeper rocks and with more open packing of quartz grains, dilated markedly after passage of the compressive shock wave.

\section{ASTERISM IN DOLOMITE}

Permanent damage to crystal lattices is shown by asterism - the scattering of X-ray spot reflections from a single grain when rotated in a Debye-Scherrer camera. The greater the crystal damage, the greater the tendency of spot reflections to merge into single lines such as are seen in $\mathrm{X}$-rays of powders. Line broadening is an additional measure of damage intensity. X-ray examination of single dolomite crystals from shatter cones in the Derby and Doe Run near the center of the Decaturville structure has been reported by Simons and Dachille (1965) and by Dachille, Gigyl, and Simons (1968). One Decaturville sample showed a complete powder arc and extreme line broadening, comparable to those damages in shocked calcite from a nuclear-explosion site and to those in shocked quartz from Meteor Crater, Ariz. (Simons and Dachille, 1965). The intensity of asterism and line broadening were much greater than that seen in shatter-coned material from impact structures at Sudbury, Ontario, Sierra Madera, Tex., and Wells Creek, Tenn. Dachille and others $(1968$, fig. 7$)$ showed that Decaturville samples have X-ray patterns similar to powders that were shocked at about 40 and $90 \mathrm{~kb}$. They correspond in damage intensity to samples from Sierra Madera, Tex. and the Steinheim Basin, Germany. Shatter cones in dolomite may form at pressures as low as $15-20 \mathrm{~kb}$ and they are also found at Sierra Madera in dolomite and limestone shocked to levels around $100 \mathrm{~kb}$ (Wilshire and others, 1972). Thus, the range of 40 to $90 \mathrm{~kb}$ suggested by the asterism study is consistent with what is known about the shock envelope in which shatter cones form in dolomite.

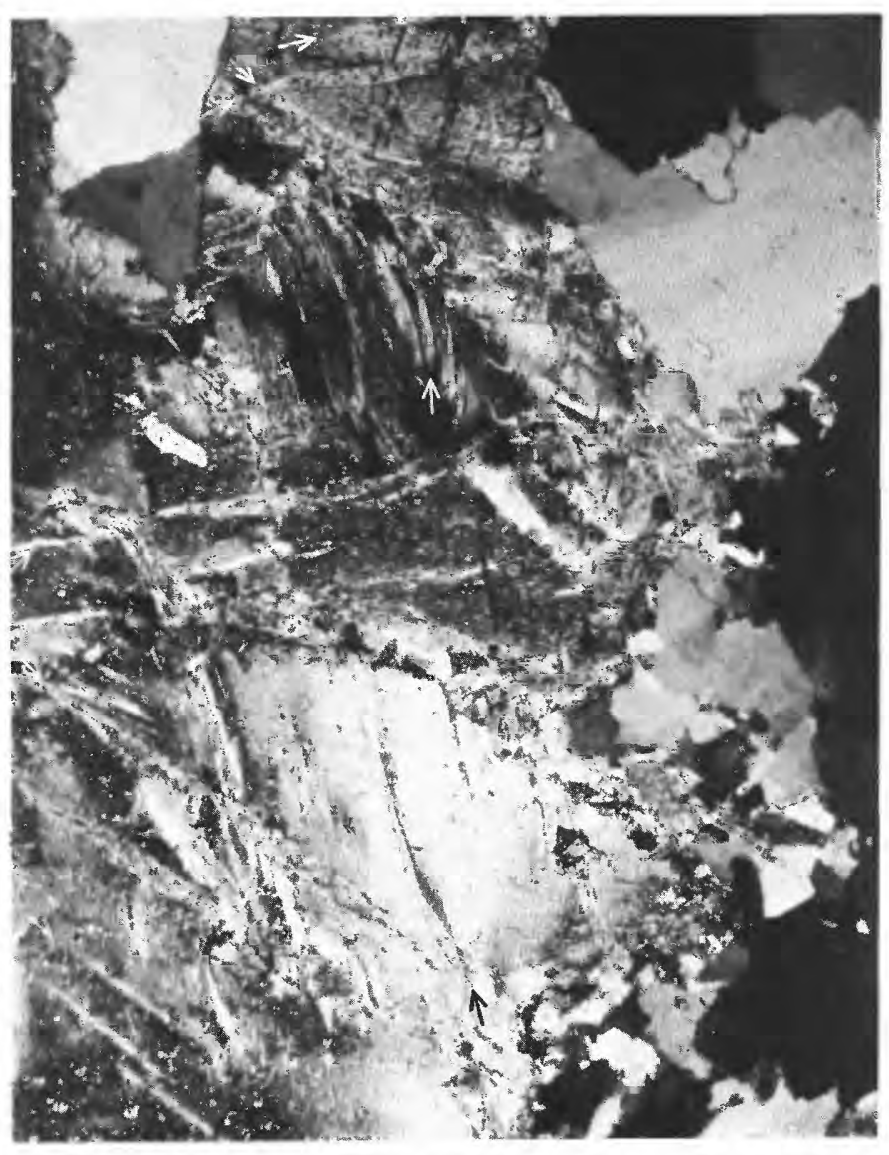

FIGURE 24.-Photomicrograph $(120 \mathrm{X})$ of muscovite grain surrounded by strained quartz in pegmatite, showing differently oriented kink bands (indicated by arrows).

\section{KINK BANDS IN MICA}

Muscovite grains in the pegmatite display kink bands (fig. 24). As many as three directions of kink axes are seen in a single mica grain. Muscovite in the schist that encloses the pegmatite is almost entirely without kink bands, suggesting that the bands develop better in rocks that cannot yield readily by slip between grains. The kink bands are too few for the kind of statistical measurements described by Horz (1970) or Cummings (1968). They vary considerably in asymmetry and width and cannot be said with certainty to have formed by shock. If the kink bands did in fact form as a result of shock, they could indicate pressure as low as $9 \mathrm{~kb}$ (Horz, 1970).

\section{SHOCK-ENVELOPE CONFIGURATION}

Control points for reconstructing the envelope of shock pressure are: (1) Probable $20 \mathrm{~kb}$ at the outer limit of shatter cone formation; (2) no more than $10-15 \mathrm{~kb}$ in the basement rocks; (3) about $50 \mathrm{~kb}$ at the top of the Lamotte; (4) 70-100 $\mathrm{kb}$ for quartz grains believed to be derived from the Davis; 


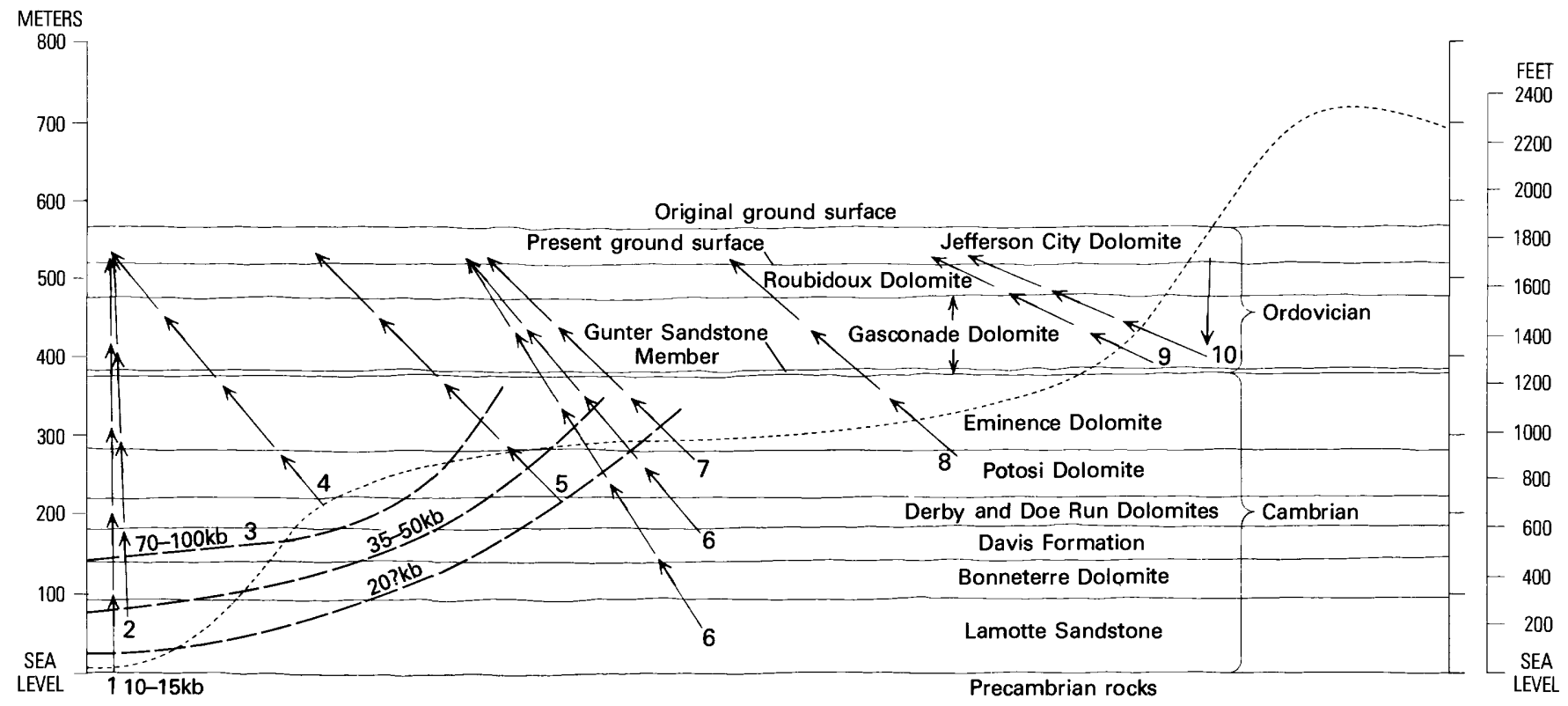

FIGURE 25.--Cross section showing inferred shock-pressure envelope (dashed lines) in undisrupted strata. Data points shown in present positions and in inferred predisruption positions, assuming about 300-m inward move of beds as central peak formed. Arrows show change in position of data points after inward and upward move. Data points are: (1) Basement rock, not certainly shocked; (2) uppermost Lamotte Sandstone with basal cleavage; (3) mixed breccia quartz grains with $\{1013\}$ features, probably derived from Davis Formation; (4) asterism suggestive of $90 \mathrm{~kb}$; (5) outer limit of shatter cones; (6) Davis and Lamotte blocks upfaulted in sulfide pit (cleavage and planar features lacking); (7) downfaulted block of Eminence Dolomite near sulfide pit; (8) fault block of shattered Potosi Dolomite; (9) cleavage in Gunter Sandstone Member of the Gasconade Dolomite; (10) downfaulted block of Jefferson City Dolomite. Dotted line, inferred profile of initial (transient) crater. Vertical and horizontal scales equal.

and (5) probable $90 \mathrm{~kb}$ for shatter-coned Derby and Doe Run at the center of the structure. Cleavage in the Gunter Sandstone Member and monolithologic breccias beyond that as far out as the ring fault suggest the passage of a decaying shock wave, with subsequent rarefaction, across the whole structure; but these features probably involved pressures of only a few kilobars.

Figure 25 shows projected envelopes for various levels of pressure, based on inferred initial positions for the control points in the original stratigraphic pile before the inward and upward movements occurred to form the central uplift. The figure also shows the present locations of the control points and straight-line paths to represent rough vector sums of their postshock displacement. The amount of upward movement is clear; the amount of inward movement is an assumption based on the amount that seems to be required by the present Gunter ring configuration (pl. 1) and by the subsurface data obtained at the center of the structure. This problem is discussed in the section on origin.

The stratigraphic level of the focus of energy release is difficult to establish. Maximum pressure levels recorded in any of the rocks preserved at the center are in the Davis and Derby and Doe Run Formations. (Shatter-coned Potosi is present there, but its degree of asterism has not been measured and no quartz fractures have been found.) We have no evidence to rule out the possibility of greater shock pressures in higher strata. If the recorded pressures described here were in fact the maximum obtained at the defined points in these strata, then the shapes of the inferred envelopes in fig. 25 suggest that the focus was in the Potosi or possibly in Derby and Doe Run. (Compare with depiction of shock-wave geometry in Gault and others, 1968, fig. 6.) It is argued in a later section that the Decaturville structure originated by impact. The shock-pressure configuration just described requires the impacting body to have penetrated some $270-390 \mathrm{~m}$ of sedimentary strata.

\section{AGE OF STRUCTURE AND DEPTH OF EROSION}

The Bainbridge Limestone is involved in the deformation, so the Decaturville structure is clearly younger than Middle Silurian. Shepard (1905, p. 116) identified an outcrop of Hannibal Shale and Sac Limestone of Early Mississippian age just north of the village of Decaturville, but we could not find this exposure in our mapping.

The Precambrian schist exposed at the center of the structure contains apatite. Fission-track counts from the apatite grains were reported by Offield, Pohn, and Naeser (1970) as indicating the age of structure to be $210 \pm 20$ m.y., or Triassic. Subsequent analysis by C. W. Naeser (written 
commun., 1973), however, shows a fission-track count corresponding to an apparent age for the schist of $147 \pm 30$ m.y. Unfortunately, the pertinence of this age-data to the time of formation of the structure is not clear. Precambrian apatite from the St. Francois Mountains of southeastern Missouri, which has not experienced heating other than through shallow burial and regional epeirogenic movement, gives an apparent fission-track age of $213 \pm 21 \mathrm{~m}$.y. Annealing of fission tracks that gives false apparent ages for Precambrian rocks of the midcontinent region evidently does not require an unusual thermal event. Possibly heat associated with the formation of the Decaturville structure caused enough annealing of apatite fission tracks so that the apparent age is less than that of Precambrian apatite from the nearby undisturbed St. Francois area. If this is true, the heating event may have caused only partial annealing and moreover could have occurred at any time after the apatite formed, and the fission-track count would thus not indicate the age of the structure. It is likely, however, that the fission-track determination does indicate a maximum age of the structure, that is, Jurassic-Cretaceous time.

An additional point bearing on the age of the structure is that the brecciation occurred after the area was mineralized. Zimmerman and Amstutz (1972) illustrated broken grains of microbanded sulfides as part of the fragments in the breccias near the center of the structure. The age of mineralization in central Missouri is not certain, but by comparison with stratigraphic dating of similar microbanded sulfide in western Missouri (A. V. Heyl, oral commun., 1974), it is at least post-Pennsylvanian and possibly as young as Cretaceous. From this argument, the structure most probably has a maximum age of Permian, but it may be younger than Cretaceous. When this is considered together with the probable maximum age of Jurassic-Cretaceous suggested by fission-track count, it seems likely that the Decaturville structure formed after Cretaceous time.

A post-Pennsylvanian date for the structure, and the regional stratigraphic pattern, permit reasonable inferences to be made concerning the position of original ground surface when the structure formed. The geologic map of Missouri (McCracken and others, 1961) shows outliers of Mississippian strata in a pattern that suggests successive onlap of Kinderhookian, Osagean, and Meramecian Series units around a high area containing Decaturville within the broader Ozark dome. A Meramecian outlier is $26 \mathrm{~km}$ southwest of Decaturville, and Osagean outliers are $35 \mathrm{~km}$ east and west; these lie on the Jefferson City Dolomite. From the map pattern it cannot be said with certainty that the Decaturville area was overlain by Osagean or Meramecian units, although Schuchert (1943, p. 684) supposed that the Osagean Burlington Limestone completely covered the Ozark dome. If these beds were deposited there, they were apparently stripped away following the uplift and the considerable erosion in Late Mississippian and Early Penn- sylvanian time. Middle Pennsylvanian shale lies upon Jefferson City Dolomite, Roubidoux Dolomite, and in one place Gasconade Dolomite on the flanks of the local high around Decaturville; outliers of the shale are found $31 \mathrm{~km}$ east, 45 $\mathrm{km}$ north, and $56 \mathrm{~km}$ west of Decaturville. Pennsylvanian sediments probably covered the dome (Melton, 1931, p. 219), but their thickness can only be estimated. It seems likely that, at a maximum, the Des Moinesian section (about $120 \mathrm{~m}$ ) would have been present. We believe it more probable that only a part of the Des Moinesian strata was deposited over the center of the locally high area within the Ozark dome.

The Ozark area was probably elevated sometime in the Permian, though possibly earlier during warping in Pennsylvanian time (Van Tuyl, 1918, p. 280). No Permian sediments are known to have been deposited in the region. No Pennsylvanian rocks are preserved in the Decaturville structure, even though they would have directly overlain Ordovician and Silurian limestones found in many places in the depressed zone. This strongly suggests that they were removed as the regional high was eroded before formation of the structure, which hypothesis meshes well with the argument for a Permian or later age of formation.

If this hypothesis is accepted, then when the structure formed probably nothing was present above the stratigraphic level of the middle part of the Jefferson City Dolomite, except some patches of Ordovician and Silurian limestones, probably in topographic lows. As discussed in the section on structure, blocks of lower units believed to be ejecta sit upon the Jefferson City or limestone surface-a strong indication that the exposed surface was at that stratigraphic level when the structure formed; and this surface was downdropped and preserved in the outer part of the structure. It follows that the area of flat-lying strata outside the ring fault has been in general eroded just enough for removal of most or all of the Jefferson City. A value typical for erosional lowering of the general plateau level in the immediate vicinity of the structure since the structure was formed is about $45 \mathrm{~m}$. More erosion may have occurred to plane off the central uplift and the crater rim depending on how much those features protruded above the level of the plateau.

These considerations suggest that except for removal of the upraised crater rim and central peak, the structure is preserved nearly in its original form rather than being the deeply eroded root of a structure that might have looked very different at a higher pre-erosion level. This point bears importantly on any explanation of origin and on any reconstruction of original appearance and subsequent alterations of the structure. Moreover, the small amount of erosion believed to have taken place after the structure formed suggests that the structure is young-quite possibly Cretaceous or younger. 


\section{ORIGIN OF THE STRUCTURE}

The Decaturville structure involves such unusual and intensive deformation in a small, sharply bounded, circular area that an explosion-like origin by sudden highly localized release of tremendous energy seems certain. No evidence exists to permit serious consideration of the intrusion of igneous material or a diapiric mass of sedimentary material as possible origins of the structure. No igneous material is involved, and diapirism is ruled out by a stratigraphic configuration that could not permit flowage of strata under the impetus of density inversion. Two hypotheses involving explosion-like origin of the structure are in contention: endogenetic volcanic gas or phreatic explosion) and exogenetic (meteorite or comet impact). An excellent summary of these arguments for cryptoexplosion structures in general has been given by French (1968), and other statements of the two viewpoints have been made by Bucher (1963) and Dietz (1963).

Any explanation for the Decaturville structure must account for its major features:

1. It is circular and sharply fault bounded, containing a central uplift and a surrounding structural depression.

2. Deformation is shallow, virtually within a $540-\mathrm{m}$ column of sedimentary strata atop a little-disrupted basement.

3. Shock features are apparent and intensity of shock deformation diminishes downward.

4. No evidence of volcanic processes has been found.

5. The central uplift involved large-scale inward and upward movements of strata by thrusting and folding.

6. Blocks of strata (basement to Potosi Dolomite) are mixed, a hundred meters out of place, in a central breccia mass below a capping layer of Derby and Doe Run Dolomites.

7. Exotic blocks of basement rock, Derby and Doe Run, and Gunter sit atop the youngest rocks in the section within the ring depression.

We believe that the type and intensity of deformation at Decaturville cannot be explained by a terrestrial volcanic event, but that they are what would be expected from a meteorite or comet impact. The two hypotheses are discussed in detail below.

\section{ENDOGENETIC ORIGIN}

In the absence of any sign of volcanism at Decaturville, the argument for endogenetic origin rests almost entirely on regional structural setting. Snyder and Gerdemann (1965) noted that Decaturville was one of eight features related to volcanism or of unusual structural character that lie nearly in a line along the 38th parallel from Illinois to Kansas (fig. 26). They considered this lineation to indicate a regional extension of the Rough Creek-Shawneetown - Palmer fault zone crossing western Kentucky, southern Illinois, and eastern Missouri (fig. 26). Snyder (1970) later extended the zone from Virginia to central Kansas, including in it eight mineralized areas, ten igneous intrusions, and eight "explosion" structures (five of which were among the features described in the 1965 report). He also added a similar lineament to the south, broad enough that features overlapped with features of the 38th parallel lineament. The two "lineaments" merge to form a zone $320 \mathrm{~km}$ wide from the Carolinas to Kansas and Oklahoma, which contains 44 areas or features of several different types and ages (fig. 27, modified from Snyder, 1970).

A zone near the 38th parallel may be a valid if somewhat nebulous structural line. McCracken (1971) suggested that the line is marked by the Ste. Genevieve fault system, the Palmer fault, and some small east-west faults near Rolla (fig. 26). She cited changes in fold trends and fold asymmetry in Paleozoic and possibly Precambrian rocks and in the distribution of pre-St. Peter rocks, all of which apparently reflect the influence of a 38th-parallel structural line. Also, along some small segments of the line are indications of breaks in regional magnetic trends. Heyl (1967) suggested that a right-lateral wrench fault underlies the line.

Of the eight features originally used by Snyder and Gerdemann (1965) to define the lineament, only Crooked Creek and Decaturville are "cryptoexplosion" structures with no evidence of volcanism. Hicks dome appears certainly to have been produced by violent expansion of volcanic gases beneath a stratigraphic cover a thousand meters thick. The Avon diatremes, scattered through an area of $260 \mathrm{~km}^{2}$ rather than on a neat structural line, represent another manifestation of explosive (mafic) volcanism at the surface. At Furnace Creek and Hazel Green there is no doubt about the presence of volcanic materials. The Rose dome area contains three domes (spanning some $32 \mathrm{~km}$ transverse to the general east-west line) associated with mafic volcanic rocks. The Weaubleau area is like none of the others; it consists of an area 11 by $5 \mathrm{~km}$ intensely broken by thrusts and normal faults, and of adjacent areas of $44 \mathrm{~km}^{2}$ containing unusual breccias. Ages of those features that were dated range from Cambrian to Cretaceous or early Tertiary.

Two of the five clearly volcanic features involved explosive processes that produced mixed breccias rather like those at Decaturville and Crooked Creek. The volcanic explosion breccias and the breccias at Weaubleau do not contain quartz that displays features indicative of shock such as have been described in this report and such as have been found at Crooked Creek (French, 1968). Only the structures at Decaturville and Crooked Creek display shatter cones. Superficially, Hicks dome may seem like the two cryptoexplosion structures, but in detail it is very different. It is a simple elongate domal uplift some $16-19 \mathrm{~km}$ across, without a surrounding structural depression and apparently with only a few small extensional faults produced by the uplift process. The Decaturville and Crooked Creek structures 


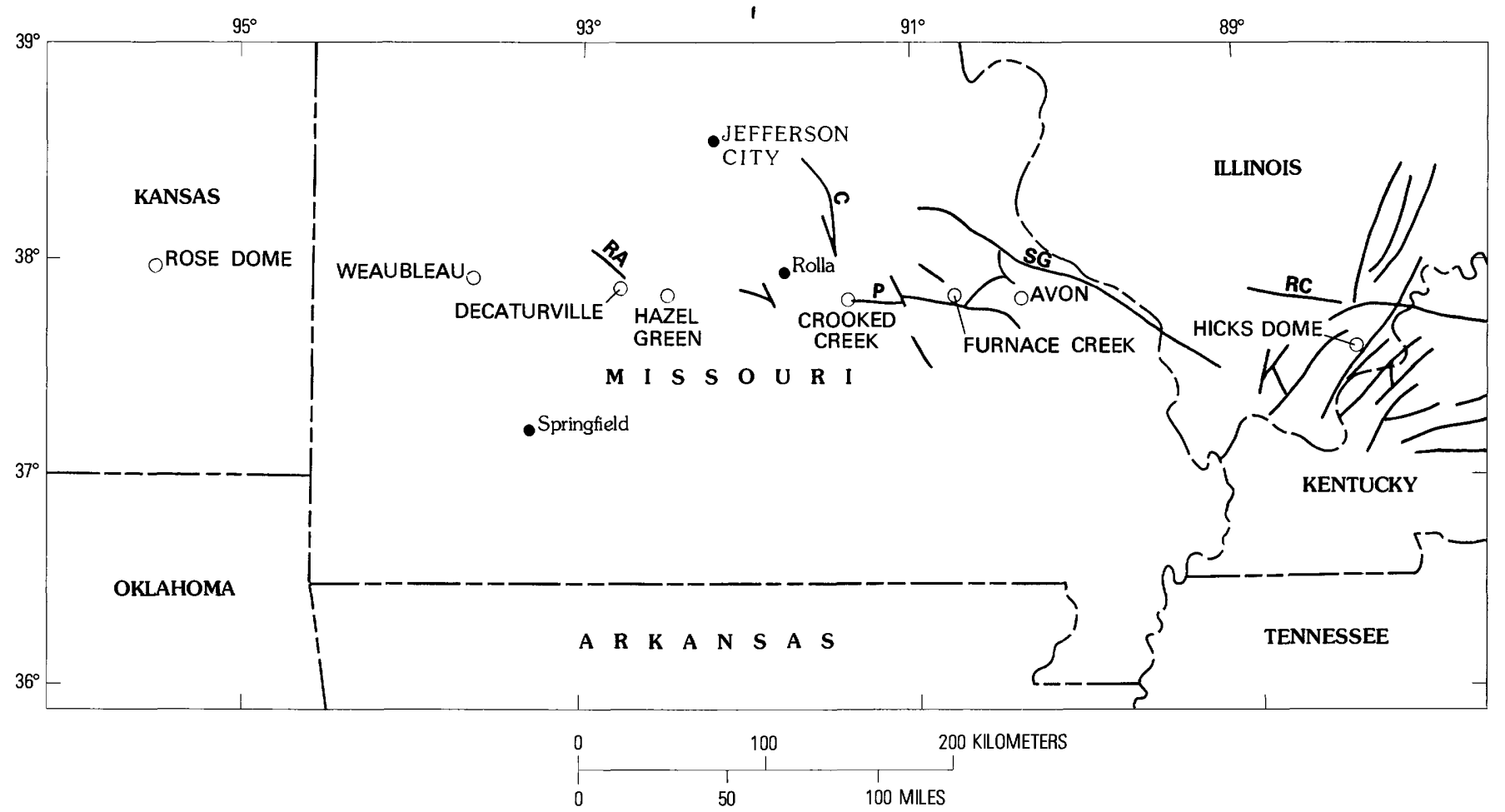

FIGURE 26.-Map showing areas of volcanism and unusual structural disturbance in apparent alinement near the 38th parallel. (Modified from Snyder and Gerdemann, 1965, p. 467.) RC, Rough Creek fault zone; SG, Ste. Genevieve fault; P, Palmer fault; C,Cuba fault; RA. Red Arrow fault.

have ring depressions and much more complex deformation involving inward movement and compressional tectonics.

Roddy (1968a, p. 307-309) presented a concise discussion of the differences between volcanic-explosion structures and impact structures, focusing particularly on the impossibility in volcanic settings of shallow buildup or containment of the necessary gas volumes and pressures and the lack of horizontal stress to produce the observed folding and thrusting.

Snyder and Gerdemann (1965) pointed out that several of the structures along the 38th parallel lie at or near intersections of local structural lines. For example, Hicks dome lies near the intersection of the east-west Rough Creek fault zone and a local anticline. The Furnace Creek volcanic center occurs near the intersection of a local fault and the east-west Palmer fault. The Crooked Creek structure lies at the west end of the Palmer fault where it would be intersected by the Cuba fault if that fault were extended $12.8 \mathrm{~km}$ southward (although no evidence for such an extension is known). Decaturville is near the intersection of the east-west lineament with the projected line of the Red Arrow fault, along the west flank of the Proctor anticline. The Red Arrow fault cannot be seen at the surface, but the magnetic map pattern suggests that at basement level it may be tangent to the ring fault on the northeast, some $3 \mathrm{~km}$ from the center of the structure. No specific structural loci along the east-west line were suggested by Snyder and Gerdemann (1965) for the Avon, Hazel Green, Weaubleau, or Rose dome features, and so the argument for local tectonic control for the "alined" structures is rather incomplete.

The presence of sulfide minerals, generally in minor amounts, also has been considered by various workers (Snyder and Gerdemann, 1965; Kiilsgaard and others, 1963; Krishnaswamy and Amstutz, 1960) as evidence of endogenetic origin of the host structures. Mineralization at Hicks dome and Crooked Creek, however, is poststructure in age and merely shows the preference of mineralizing solutions for fractured rock. At Decaturville the sulfide minerals are older than the structure; no great coincidence is called for to have a structure form (by impact or other means) in mineralized ground because sulfide mineral localities are dispersed abundantly in central Missouri (Heyl, 1968).

The argument for endogenetic origin of the Decaturville structure (and its near-twin Crooked Creek) thus deals strictly with a series of geologic associations. Existence of a discrete structural line along the 38th parallel is made doubtful by the fact that the features said to define it are of five or possibly six significantly different types, ages, and origins. The fact that five of eight features are of volcanic association cannot be shown to bear directly on the origin of the remaining three. Moreover, the 38th parallel is within a zone of many different features (fig. 27) through which lines in any direction desired could be drawn. Structural loci for the features are lacking, or depend on projections of faults, or are in fact not at but only near the features. In any event, 

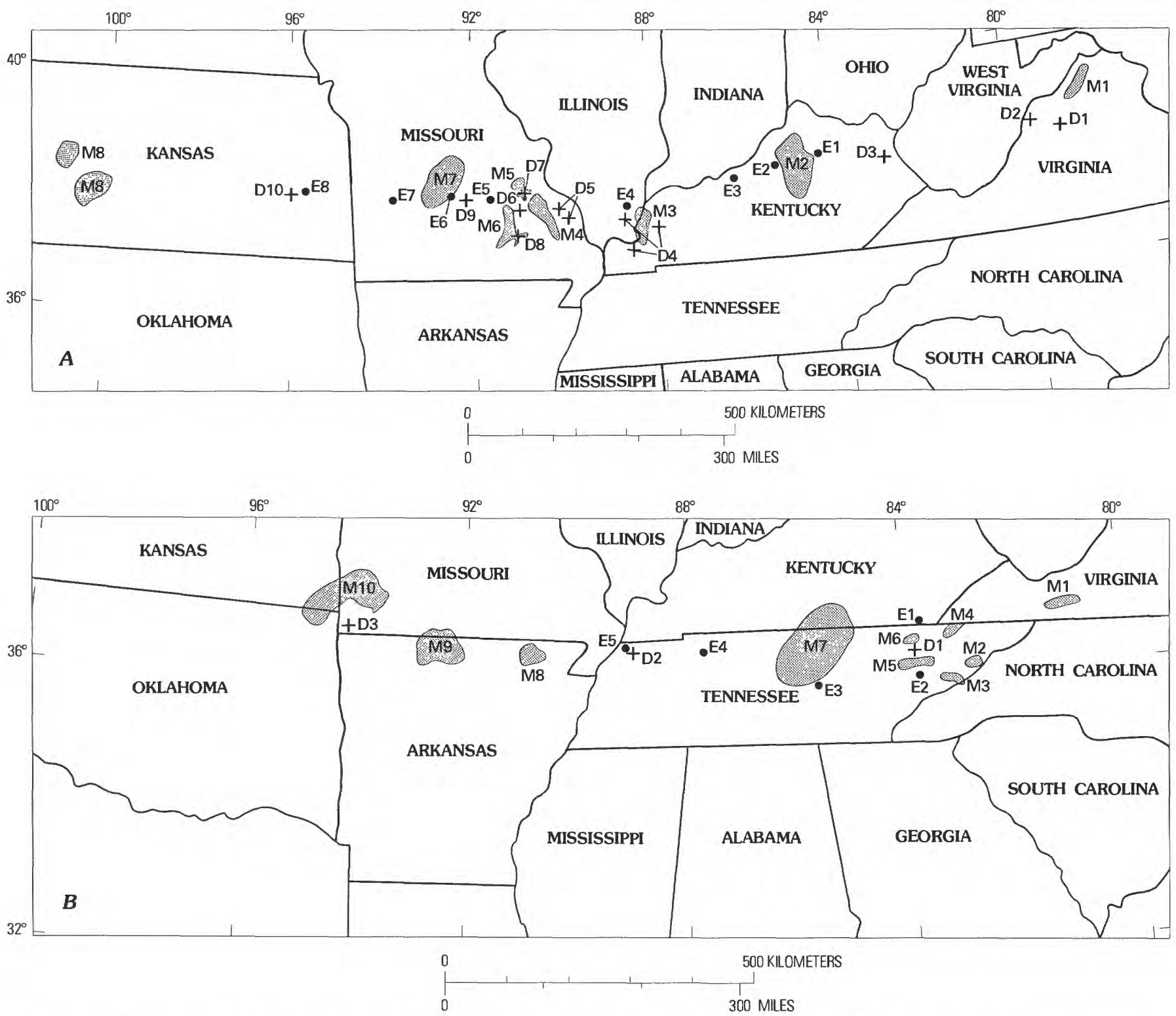

FIGURE 27.- Maps modified from Snyder (1970) showing mineralized areas, igneous intrusions, and "explosion structures" in what are construed to be two separate zones trending east-west. $A$, lineament near the 38th parallel, with eight mineralization areas (irregular heavy outlines) numbered M1-M8, ten igneous intrusions (crosses) numbered D1-D10, and eight "explosion structures" (small circles) numbered E1-E8. B, Tennessee lineament with ten mineralization areas (irregular heavy outlines) numbered M1-M10, three igneous intrusions (crosses) numbered D1-D3, and five "explosion structures" (small open circles) numbered E1-E5.

location of random impacts on regional structures is not unknown. Meteor Crater, Ariz., is on a local fold within a major area of explosive volcanic vents; Gosses Bluff, Australia (with impact melt and abundant shock features), lies on a regional anticline (Milton and others, 1972); Sierra Madera, Tex. (with melt and shock features), is along the projected trend of structure in the nearby Glass Mountains (Wilshire and others, 1972) and near the speculated Texas lineament; Flynn Creek, Tenn., lies along the extension of a major fault zone (D. J. Roddy, written commun., 1974).

Referring again to the seven observations which must be explained by a hypothesis of origin for the Decaturville structure (see the section "Origin of the structure"), an endogenetic explosion might produce the breccia core and possibly even the presumed ejecta blocks if venting occurred. It is not consistent with the other five listed observations.

\section{EXOGENETIC ORIGIN}

Three features of the structure in particular are strong evidence of impact origin: shallow deformation, shock indicators (with downward lessening of shock intensity), and 
centripetal movement of strata to form the uplift.

Drillhole information obtained at the center and the minor amount of basement rock in the breccia indicate that most of the disturbance was confined to the cover sequence of sedimentary rocks, probably little more than $550 \mathrm{~m}$ thick. At Crooked Creek, where the sedimentary cover probably was about the same as at Decaturville, the disturbance is not known to have affected basement rock (Snyder and Gerdemann, 1965).

This evidently shallow character of deformation is consonant with the shock-envelope reconstruction presented in fig. 25. From the shock criteria discussed earlier, we infer that a release of energy sufficient to produce pressures of $60-100 \mathrm{~kb}$ at the stratigraphic level of the Derby and Doe Run or Davis occurred at that level or higher. If it was higher, then still greater pressures may have been exerted on materials not now preserved in the structure core. The envelope is reasonably established from the observed shock features and it indicates that pressures markedly diminished downward, probably to less than $20 \mathrm{~kb}$ at the basement surface. Thus, disturbance by endogenetic means requires that gas migrated upward from the basement until it suddenly reached a point within probably $370 \mathrm{~m}$ of the surface where it was released instantaneously to generate tremendous pressures. One perspective on such an event is provided by the calculation of 3-kb pressure for the 1956 eruption of the volcano Bezymianny in the Soviet Union, which ejected blocks to a distance of $30 \mathrm{~km}$ (Gorshkov, 1959). Explosions produced by gas expansion or instantaneous conversion of water to steam cannot much exceed that level of pressure. Moreover, it is difficult to understand how pressures from below reaching $60-100 \mathrm{~kb}$ could have been contained until the gas reached $370 \mathrm{~m}$ from the surface. Lithostatic pressure at that point would have been only about 100 bars; explosive release obviously would have had to occur very much deeper. This point is considered quantitatively by Roddy (1968a, p. 307).

The structural geometry, with beds crowded inward and upward to form a central uplift and concomitant development of a surrounding ring depression, is not like any terrestrial structures except diapirs. However, origin of the Decaturville structure by diapirism is ruled out by the lack of low-density material, too thin a sedimentary sequence, the presence of the breccia core, the shock features, and the blocks best explained as ejecta. Upbulging of strata by a subterranean explosive volcanic-gas expansion, as at Hicks dome, produces dilation that is represented generally by simple upward or downward movements on steeply dipping faults. This is vastly different from the pattern observed at Decaturville and most of the "cryptoexplosion" structures now believed to be impact structures, where horizontal stress components were dominant (Roddy, 1968a, p. 309). The structural pattern resulting from centripetal displacements provides a key argument in favor of impact origin (Wilshire and Howard, 1968) that directly applies to the Decaturville structure where inward thrusting and telescoping of beds are such conspicuous phases of deformation.

Uplifts surrounded by depressions, and with structural patterns indicating centripetal movements, were produced in high-explosive cratering tests in Canada (Diehl and Jones, 1967; Roddy and others, 1969). Tracing of marker canisters buried in the cratered ground clearly showed ground movements inward and upward, with folding and faulting of strata, to make the uplift. Some canisters ejected from the crater came from below the floor of the apparent crater. Conspicuous circumferential and radial cracks developed in the ring depression and outside the crater. Roddy (1968b; Roddy and others, 1969) noted that this experiment resulted in forms most directly analogous to those mapped in terrestrial structures when the explosive charges were at the ground surface rather than buried. He suggested, on the basis of this comparison and of calculations of energy relationships, that structures having central uplifts are caused by the impact of low-density bodies, such as comets, that do not deeply penetrate the ground owing to shock vaporization at or near the ground surface. As Wilshire and others (1972) have commented, central uplifts are found in known or suspected terrestrial impact structures at least 2.4-3.2 $\mathrm{km}$ wide (at least in sedimentary rocks); on the Moon, where gravity is one-sixth that on Earth, central peaks occur in craters wider than $19 \mathrm{~km}$.

Terrestrial structures with central uplifts and ring depressions in layered materials commonly show close similarities in the ratio of maximum stratigraphic displacement in the uplift to outer diameter of the depression or final crater form. The main inner depression is used for the calculation in cases where multiple ring structures are present. Values close to 1:10 for uplift: ring diameter ratio are calculated for Sierra Madera, Tex. (Wilshire and others, 1972); Gosses Bluff, Australia (Milton and others, 1972); Flynn Creek, Tenn. (Roddy, 1968a); Wells Creek, Tenn. (Wilson and Stearns, 1968); and Decaturville. Recent work at Steinheim, Germany (D. J. Roddy, written commun., 1974) indicated a 1:10 relationship for that structure also. Canisters buried $9 \mathrm{~m}$ deep were ejected during excavation of a $100-\mathrm{m}$ crater in one Canadian explosion-cratering experiment (D. J. Roddy, oral commun., 1970). Other similar structures, such as Jeptha Knob, Ky.; Serpent Mount, Ohio (Bucher, 1936); and Crooked Creek, Mo. (Hendriks, 1954), have ratios of $1: 15$ to $1: 18$ as based on the available literature. These structures typically are not well exposed, however, and it is possible that isolated exotic fragments from deep formations were present but not mapped and so the uplift estimate is smaller than the true value. It is also possible that a ratio of $1: 10$ cannot be attained if the ring depression is not sharply bounded and completely developed, as seems to be true for Crooked Creek and Jeptha Knob.

Two remaining features that impact origin of Decaturville must explain are (1) the breccia core capped by a broken and 
crushed but apparently continuous stratum and (2) probable ejecta blocks in the ring depression. A subterranean explosion could explain the breccia core but (aside from previously stated arguments against it) does not seem likely to have ejected material through the $370 \mathrm{~m}$ of rock overlying the capping bed of Derby and Doe Run. One possible explanation may come from high-explosive cratering experiments (D. J. Roddy, oral commun., 1973). Charge detonation at or above the ground surface has been observed to produce uplifts in which cores of jumbled material are developed below uplifted and folded strata which are locally continuous but which are broken by complex faulting. Again it is difficult to explain ejection of material from the base of the breccia column, although as cited above, subcrater material has been found in ejecta. The presence of such ejecta implies that either transient openings exist below what becomes the final crater floor or material is somehow drawn up and ejected with great force from below the deepest crater surface. Transient openings seem the more likely explanation; this interpretation bears importantly on our attempt to determine the dimensions of the original crater at Decaturville.

\section{INTERPRETED CRATER PROFILE AND POST-}

\section{CRATER DISRUPTION}

Two models of original (transient) impact crater size and shape are considered basically to fit most of the field observations as well as what has been seen in cratering experiments. One model calls for very shallow or no penetration of a low-density impacting body. From cratering experiments, this may be expected to result in excavation of a shallow crater with central uplift, possibly containing a disrupted and brecciated core. In this model the observed breccia core has a cap of Derby and Doe Run because these formations would not have been excavated, but merely uplifted. Lateral movement might have occurred during formation of the uplift but likely would have been small as compared to the vertical displacements involved. The crater would have bottomed no deeper than the top of the Derby and Doe Run and thus would have been less than $330 \mathrm{~m}$ deep. Brecciation below the Derby and Doe Run would represent the effect of bulking as the uplift formed during relaxation after passage of the shock wave. This explanation accounts well for the observation that except for small amounts of Potosi, all fragments in the breccia core come from Derby and Doe Run and older formations; it also could explain the orientation of large blocks pointing inward and upward. It does not seem to account for basement ejecta, unless jetting of deep material occurred along transient fractures that extended some $180 \mathrm{~m}$ below the crater floor. The model also does not appear to accord with the inferred scale of lateral movement of strata, or to explain the inferred shock-envelope configuration.

The second model, our preferred model of crater shape, is highly inferential, but it takes account of every pertinent observation. We have no direct evidence on depth of penetration, but from the configuration of probable shock envelopes (fig. 25), the burst point seems likely to have been at about the level of the Potosi, too deep for a low-density impacting body. Thus the cratering mechanics probably were substantially different from those of the shallow-burst cratering experiments. Moreover, it seems clear that the basement must have been adjacent to a free surface, at least transiently. With a probable burst point as deep as Potosi, excavation to the basement at the very center of the crater is not unlikely, and we infer that the instantaneous excavation (or transient cavity) bottomed at or near the basement surface, as shown in fig. 25.

This means that the Derby and Doe Run, which now lie completely over the central area, would necessarily have been excavated. Inward movement of about $300 \mathrm{~m}$ from all sides is indicated by the structural pattern at the Gunter level; by general comparison with inferences from shatter-cone orientations at Gosses Bluff (Milton and others, 1972), inward movement of deeper strata may have been even greater. We thus infer that the Derby and Doe Run moved inward a minimum of $300 \mathrm{~m}$ and closed over the bottom one-third of the crater, now filled with blocks that spalled from the crater walls during the shock unloading phase, and as the strata moved inward. The movement of the Derby and Doe Run and subjacent beds involved bedding-plane slip, block displacements, and considerable flowage (as shown by thinning of the Derby and Doe Run and Davis at the sulfide pit and flow deformation in the Lamotte as well as the mixed breccia). Formations below the Derby and Doe Run and the Derby and Doe Run themselves make up most of the breccia core. The Derby and Doe Run probably slid more readily and farther than lower beds because it was moving atop the well-lubricated limy shale beds of the Davis.

The blocks overridden by the Derby and Doe Run now form the breccia core, changed in shape from a filling of the lower part of the crater to a tall column by the crushing inward move of the crater walls. This explanation accounts for the observed tendency of long blocks in the megabreccia core to stand nearly on end, pointing inward and upward in an acicular pattern. The inferred $300 \mathrm{~m}$ of movement permits us to establish the position of the crater wall at the level of the Derby and Doe Run prior to the inward move (near point 4 in fig. 25). Above that level the crater probably widened sharply as shown in fig. 25 . Small inner craters that extend below the main shallower craters are seen at least partly developed in Odessa Crater, Tex. (Shoemaker and Eggleton, 1961) and in a crater produced experimentally in granite (Hörz, 1969). Our conjectured initial, transient crater is a shallow bowl with a deeper excavation at its center.

The inward move of Derby and Doe Run across the deep inner crater accounts for the absence of blocks from strata above the Derby and Doe Run (except for a minor amount 
of Potosi which probably fell in during the move). Higher strata would have been excavated over the wider area of the main crater bowl and would be present in the central column only as minor pieces of fallback material. Even fallback pieces of upper strata would not be expected to be present if the Derby and Doe Run beds had closed the lower part of the crater before vertically ejected material could fall back. That this is feasible is indicated by the fact that at Gosses Bluff, blocks had risen more than $1,830 \mathrm{~m}$ to stand in open space and then toppled or were thrown outward apparently before airborne ejecta landed in the area (Milton and others, 1972). The time required for such dramatic movement in the uplift obviously must be measured in seconds. The most highly shocked material would have been ejected, but some would have been mixed with rubble on the crater floor. This material is now found only in the mixed breccia, tremendously diluted by the addition of grains and fragments produced by the grinding together of the large blocks spalled from the crater walls.

The inferred profile of the main crater bowl is based primarily on three points of information. A downdropped block of Eminence at point 7 in figure 25 indicates that Eminence was not entirely excavated there and thus must have been below the crater floor. A similar argument can be made to explain the presence of a Jefferson City block at point 10 , and this occurrence puts a probable limit on the diameter of the crater at the original ground surface. Additional surmises are that cleavage in the Gunter (point 9 in fig. 25) indicates proximity to a free surface-probably the crater wall-and that the Gunter tectonic style suggests involvement in the crater rim and overturned flap (such as described at Meteor Crater by Shoemaker, 1960). For example, the only reasonable explanation for the presence of the enormous Gunter block at the village of Decaturville, atop rocks that would have been at ground surface, is that the block slid into place as a projection of the overturned flap.

The inferred crater shown in figure 25 has a maximum depth of about $550 \mathrm{~m}$ and a rim diameter of about $3,000-3,300 \mathrm{~m}$. This crater, produced by nearly instantaneous excavation, was modified in a matter of seconds by the inward and upward move of strata in the surrounding ground. The physical impetus for such movement is not completely understood, but the movement can be considered roughly as a rebound that followed intense compression by the shock wave. D. J. Roddy (written commun., 1974) indicated that recent large-scale cratering experiments and computer simulations of shock-wave cratering show inward crater-floor movements to be common in surface-burst events.

Figure 28 shows a highly schematic time sequence of inferred stages in the development of the structure from transient cavity through postcrater disruption. Instantly after or even during crater excavation, the inward mass displacement involved in the initiation of the central uplift produced the ring fault. The position of such a ring fault in impact structures may depend on the depth to which strata are disturbed. In general, movement of strata downward and inward along the boundary fault produces a ring depression and provides further impetus for the rise of a central peak, and this push-pull mechanism seems to have acted effectively at Decaturville. The inferred linkage of uplift and ring fault may explain the difference between Decaturville and Crooked Creek. Uplift must be supported by flow and slippage of strata inward and upward. This movement may not be able to develop fully if the ring depression is incomplete. It seems possible that a configuration like that at Crooked Creek (a central horst with a dome collapsed around it) would occur if initial uplift were unsupported and partial collapse then ensued because a ring fault did not form to provide additional impetus for inward movement of material.

The schematic cross sections of figure 28 illustrate an inferred sequence of stages in the development of the Decaturville structure, a sequence which probably occupied a few minutes at most. Present ground surface and geologic features at that surface along or near a northeast-southwest section are portrayed as observed; features shown above and below the ground surface are intended only to convey a general sense of the hypothetical deformation sequence.

Section $A$ shows the initial crater or transient cavity, with a rim formed largely by the outward-overturning of a flap of strata from the top part of the excavated sequence. The overturned flap would be much more broken and jumbled than portrayed and would undoubtedly have extended farther outward as a thin discontinuous cover of loose blocks. Ejecta blocks of Precambrian rock and the Derby and Doe Run Dolomites are shown still falling, to represent the two blocks actually present in the northeast part of the structure. The clean, sharp crater represented presumably could not really have existed even momentarily because of fallback and rubble not ejected, and because spalling and centripetal movement of beds would have been taking place even before excavation was complete.

Section $B$ shows the beginning of structural adjustments following the crater-excavation phase and passage of the shock wave. A large block of Gunter Sandstone Member of Gasconade Dolomite has slid outward from the crater rim into place at the village of Decaturville. Inward and upward movement of beds closes the inner crater, lifts the rim zone, and modifies the crater profile. The ring fault forms in response to inward movement at the center, and folds and small faults form in the moving beds. Closure of the inner crater involves the crowding and crushing of blocks of all sizes which spalled from various formations in the inward-moving crater walls.

Sections $C$ and $D$ show the changing crater and structural adjustments as centripetal movement of beds continues. Crushing at the center produces a cylindrical mass of breccia which increases in height because of addition of new material and squeezing from all sides by the inward-moving strata. 
The breccia column is overridden by the Derby and Doe Run and Potosi. Lateral movement of beds involved many small thrust faults; these are portrayed in the upper beds where they exist along the present surface profile. Deformation style in the deeper beds probably involved bedding-plane slippage and thickness changes, but many thrusts and normal faults probably occurred also. In section $C$, steep faults are shown forming along the flanks of an upward bulge which is part of a fold ring surrounding the center of the structure. This faulting raised the large block seen at the sulfide pit; much of the upward impetus, and support for the block once it was raised, was provided by inflow of Lamotte Sandstone. Upfaulting in this area is completed in section $D$ to give the presently observed configuration of blocks. Mixed breccia is shown as being piped or injected from the central column into fault channels in the sulfide-pit area.

The centripetal movement of beds in the central peak area is clear and apparently was an early phase in a very complex structural sequence. Beds in the ring depression on the southwest side also moved inward, largely before steep faults and outward thrusts formed. Elsewhere on the west side of the structure in the ring depression, outward thrusting seems to have dominated the other phases of movement. We believe that the outward movement primarily was gravity sliding of beds from the central peak. Some sliding may have occurred as the peak was being lifted, but most probably occurred after most of the peak was formed. In other sectors of the perimeter of the peak, late outward sliding of layers may have been precluded by fault-block topography. Block faulting was the dominant structural phase on the north and south sides and outward thrusts have not been identified in those areas.

The push-pull mechanism of ring fault-central uplift has been discussed for lunar craters, where the slump of large masses on crater walls is believed to have contributed energy and mass to the formation of central peaks (Dence, 1968). The final configuration at Decaturville may have been much like that of lunar craters, with blocks unevenly downfaulted inside the ring boundary and a central peak that, as it formed, nearly instantly destroyed the initial crater outlined in figure 25 .

No direct evidence concerning the impacting body or its direction and angle of impact was obtained in our study. Most of the body presumably would have vaporized at levels above the rocks now preserved at the center. Its azimuth, however, may be indicated by the northeast-southwest axis of rough symmetry in the inner part of the central uplift. This direction is marked by ejected material in the northeast part of the structure and elongation of the gravity map contours. The outcrop and the gravity patterns may merely indicate greater inward movement from the northwest and southeast, possibly influenced by such factors as regional joints. We suspect, however, that the oval shape may relate to the original pattern of crater development. Study of the Gunter ring, for example, shows that the sandstone is dominantly very steep to overturned on the northeast and dips gently on the southwest. This asymmetry in tilting of strata and the distribution of ejecta suggest the possibility of a low-angle impact from the southwest, if small missile-impact structures are valid analogs (Moore, 1969). Overturning of the Gunter on the northwest is consonant with our belief that it was part of the overturned flap around the crater rim and helps further to understand the presence of the exotic block at the village of Decaturville.

\section{IMPLICATIONS FOR OTHER ASTROBLEMES}

No other cratering events so far studied in layered rocks are reported to have resulted in beds moving inward over a preserved core of breccia to form a central uplift (although subsurface data are seldom available to reveal such a core). Other facets of our proposed reconstruction, however, may have more general application to other astroblemes and may help to explain some puzzling aspects of published studies. Decaturville had always been considered to be deeply eroded, not on the basis of field evidence but mostly because the presumed crater topography seemed to have been removed. There is, however, no reason to suppose deep erosion. Paleogeographic evidence neither requires nor provides support for there having been more strata atop the presently existing section at the time of impact; certainly no higher strata are now found in the structure. Moreover, the huge block of Gunter seems possible to emplace (atop the highest preserved beds in the section) only as part of the flap of strata overturned outward around the crater to lie in scattered blocks upon the ground surface. An exotic block of Derby and Doe Run and fragments from the basement lie atop the whole section like the Gunter block, but they are from sufficient depth that they must be ejecta. The basement fragments seem to be caught in the ring fault.

We have estimated about $45 \mathrm{~m}$ of post-structure erosion. Thus the Decaturville structure immediately after its formation would have shown a ring zone dropped as much as 120 $\mathrm{m}$ below the surrounding plateau surface. If our reconstructed initial crater profile is approximately correct, the central peak probably was at most $30-60 \mathrm{~m}$ higher than today. The raised rim of the destroyed crater stood on the flanks of the central peak as an easily eroded pile of broken rock perhaps as much as $180 \mathrm{~m}$ above the plateau level.

Erosion at Sierra Madera was conjectured by Wilshire and others (1972) to have amounted to a few thousand feet, and the present surface was considered to show the style of deformation at a deep level in the impact structure. Shatter-coned Permian rocks from the central peak area are found along ring faults in Cretaceous strata at the present topographic rim, $3.2 \mathrm{~km}$ outside the shatter-cone envelope. Wilshire and others (1972) conjectured that such blocks were driven outward and upward along curved faults. We suggest instead that, as with the exotic blocks near the village of 
SOUTHWEST
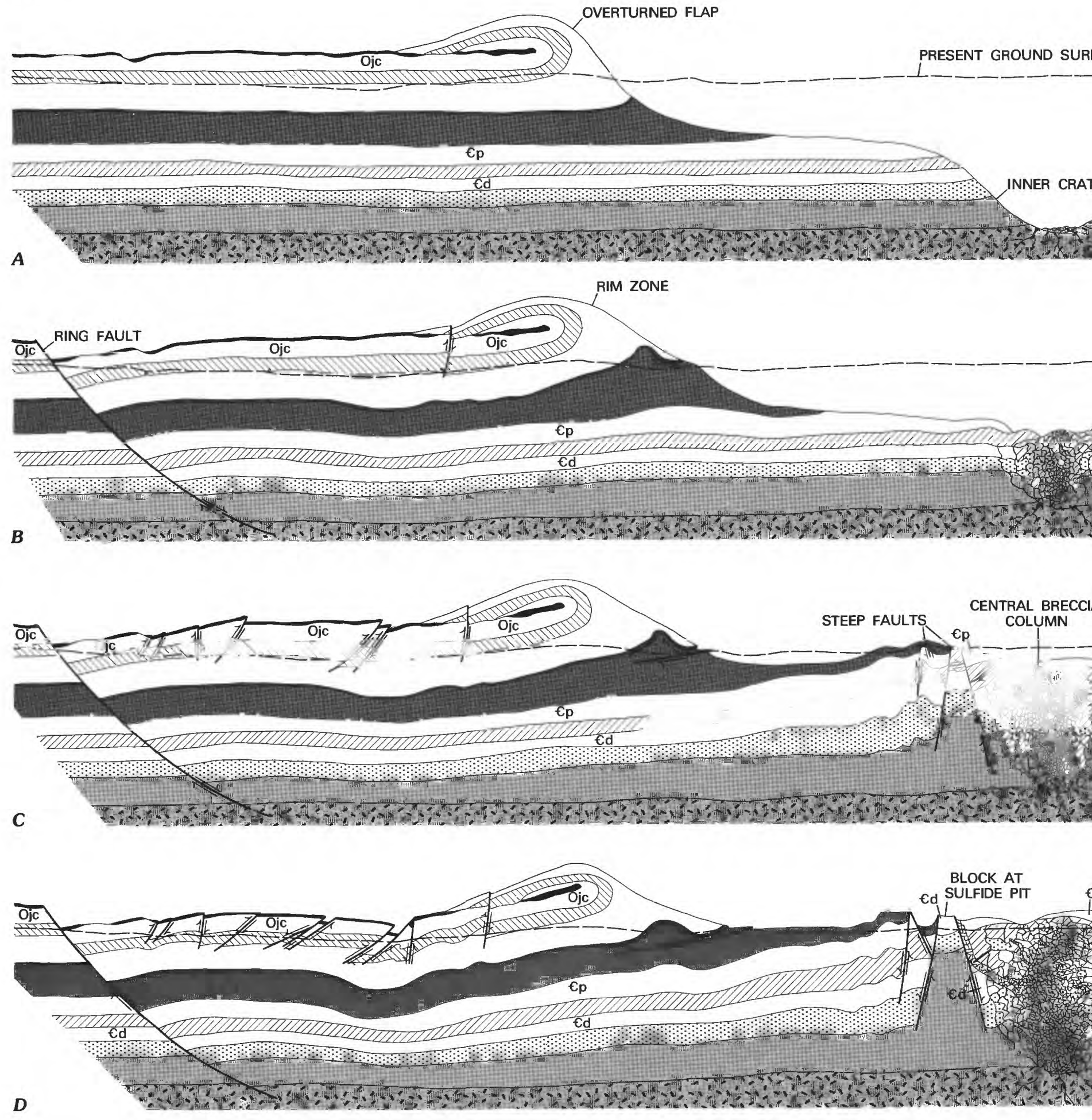

FIGURE 28.-Schematic northeast-southwest cross section showing inferred time sequence of 
NORTHEAST GUNTER EXOTIC
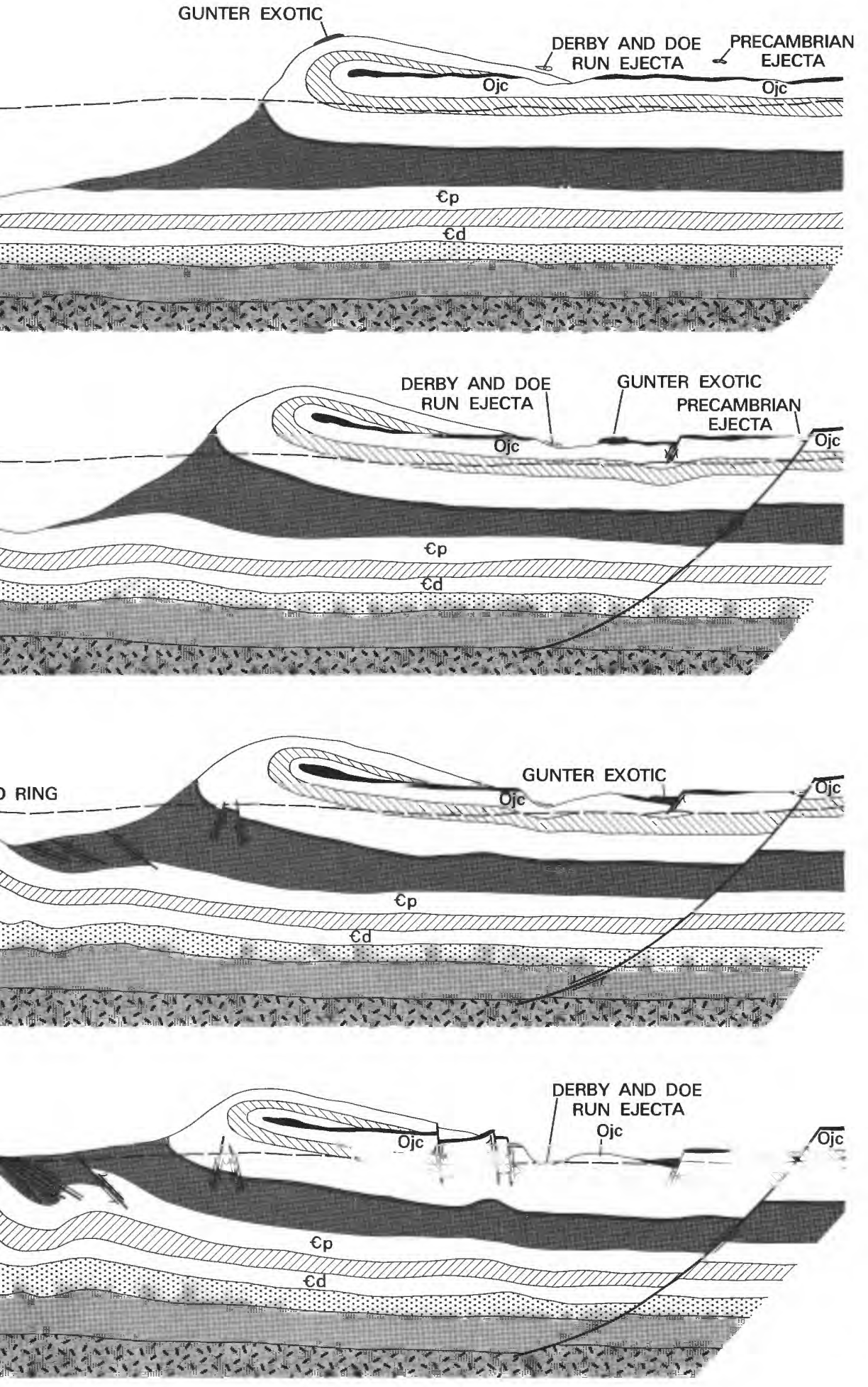

structural movements during cratering event at Decaturville structure; section $\boldsymbol{A}$ is earliest.

\section{EXPLANATION}

Silurian and Ordovician limestones ORDOVICIAN
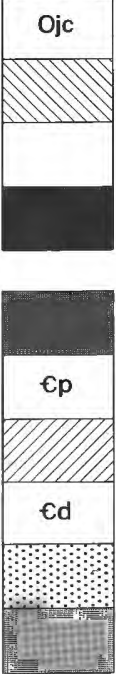

Jefferson City Dolomite

Roubidoux Dolomite

Upper part, Gasconade Dolomite

Gunter Sandstone Member,

Gasconade Dolomite

\section{CAMBRIAN}

Eminence Dolomite

Potosi Dolomite

Derby and Doe Run Dolomites

Davis Formation

Bonneterre Dolomite

Lamotte Sandstone

Precambrian granite and schist

Mixed breccia of Silurian, Ordovician, Cambrian, and Precambrian rocks

\section{CONTACT}

$\Longrightarrow$ FAULT-Arrows show direction of relative movement
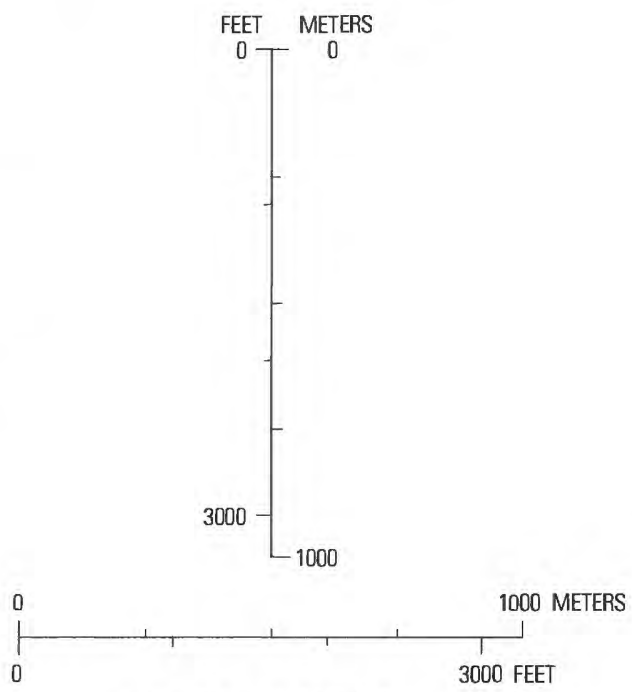

NO VERTICAL EXAGGERATION 
Decaturville, these blocks are ejecta trapped in faults at or not far below original ground surface as jostling occurred in the ring-boundary zone. This explanation seems to fit well with the presence of highly shocked or even melted mixed breccia material filling cracks and blanketing hillsides in the central uplift. If the present surface of the central uplift is little different from the original surface after the structure formed, then the mixed breccia may well represent material deposited on the crater floor. The highly granulated and partly fluidized breccia would naturally have drained or flowed into cracks between blocks in the rising central peak. Scaling from Decaturville, the transient cavity at Sierra Madera would have been about 7,300 m across; the rim would have been just outside the outermost mapped occurrences of mixed breccia.

At Gosses Bluff, the presence of impact melt at the present surface suggests that little post-crater erosion can have taken place; Milton and others (1972) speculate that Mt. Pyroclast, $5 \mathrm{~km}$ from the center of the structure, may represent a mass of suevite-like material which was plastered against the crater wall. Other evidence suggests that the central peak formed as ejected material was still falling or moving laterally along the surface, as we now surmise for Decaturville and Sierra Madera, and which was observed at the Snowball experimental cratering event (D. J. Roddy, written commun., 1976). It is interesting to note that, if Mt. Pyroclast marks the position of the transient cavity wall, then the cavity diameter was approximately half the 20-22 $\mathrm{km}$ diameter of the final disturbed area, essentially as inferred for the ratio of transient cavity to final ring diameter at Decaturville.

The implications for the structure of lunar craters have been discussed by Wilshire and others (1972) and Milton and others (1972). They make the reasonable analogy that, as in terrestrial impact structures, peaks in lunar craters consist of rocks brought up from deep below the crater floor. We would only add the thought that the ratio of upward displacement to final ring diameter probably varies considerably depending on layering of the excavated rocks and their ability to flow or slip. In lunar terrain of massive basalt layers, that ratio might be much less than 1:10. In terrain where fragmental material is extremely deep and could move by granular flow, the ratio might be significantly larger than 1:10.

\section{REFERENCES CITED}

Ahrens, T. J., and Gregson, V. J., Jr., 1964, Shock compression of crustal rocks-Data for quartz, calcite, and plagioclase rocks: Jour. Geophys. Research, v. 69 , no. 22 , p. $4839-4874$.

Amstutz, G. C., 1959, Polygonal and ring tectonic patterns in the Precambrian and Paleozoic of Missouri, U.S.A.: Eclogae Geol. Helvetiae, v. 52, no. 2, p. 904-913.

1964a, Impact, cryptoexplosion, or diapiric movements? (A discussion of the origin of polygonal fault patterns in the Precambrian and overlying rocks in Missouri and elsewhere): Kansas Acad. Sci. Trans., v. 67 , no. 2 , p. $343-356$.
$1964 \mathrm{~b}$, Tectonic and petrographic observations on polygonal structures in Missouri, in Geological problems on lunar research: New York Acad. Sci. Annals, v. 123, art. 2, p. 876-894.

Amstutz, G. C., and Zimmermann, R. A., 1966, Decaturville sulfide breccia of south-central Missouri-A fossil mud volcano, in Abstracts for 1965: Geol. Soc. America Spec. Paper 87, p. 4.

Ball, J. R., 1939, Type section of Bainbridge formation of southeastern Missouri: Am. Assoc. Petroleum Geologists Bull., v. 23, no. 4, p. 595-601.

Ball, S. H., and Smith, A. F., 1903, The geology of Miller County: Missouri Bur. Geology and Mines, 2d ser., v. 1, 207 p.

Beals, C. S., Innes, J. M. S., and Rottenberg, J. A., 1963, Fossil meteor craters, in Middlehurst, B. M., and Kuiper, G. P., eds., The moon, meteorites, and comets, v. 4, of The solar system: Univ. Chicago Press, p. 235-284.

Boon, J. D., and Albritton, C. C., Jr., 1936, Meteorite craters and their possible relationship to "cryptovolcanic structures": Field and Laboratory, v. 5, no. 1, p. 1-9.

Branco, W., and Fraas, E., 1905, Das Kryptovulkanische Becken von Steinheim: Akad. Wiss. Berlin, Phys.-Math. K1 Abh., v. 1, p. 1-64.

Bray, J. G., and others, 1966, Shatter cones at Sudbury: Jour. Geology, v. 74 , no. 2 , p. $243-245$.

Bucher, W. H., 1936, Cryptovolcanic structures in the United States [with discussion]: 16th Internat. Geol. Cong., Washington, D.C., 1933, Rept., v. 2, p. 1055-1084.

1963, Cryptoexplosion structures caused from without or from within the Earth? ("astroblemes" or "geoblemes"?): Am. Jour. Sci., v. 261 , no. 7 , p. $597-649$.

Buehler, H. A., and McQueen, H. S., 1933, Guidebook, Kansas Geol. Soc., 7th Ann. Field Conf., p. 19.

Bunch, T. E., 1968, Some characteristics of selected minerals from craters, in French, B. M., and Short, N. M., eds. Shock metamorphism of natural materials, 1st Conf., 1966, Proc.: Baltimore, Md., Mono Book Corp., p. 413-432.

Carter, N. L., 1968, Dynamic deformation of quartz, in French, B. M., and Short, N. M., eds. Shock metamorphism of natural materials, 1st Conf., 1966, Proc.: Baltimore, Md., Mono Book Corp., p. 453-474.

Carter, N. L., and Friedman, Melvin, 1965, Dynamic analysis of deformed quartz and calcite from the Dry Creek Ridge anticline, Montana: Am. Jour. Sci., v. 263 , no. 9 , p. $747-785$.

Chao, E. C. T., 1967, Shock effects in certain rock-forming minerals: Science, v. 156 , no. 3772 , p. $192-202$.

Christie, J. M., Heard, H. C., and LaMori, P. N., 1964, Experimental deformation of quartz single crystals at 27 to 30 kilobars confining pressure and $24^{\circ} \mathrm{C}$ : Am. Jour. Sci., v. 262, no. 1, p. 26-55.

Cummings, David, 1968, Shock deformation of biotite around a nuclear explosion, in French, B. M., and Short, N. M., eds., Shock metamorphism of natural materials, 1st Conf., 1966, Proc.: Baltimore, Md., Mono Book Corp., p. 211-217.

Dachille, Frank, Gigl, Paul, and Simons, P. Y., 1968, Experimental and analytical studies of crystalline damage useful for the recognition of impact structures, in French, B. M., and Short, N. M., eds., Shock metamorphism of natural materials, Ist Conf., 1966, Proc.: Baltimore, Md., Mono Book Corp., p. 555-569.

Dake, C. L., 1930, The geology of the Potosi and Edgehill quadrangles: Missouri Bur. Geology and Mines Rept., 2d ser., v. 23, 233 p.

Dake, C. L., and Bridge, Josiah, 1927, Early diastrophic events in the Ozarks [abs.]: Pan-Am. Geologist, v. 38, no. 2, p. 155-156.

Dence, M. R., Innes, M. J. S., and Robertson, P. B., 1968, Recent geological and geophysical studies of Canadian craters, in French, B. M., and Short, N. M., eds., Shock metamorphism of natural materials, Ist Conf., 1966, Proc.: Baltimore, Md., Mono Book Corp., p. 339-362.

Diehl, C. H. H., and Jones, G. H. S., 1967, The Snowball crater, general background information: Defence Research Establishment (Canada) Suffield Expt. Sta., Tch. Note 187, 23 p. 
Dietz, R. S., 1946, Geological structures possibly related to lunar craters: Pop. Astronomy, v. 54, no. 9, p. 465-467.

1959, Shatter cones in cryptoexplosion structures (meteorite impact?): Jour. Geology, v. 67, no. 5, p. 496-505.

1963, Cryptoexplosion structures-A discussion [of paper by W. H. Bucher, 1963]: Am. Jour. Sci., v. 261, no. 7, p. 650-664.

Eggleton, R. E., and Shoemaker, E. M., 1961, Breccia at Sierra Madera, Tex., in Short papers in the geologic and hydrologic sciences: U.S. Geol. Survey Prof. Paper 424-D, p. D151-D153.

Fairbairn, H. W., 1939, Correlation of quartz deformation with its crystal structure: Am. Mineralogist, v. 24, no. 6, p. 351-368.

French, B. M., 1968, Shock metamorphism as a geological process, in French, B. M., and Short, N. M., eds., Shock metamorphism of natural materials, 1 st Conf., 1966, Proc.: Baltimore, Md., Mono Book Corp., p. 1-17.

Gash, P. J. S., 1971, Dynamic mechanism for the formation of shatter cones: Nature; Phys. Sci., v. 230, no. 2, p. 32-35.

Gault, D. E., Quaide, W. L., and Oberbeck, V. R., 1968, Impact cratering mechanics and structures, in French, B. M., and Short, N. M., eds., Shock metamorphism of natural materials, ist Conf., 1966, Proc.: Baltimore, Md., Mono Book Corp., p. 87-99.

Gorshkov, G. S., 1959, Gigantic eruption of the volcano Bezymianny: Bull. Volcanology, 2d ser., v. 20, p. 77-109.

Hargraves, R. B., 1961, Shatter cones in the rocks of the Vredefort Ring: Geol. Soc. South Africa Trans., v. 64, p. 147-153.

Hendriks, H. E., 1954, The geology of the Steelville Quadrangle, Missouri: Missouri Div. Geol. Survey Water Resources Rept. 36, 2d ser., 82 p.

Heyl, A. V., 1967, The 38th parallel lineament and its relationship to ore deposits [abs.]: Mining Eng., v. 19, no. 12, p. 33.

1968, Minor epigenetic, diagenetic, and syngenetic sulfide, fluorite, and barite occurrences in the central United States: Econ. Geology, v. 63 , no. 6, p. $585-594$.

Hőrz, Friedrich, 1968, Statistical measurements of deformation structures and refractive indices in experimentally shock loaded quartz, in French, B. M., and Short, N. M., eds., Shock metamorphism of natural materials, 1st Conf., 1966, Proc.: Baltimore, Md., Mono Book Corp., p. 243-353.

1969, Structural and mineralogical evaluation of an experimentally produced impact crater in granite: Contr. Mineralogy and Petrology, v. 21 , no. 4 , p. $365-377$.

1970, Static and dynamic origin of kink bands in micas: Jour. Geophys. Research, v. 75, no. 5, p. 965-977.

Howard, K. A., and Offield, T. W., 1968, Shatter cones at Sierra Madera, Texas: Science, v. 162, no. 3850, p. 261-265.

Johnson, J. P., and Talbot, R. J., 1964, A theoretical study of the shock wave origin of shatter cones: U.S. Air Force Inst. Tech. School Eng., unpub. thesis, $90 \mathrm{p}$.

Kiilsgaard, T. H., Heyl, A. V., and Brock, M. R., 1963, The Crooked Creek disturbance, southeast Missouri, in Geological Survey research 1962: U.S. Geol. Survey Prof. Paper 450-E, p. E14-E19.

Koenig, J. W., 1967, The Ozark uplift and midcontinent Silurian and Devonian stratigraphy, in Symposium-Silurian-Devonian rocks of Oklahoma and environs: Tulsa Geol. Soc. Digest, v. 35, p. 119-147.

Krishnaswamy, D. S., and Amstutz, G. D., 1960, Geology of the Decaturville disturbance in Missouri [abs]: Geol. Soc. America Bull., v. 71 , no. 12 , pt. 2 , p. 1910.

McCracken, M. H., 1971, Structural features of Missouri: Missouri Geol. Survey Water Resources Rept. Inv. 49, 77 p.

McCracken, M. H., and others, 1961, Geologic map of Missouri: Div. Geol. Survey Water Resources, Rolla, Missouri.

Manton, W. I., 1965, The orientation and origin of shatter cones in the Vredefort ring, in Geological problems in lunar research: New York Acad. Sci. Annals, v. 123, art. 2, p. 1017-1049.

Melton, F. A., 1931, Post-Pennsylvanian denudation of the Ozark dome: Am. Jour. Sci., 5th ser., v. 21, p. 214-219.
Milton, D. J., and others, 1972, Gosses Bluff impact structure, Australia: Science, v. 175 , no. 4027 , p. 1199-1207.

Missouri Division Geological Survey Water Resources, 1943, Magnetic map of Missouri: Rolla, Missouri.

Missouri Division Geological Survey Water Resources, 1962, Aeromagnetic map of Macks Creek and Stoutland Quadrangles: Rolla, Missouri.

Moore, H. J., 1969, Subsurface deformation resulting from missile impact, in Geological Survey research 1969: U.S. Geol. Survey Prof. Paper 650-B, p. B107-B112.

Naeser, C. W., and Faul, Henry, 1969, Fission-track annealing in apatite and sphene: Jour. Geophys. Research, v. 74, no. 2, p. 705-710.

Nichols, C. E., 1973, Geology of the southern half of the Stoutland, Missouri Quadrangle: Missouri School of Mines, $\mathrm{Ph}$. D. thesis.

Offield, T. W., Pohn. H. A., and Naeser, C. W., 1970, The character and origin of the Decaturville, Missouri, cryptoexplosion structure, in Abstracts with programs: Geol. Soc. America, v. 2, no. 7, p. 639.

Robertson, P. B., Dence, M. R., and Vos, M. A., 1968, Deformation in rock-forming minerals from Canadian craters, in French, B. M., and Short, N. M., eds., Shock metamorphism of natural materials, 1st Conf., 1966, Proc.: Baltimore, Md., Mono Book Corp., p. 433-452.

Roddy, D. J., 1968a, The Flynn Creek crater, Tennessee, in French, B. M., and Short, N. M., eds., Shock metamorphism of natural materials, 1st Conf., 1966, Proc.: Baltimore, Md., Mono Book Corp., p. 291-322.

Roddy, D. J., 1968b, Comet impact and formation of Flynn Creek and other craters with central peaks [abs.]: Am. Geophys. Union Trans., v. 49 , no. 1, p. 272.

Roddy, D. J., and Davis, L. K., 1969, Shatter cones at TNT explosion craters [abs.]: Am. Geophys. Union Trans., v. 50, no. 4, p. 220.

Roddy, D. J., Jones, G. H. S., and Diehl, C. H. H., 1969, Similarities of 100 and 500 ton TNT explosion craters and proposed comet impact craters [abs.]: Am. Geophys. Union Trans., v. 50, no. 4, p. 220.

Ruhl, Otto, 1904, Observations at Pegmatite Hill, Camden County, Missouri: Drury College, Bradley Geol. Field Sta. Bull. 1, p. 36-40.

Savage, T. E., 1909, The Ordovician and Silurian formations in Alexander County, Ill.: Am. Jour. Sci., 4th ser., v. 28, p. 509-519.

Schuchert, Charles, 1943, Stratigraphy of the eastern and central Untied States: New York, John Wiley \& Sons, 1013 p.

Searight, T. K., 1955, The geology of the Lebanon Quadrangle, Missouri: Missouri Div. Geol. Survey Water Resources Rept. Inv. 18, 33 p.

Shepard, E. M., 1905, Spring systems of the Decaturville dome, Camden County, Mo.: U.S. Geol. Survey Water Supply Paper 110, p. 113-125.

Shoemaker, E. M., 1960, Penetration mechanics of high velocity meteorites, illustrated by Meteor Crater, Arizona: 21 st Internat. Geol. Cong., Copenhagen, 1960, Rept., pt. 18, p. 418-434.

Shoemaker, E. M., and Eggleton, R. E., 1961, Terrestrial features of impact origin, Paper A in Proc. Geophys. Laboratory-Lawrence Radiation Laboratory Cratering Symposium: California Univ., Livermore, Lawrence Radiation Lab. Rept. UCRL-6438, pt. 1, p. A1-A21.

Short, N. M., 1966, Shock processes in geology: Jour. Geol. Education, v. 14 , no. 4 , p. $149-166$.

Short, N. M., and Bunch, T. E., 1968, A worldwide inventory of features characteristic of rocks associated with presumed meteorite impact craters, in French, B. M., and Short, N. M., eds., Shock metamorphism of natural materials, 1st conf., 1966, Proc.: Baltimore, Md., Mono Book Corp., p. 255-266.

Shumard, B. F., 1873, Laclede County, Chapt. 12 of Reports on the geological survey of the State of Missouri, 1855-1871: p. 213-222.

Simons, P. Y., and Dachille, Frank, 1965, Shock damage of minerals in shatter cones [abs.]: Geol. Soc. America Ann. Mtg. program, p. 156-157.

Snyder, F. G., 1970, Structural lineaments and mineral deposits, eastern United States, in Rausch, D. O., and Mariacher, B. C., eds., Mining and concentrating of lead and zinc, v. l, of AIME world symposium on mining and metallurgy of lead and zinc, [Proc.]: Am. Inst. Mining, Metall., and Petroleum Engineers, p. 76-94. 
Snyder, F. G., and Gerdemann, P. E., 1965, Explosive igneous activity along an Illinois-Missouri-Kansas axis: Am. Jour. Sci., v. 263, no. 6, p. 465-493.

Snyder, F. G., and others, 1965, Cryptoexplosion structures in Missouri: Geol. Soc. America Field Trip Guidebook, 72 p.

Tarr, W. A., 1935, The origin of the Decaturville dome, Camden County, Missouri [abs.]: Missouri Acad. Sci. Proc., v. 1, p. 99-101.

Thompson, T. L., and Satterfield, I. R., 1975, Stratigraphy and conodont biostratigraphy of strata contiguous to the Ordovician-Silurain boundary in eastern Missouri: Missouri Geol. Survey Rept. Inv. 57, pt. 2, p. 61-108.

Tilton, G. R., Wetherill, G. W., and Davis, G. L., 1962, Mineral ages from the Wichita and Arbuckle Mountains, Oklahoma, and the St. Francois Mountains, Missouri: Jour. Geophys. Research, v. 67, no. 10, p. $4011-4019$.

Tolman, Carl, and Landes, K. K., 1939, Igneous rocks of the Mississippi Valley lead-zinc districts: Geol. Soc. America Spec. Paper 24, p. 71-103.

Van Tuyl, F. M., 1918, The physical history of the upper Mississippi Valley during the late Paleozoic [abs.]: Illinois Acad. Sci. Trans., v. 10, p. 280.

Weller, Stuart, and St. Clair, Stuart, 1928, Geology of Ste. Genevieve County, Missouri: Missouri Bur. Geology and Mines Rept., 2d ser., v. 22,352 p.
Wilshire, H. G., and Howard, K. A., 1968, Structural pattern in central uplifts of cryptoexplosion structures as typified by Sierra Madera: Science, v. 162 , no. 3850 , p. $258-261$.

Wilshire, H. G., Howard, K. A., and Offield, T. W., 1971, Impact breccias in carbonate rocks, Sierra Madera, Texas: Geol. Soc. America Bull., v. 82 , no. 4, p. 1009-1018.

Wilshire, H. G., Offield, T. W., Howard, K. A., and Cummings, David, 1972, Geology of the Sierra Madera crytoexplosion structure, Pecos County, Texas: U.S. Geol. Survey Prof. Paper 599-H, 42 p.

Wilson, C. W., Jr., Stearns, R. G., Tiedemann, H. A., Wilcox, J. T., and Marsh, Phyllis, 1968, Geology of the Wells Creek structure, Tennessee: Tennessee Div. Geology Bull. 68, 236 p.

Winslow, Arthur, 1894, Lead and zinc deposits: Missouri Geol. Survey Rept., v. 7, p. $432-434$.

Zimmermann, R. A., and Amstutz, G. C., 1965, The polygonal ring structure at Decaturville, Missouri-New tectonic observations: Neues Jahrb. Mineralogie Monatsh., v. 9, no. 11, p. 288-307.

1972, The Decaturville sulfide breccia-A Cambro-Ordovician mud volcanoe: Chemie der Erde, v. 17, bd. 31, p. 253-273. 